\title{
Brokering Developmente
}

Enabling Factors for Public-Private-Producer Partnerships in Agricultural Value Chains

\section{Jodie Thorpe and Mar Maestre} June 2015

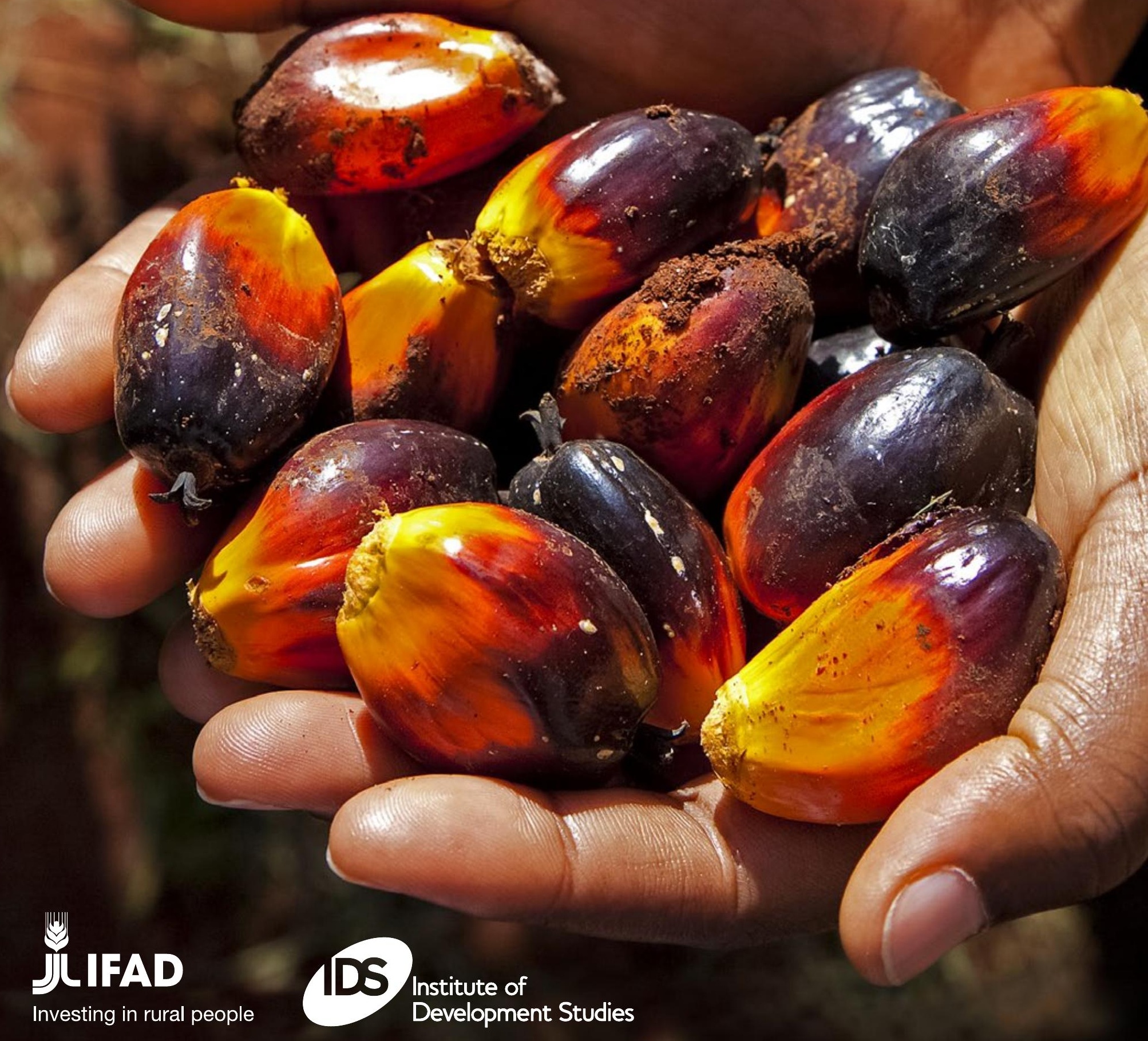




\section{Acknowledgements}

Front cover A farmer

shows oil palm fruits in Uganda.

()IFAD/SUSANBECCIO

We are grateful to the many people who made this report possible. In particular we would like to thank the authors of the country case studies that the report is based on: Daniel Bruce Sarpong and Henry Anim-Somuah of the Department of Agricultural Economics and Agribusiness of the University of Ghana; Ronnie S. Natawidjaja of the Center for Agrifood Policy and Agribusiness Studies, Padjadjaran University, Bandung (Indonesia); Jean-Marie Byakweli and Felix Nzeyimana (Rwanda) and Eddie Nsamba-Gayiiya and Herbert Kamusiime of Associates Research Uganda. We are also extremely grateful to Lorenzo Cotula and Bill Vorley of the International Institute for Environment and Development, who advised the research. The report and underlying country case studies have been reviewed by IFAD staff and we are most thankful for the comments received from Willem Bettink, Marco Camagni, Mylene Kherallah and Philipp Baumgartner (on main report and country studies). Finally, we also thank IFAD country teams for their comments and support during the field research: Ulaç Demirag and Niels Bossen (Ghana), Ronald Hartmann and Sarah Hessel (Indonesia), Francisco Pichon (Rwanda), and Alessandro Marini and Line Kaspersen (Uganda).

IDS disclaimer

This publication is copyright, but may be reproduced by any method without fee for teaching or nonprofit purposes, but not for resale. Formal permission is required for all such uses, but normally will be granted immediately. For copying in any other circumstances, or for re-use in other publications, or for translation or adaptation, prior written permission must be obtained from the publisher and a fee may be payable.

\section{IFAD disclaimer}

The designations employed and the presentation of material in this publication do not imply the expression of any opinion whatsoever on the part of the International Fund for Agricultural Development of the United Nations concerning the legal status of any country, territory, city or area or of its authorities, or concerning the delimitation of its frontiers or boundaries. The designations 'developed' and 'developing' economies are intended for statistical convenience and do not necessarily express a judgement about the stage reached by a particular country or area in the development process.

This publication or any part thereof may be reproduced without prior permission from IFAD, provided that the publication or extract therefrom reproduced is attributed to IFAD and the title of this publication is stated in any publication and that a copy thereof is sent to IFAD. 


\section{Contents}

Abbreviations 2

1 Executive summary 3

$\begin{array}{ll}2 \text { Introduction } & 7\end{array}$

Background $\quad 8$

Methodology 9

$\begin{array}{ll}\text { Report outline } & 10\end{array}$

3 Approach to analysis $\quad 11$

The rationale for public-private-producer partnerships 11

Partnership dynamics during design and implementation 12

Partnership brokers $\quad 13$

Development outcomes for smallholders and rural communities $\quad 13$

4 Case studies $\quad 14$

Introduction $\quad 14$

Ghana 15

$\begin{array}{ll}\text { Indonesia } & 18\end{array}$

Rwanda $\quad 21$

$\begin{array}{ll}\text { Uganda } & 24\end{array}$

$\begin{array}{ll}\text { Development outcomes } & 27\end{array}$

5 Enabling factors for agricultural value chain PPPPs 29

5.1 Define the rationale and underlying assumptions 29

5.2 Ensure a clear market pull 31

5.3 Prioritise farmer ownership of the PPPP 32

5.4 Align incentives of partners and build trust 34

5.5 Manage risks through identification, distribution and mitigation 36

5.6 Build the capacity to respond to changes in complex market systems 36

5.7 Take a proactive approach to public accountability and transparency 38

5.8 Facilitate sustainable market systems 39

$\begin{array}{ll}6 \text { PPPP checklist } & 40\end{array}$

$\begin{array}{ll}7 \text { Conclusions } & 42\end{array}$

Annex 1: Summary of outcomes identified and links to PPPP design and implementation 45

Annex 2: Bibliography 46

$\begin{array}{ll}\text { Endnotes } & 50\end{array}$ 


\section{Abbreviations}

\begin{tabular}{|c|c|}
\hline BRD & Banque Rwandaise de Developpement \\
\hline BUL & Bidco Uganda Ltd \\
\hline CDC & Cocoa Development Centre \\
\hline COTHEGAB & Coopérative des Théiculteurs de Gatare-Buruhukiro \\
\hline DVCC & District Value Chain Committee \\
\hline FBO & farmer-based organisation \\
\hline ffbs & fresh fruit bunches \\
\hline FGD & focus group discussion \\
\hline $\mathrm{FO}$ & farmers' organisation \\
\hline IFAD & International Fund for Agricultural Development \\
\hline KOPGA & Kalangala Oil Palm Growers Association \\
\hline KOPGT & Kalangala Oil Palm Growers Trust \\
\hline MNC & multinational corporation \\
\hline $\mathrm{MoU}$ & memorandum of understanding \\
\hline NGO & non-governmental organisation \\
\hline NRPG & Northern Rural Growth Programme \\
\hline OPUL & Oil Palm Uganda Limited \\
\hline PDCRE & Smallholder Cash and Export Crops Development Project \\
\hline PPP & public-private partnership \\
\hline PPPP & public-private-producer partnership \\
\hline PRICE & Project for Rural Income Through Export \\
\hline READ & Rural Empowerment and Agricultural Development \\
\hline SACCO & Savings and Credit Co-operative \\
\hline SFMC & Savannah Farmers Marketing Company \\
\hline SME & small and medium-sized enterprise \\
\hline VCC & Village Cocoa Centre \\
\hline VODP & Vegetable Oil Development Project \\
\hline
\end{tabular}




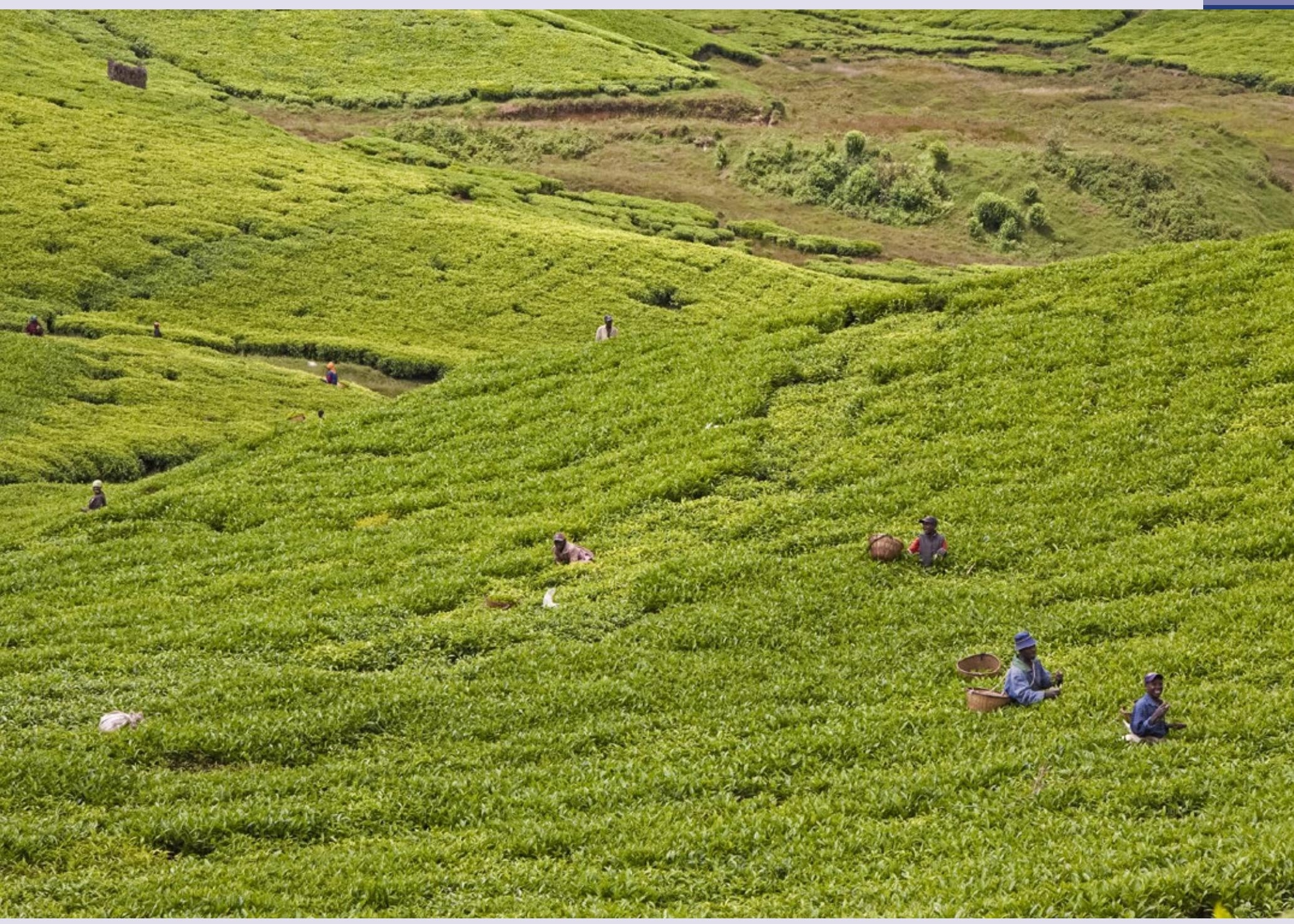

\section{Executive summary}

Markets are central to agriculture and rural development. Making markets, value chains and the systems that support them work better for the poor has therefore become a central aim of many donors, governments and nongovernmental organisations. This research seeks to understand how public-private-producer partnerships (PPPPs) in agricultural value chains can be designed and implemented to achieve more sustained increases in income for smallholder farmers and broader rural development. PPPPs involve cooperation between government and business agents, working together to reach a common goal or carry out a specific task, while jointly assuming risks and responsibilities, and sharing resources and competences. ${ }^{1}$ They also explicitly involve farmers (or producers), hence the fourth ' $\mathrm{P}$ ' is added to the more familiar designation of 'public-private partnerships'. The research also considers the role of PPPP brokers as independent facilitators who support the process of exploring, designing and implementing PPPPs.

The research is based on four case studies of agricultural value chain PPPPs developed through projects financed by the International Fund for Agricultural Development (IFAD) in Ghana, Indonesia, Rwanda and Uganda. In each country, local research teams collected data through a mixture of semi-structured interviews, field visits and focus group discussions (FGDs) with local market chain actors, smallholder farmers and other community members, and relevant experts. These were not impact assessments, and represent instead a snapshot in time. However, the aim was to gain insights into the outcomes of the PPPPs so far, and how these have been influenced by the way the PPPP was designed, implemented and brokered.
A Tea estate in Nshili, Nyaruguru, just $8 \mathrm{~km}$ from the Burundi border, Rwanda. () IFAD/SUSAN BECCIO 


\section{Case studies}

These PPPPs aimed to either bring new smallscale farmers into the value chain of crops such as oil palm and tea, or to improve the terms on which farmers were included through better access to credit or training. The case studies do not involve full impact assessments. However, they explore initial outcomes being observed in terms of smallholder livelihoods and rural development, and how these have been influenced by PPPP design and implementation.

Ghana: The Northern Rural Growth Programme involves a series of PPPPs that aim to address the challenges facing smallholder farmers in northern Ghana. The PPPPs aim to improve farmer access to finance, infrastructure, production and marketing, by linking smallscale producers to private sector companies. The research focused specifically on the PPPP value chain arrangement for maize, which is both a staple and a cash crop in northern Ghana. Average maize yields rose from $0.8 \mathrm{MT} /$ ha in 2007 to between 1.5MT/ha to $3.2 \mathrm{MT} /$ ha in 2014, boosting household incomes and livelihoods in some cases. The PPPP has also strengthened vital value chain linkages for smallholder farmers, and has given farmers more voice although women's participation was low. On the other hand, income stability has not improved while high exposure to risk on the part of farmers and rural banks threatens programme sustainability.

Indonesia: The PPPP in Indonesia evolved from the Rural Empowerment and Agricultural Development (READ) Programme in Central Sulawesi. Cocoa production in the region faced serious problems of ageing plants, pests and diseases, insufficient improved planting material and technologies, and poor farm management practices. The READ programme was redesigned to include a PPPP with Mars Symbioscience Inc, a major cocoa buyer, to establish five Cocoa Development Centres (CDCs) supporting farmers concerning improved farm management techniques. In those areas where the CDC model is functioning well, productivity has reached $100 \mathrm{~kg}$ to $200 \mathrm{~kg}$ per tree per month, up from an average of 50kg in 2010. Quality has also improved with the average weight of cocoa beans increasing by 10 to 15 per cent. However, at the time of the fieldwork, most farmers, especially in remote districts, were yet to see the benefits due to slow CDC development and the time lag for improved techniques to raise yields. Although 150 key farmers and extension agents have been trained, they still require ongoing technical support from Mars, raising questions of long-term sustainability.

Rwanda: The case study in Rwanda involves PPPPs in two tea estates in the southern province of the country, one in Nshili and one in Mushubi. These PPPPs were designed and implemented as part of the government's privatisation of the tea sector. The aim of the PPPPs was to secure substantial public and private sector investment to drive an increase in smallholder incomes and generate new employment opportunities in tea-growing regions in marginalised areas of the country. Tea growers have increased their incomes, households are investing in assets, food security has improved and in a region where up to 40 per cent of the labour force previously would migrate to seek work, a large number of permanent and seasonal jobs has been created. However, yields of green leaf of $0.7 \mathrm{~T} / \mathrm{ha} /$ year in 2013 in Nshili and 2.5T/ha/year in 2013 in Mushubi are still well below the expectations of 6 to $7 \mathrm{~T} /$ ha/year, due to poor maintenance of plots and weak farmer commitment and ownership. Low productivity is undermining the sustainability of farmer loans and leaving factories operating well below nominal capacity - 30 per cent in Mushubi and 40 per cent in Nshili.

Uganda: The PPPP in Uganda aimed to establish oil palm production (a new cash crop in Uganda) through private sector-led agroindustrial development in Kalangala District on Bugala Island in Lake Victoria. Specific aims of the PPPP were to achieve import substitution of edible oil, raise smallholder incomes, improve population health through increased uptake of vegetable oil, and diversify exports. Farmers who have started harvesting have benefited from improved incomes and income stability, enabling households to meet basic health and education needs, and invest in assets. Significant investments in public infrastructure such as roads and water transport have also benefited local communities, with more than 80 per cent of farms now reported to be linked to the road network, and a new ferry service to the island. However, unintended consequences include conflict linked to changing land tenure rights 
and gender roles, and questions over long-term food security. The PPPP also experienced major delays and additional costs due to limited engagement by smallholders and public opposition, especially early on, and government difficulties in acquiring sufficient land.

\section{Eight enabling factors}

The analysis of these PPPPs was based on three aspects that were identified as influencing the ability of PPPPs to successfully deliver development outcomes: (a) the rationale for the PPPP - what were the constraints that the PPPP sought to overcome and why did partnership present a solution which neither the public nor private sectors could achieve alone;

(b) partnership dynamics including ownership, involvement and interdependence of all partners, governance mechanisms linked to transparency, accountability and trust, risk management, communication and dialogue, and monitoring and evaluation; and (c) the role of partnership brokers. From this analysis, eight enabling factors for PPPPs in agricultural value chains emerged.

\section{Define the rationale and underlying} assumptions. PPPPs should have a clear rationale, responding to the key questions 'what is the constraint to be overcome?' and 'how will working with the private sector overcome this constraint?'. Potential partners with the right competencies need to be identified, e.g. through competitive bidding, partner due diligence processes, or working with already established partners. Assumptions behind the rationale and proposed solutions need to be identified and feasibility tested.

\section{Ensure a clear market pull. Value chain} PPPPs offer the specific opportunity to secure market access for smallholder farmers by connecting them directly with markets. Outcomes will depend on aspects of design, including risk-sharing and mechanisms that address unequal power relations that exist in vertically coordinated value chains.

3 Prioritise farmer ownership of the PPPP. The PPPP is a partnership, not only of public and private sectors, but also of farmers. For PPPPs to be successful, all partners, including farmers, need to have ownership of the PPPP, with clear roles and responsibilities that reflect their priorities and interests.

4 Align incentives of partners and build trust. Agreements are needed to create incentives for partners to perform their intended roles - and to feel confident that the other partners will perform their roles. Incentives are most fully aligned when all partners own the PPPP objectives and where each has something to lose if the objectives are not achieved. Building trust between parties who are not used to working together or thinking of each other as partners - or who have a history of poor relationships requires significant leadership from within the partnership organisations or from brokers.

5 Manage risks through identification, distribution and mitigation. Unless risk is managed, the weakest value chain actors (normally the farmers) bear a disproportionate share, and this can also raise costs and undermine the sustainability of the PPPP as a whole. PPPP design should firstly identify risks and how risks are distributed. Mechanisms are then needed to manage, mitigate or share risk, avoiding an excessive unmitigated risk burden on one party.

6 Build the capacity to respond to changes in complex market systems. Agricultural markets consist of many individual but interdependent parts, with the dynamics of the system emerging from interactions between these parts. PPPP interventions may lead to unforeseen outcomes - challenges as well as opportunities. PPPPs need mechanisms to identify these changes, and the flexibility to respond and adapt to the unexpected. This includes performance monitoring, with indicators that reflect joint PPPP objectives, and spaces for communication, negotiation and conflict resolution.

7 Take a proactive approach to public accountability and transparency. The impacts of PPPPs frequently extend beyond direct partners to a wider group of external stakeholders. The larger the scale of PPPP activities and its likely impacts, the more important it is to proactively identify and address negative externalities, engaging and involving potentially affected stakeholders.

8 Facilitate sustainable market systems. Agricultural value chain PPPPs are timelimited interventions to establish new market, institutional or systemic arrangements that address underlying constraints in areas such as input markets, credit systems and technology diffusion. Interventions need to focus on actions that modify the incentives, capabilities and behaviour of different actors to ensure that they will continue their roles in the long term. 


\section{Role of brokers}

Drawing on the enabling factors and the roles of brokers identified through the case studies, the findings also identify key roles that brokers can fulfil, supporting different steps of the PPPP process. They can:

- facilitate contact between potential partners, helping them explore the potential benefits of partnership, identify common objectives and build trust and understanding;

- ask the right questions early on, identify and justify assumptions and ensure effective feasibility studies;

- provide or procure technical expertise as needed;

- involve farmers directly as partners in the PPPP, building farmer capacity to organise effectively, access information and negotiate a fair deal;

- help ensure transparency and dialogue within the PPPP, and between the PPPP and external stakeholders;

- support monitoring processes, facilitate dialogue around conflicts or differences, and encourage partners to develop and own joint solutions;

- ensure actors have long-term capacity, financing and incentives to play new roles.

Brokers also need to develop a clear exit strategy from the outset. Otherwise the risk is that brokers become part of how PPPP implementation works, creating dependence, particularly on the part of the less powerful partners.

\section{Discussion of findings}

While the four case studies point overall to the potential for PPPPs to deliver positive development outcomes, the jury is still out in terms of the long-term impacts on poverty and rural development. This evidence gap is not particular to IFAD, and many of the criticisms of PPPPs and other value chain approaches are linked to perceptions that claims of positive outcomes are not substantiated by the evidence. There is a need for the public sector, including donors, to invest more in creating a solid evidence base that identifies the impacts of PPPPs over the long term and measures broader impacts (positive and negative) beyond participating farmers.
Despite this evidence gap, PPPPs remain popular because they promise better development outcomes from the involvement of the public sector, and more commercially viable results through the involvement of the private sector. Yet this research highlights that just securing the involvement of public and private actors is not enough to achieve these goals. Strong government ownership of the PPPP did not emerge as a key enabling factor to improve the livelihoods of farmers, which depends more on the way the PPPP is designed, including especially the role of the 'fourth $\mathrm{P}^{\prime}$ (producers). It may, however, generate wider, horizontal impacts that benefit those who are unlikely to be reached by private sector value chains.

Nor does involving the private sector guarantee long-term commercial viability. Indeed, sustainability and scalability are also challenges for company-led 'inclusive business' approaches. The risk with both company-led and PPPP approaches is that the effort invested to ensure the success of pilot projects undermines the ability to reach commercial scale, particularly for 'greenfield' interventions supporting smallholders to enter new value chains (Vorley and Thorpe 2014). In this respect, the PPPP in Ghana - although not without challenges - offers a promising model since it works through already existing market systems, influencing the behaviour of different market actors (through partnerships but also other modes of engagement) to overcome constraints faced by farmers. Approaches that work to improve existing market systems offer the potential for large-scale impact through reaching diffuse beneficiaries, but intensify the challenge of measuring impact and attributing it to programme interventions. However, methodologies do exist that can support the evaluation of system-level changes. ${ }^{2}$

Overall, the conclusion is that agricultural value chain PPPPs are a variation on, rather than a radical departure from, other value chain approaches, bringing similar opportunities but also similar challenges. The enabling factors and PPPP checklist set out in this report support partners and brokers to design and implement PPPPs in ways that can lead to better development outcomes. More evidence is still needed, however, around the long-term impacts of PPPPs for both smallholder livelihoods and broader rural development. 


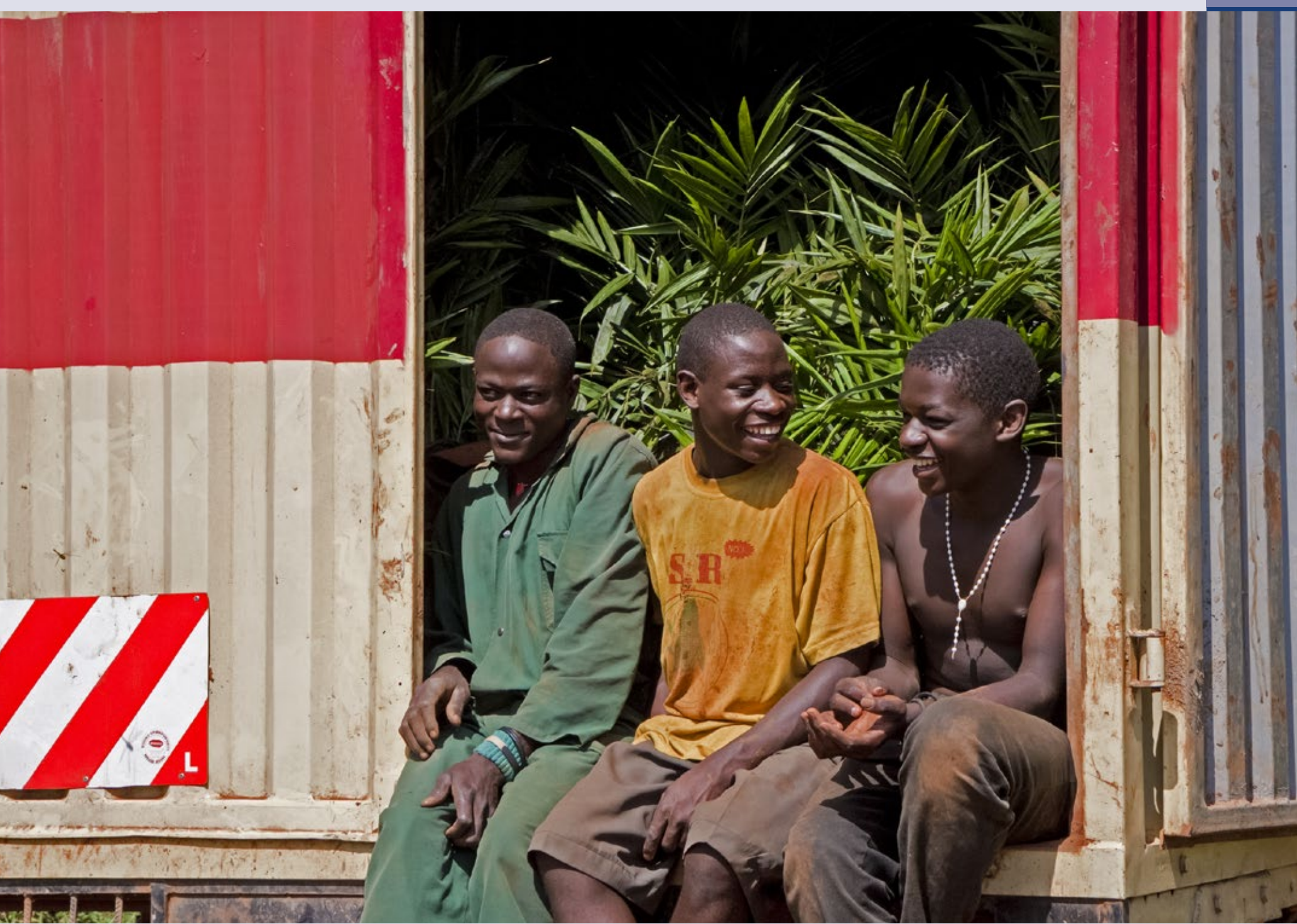

\section{Introduction}

Markets are central to agriculture and rural development. Making markets, value chains and the systems that support them work better for the poor has therefore become a central aim of many donors, governments and non-governmental organisations (NGOs) (Elliott et al. 2008; Tschumi and Hagen 2008; Jochnick 2012; Heinrich 2013). This research focuses on one mechanism - public-privateproducer partnerships (PPPPs) - through which development actors work with companies to improve the way that agricultural markets work for small-scale farmers and rural communities. The term 'PPPP' (rather than the more usual 'PPP' - public-private partnerships) is chosen to underscore the role of farmers as part of the partnerships (see page 8 for definitions). The research seeks to understand how PPPPs can be designed and implemented in order to bring more sustained increases in income for smallholder farmers and broader rural development. To do so, it explores four agricultural value chain PPPPs supported by the International Fund for Agricultural Development (IFAD) in Ghana, Indonesia, Rwanda and Uganda in order to derive lessons for more robust and systematic approaches. ${ }^{3}$

The research takes a development perspective, and is directed at those in the public sector, including governments and donors, that are initiating or engaging in partnerships (PPPs or PPPPs). However, agricultural PPPs are not only instigated by the public sector. Companies are both collaborators in and instigators of partnerships, in order to secure the supply of commodities, ensure food safety standards are met or as part of their 'corporate social responsibility' (Bitzer et al. 2009). Companies work through partnerships in order to access
A Kalangala island. A truck distributes young oil palm plants to farmers on the island. ( IFAD/SUSAN BECCIO 
public sector funding, skills and expertise, and to share risks (Kindornay et al. 2012). The findings of this research are relevant to both public and private sector-led partnerships, though with the aim of maximising development benefit.

\section{Background}

Agriculture is a private sector activity. The trading of agricultural produce, whether through local markets or across international trade networks, resides largely in the hands of private individuals and enterprises. With notable exceptions ${ }^{4}$ the state role in agriculture, through agricultural extension, research and development, infrastructure and finance, is a relatively recent phenomenon, dating back no more than 200 years. However, in these areas that are considered public responsibilities, governments are now seeking to leverage private sector resources - both technical and financial - and to work with the private sector to secure access to markets for smallholder producers.

Development cooperation partnerships first came to public attention at the United Nations World Summit for Sustainable Development in 2002. But the real growth in interest has been in the last few years. For members of the Organisation for Economic Co-operation and Development (OECD) Development Assistance Committee, for example, spending through public-private mechanisms has risen from US\$234m in 2007 to US\$903m in 2010, emphasising health (40.9 per cent), economic infrastructure (31.8 per cent), agriculture (15.2 per cent), and environmental protection (6 per cent) (Tomlinson 2012). At the Fourth High Level Forum on Aid Effectiveness in Busan in 2011, PPPs in development cooperation received significant attention. In 2013, the G8 launched the 'New Alliance for Food Security and Nutrition', a 'mega-PPP' designed to foster joint African government, donor and private sector commitments to agricultural investment and policy reform. Despite this growing interest, however, many interventions are still at the 'proof-of-concept' stage (Poulton and Macartney 2012).

\section{What is a 'public-private' or a 'public- private-producer' partnership?}

There is no single agreed definition of a public-private partnership. The term is used to refer to a variety of arrangements including sometimes quite informal agreements between public and private sector entities, such as knowledge-sharing networks. For this research, the following definition is used:

PPPs involve cooperation between government and business agents that agree to work together to reach a common goal or carry out a specific task, while jointly assuming risks and responsibilities, and sharing resources and competences. ${ }^{5}$

Captured in this definition is the sense of a unique relationship between the government and a private firm. While the government retains ultimate responsibility, the private sector is a partner in both decision-making and delivery. Importantly, PPPs can be distinguished from other relationships between public and private sectors (e.g. public procurement) based on whether a sufficient amount of risk has been transferred (OECD 2008).

Many different types of PPPs in agriculture have been identified (Ferroni and Castle 2011; Narrod et al. 2009; Spielman et al. 2010; Brinkerhoff and Brinkerhoff 2011), such as those developed to build required infrastructure; to collaborate on agricultural research and development (R\&D) or crop markets; to deliver (normally public) services, such as extension services; or to create value chain linkages either bringing smallholders into new value chains or improving existing chain linkages through overcoming high costs or risks associated with sourcing from smallholders. Since this last form of partnership explicitly involves farmers (or producers) as a key component of the arrangements being created, they can be considered 'public-private-producer' partnerships (PPPPs).

The PPPPs explored in this research are primarily focused on value chain linkages (Ghana, Rwanda, Uganda), although in Indonesia the focus is on extension and agricultural technology. These partnerships often include other elements (e.g. development of infrastructure, access to finance). However the private sector role focuses on value chain development or strengthening and agricultural technology. 


\section{Methodology}

The objective of the research is to identify the key factors driving the effectiveness of PPPPs at bringing sustained increases in income for smallholder farmers at scale and delivering positive development outcomes across rural communities. To provide insight into this overarching question, four case studies were selected and then analysed based on the following questions:

a. What constraints was the PPPP set up to overcome, and what was its theory of change?

b. What were the key features of how the PPPP was brokered, designed and implemented?

c. What have been the development outcomes for smallholders and rural communities to date?

d. How have these outcomes been influenced by the PPPP's brokering, design and implementation?

\section{Case study selection}

The four case studies were selected from among a sample of 24 IFAD project-supported PPPPs (IFAD 2013). The longlist of PPPPs was mapped against two functional elements of the partnership with the private sector: (a) the main focus of the partnership, based on how the PPPP sought to deliver improvements in farmer livelihoods and rural development; and (b) the process for identifying the private sector partner - whether a structured or semistructured process ${ }^{6}$ was in place, or whether a more opportunistic approach ${ }^{7}$ was used which largely responded to events.

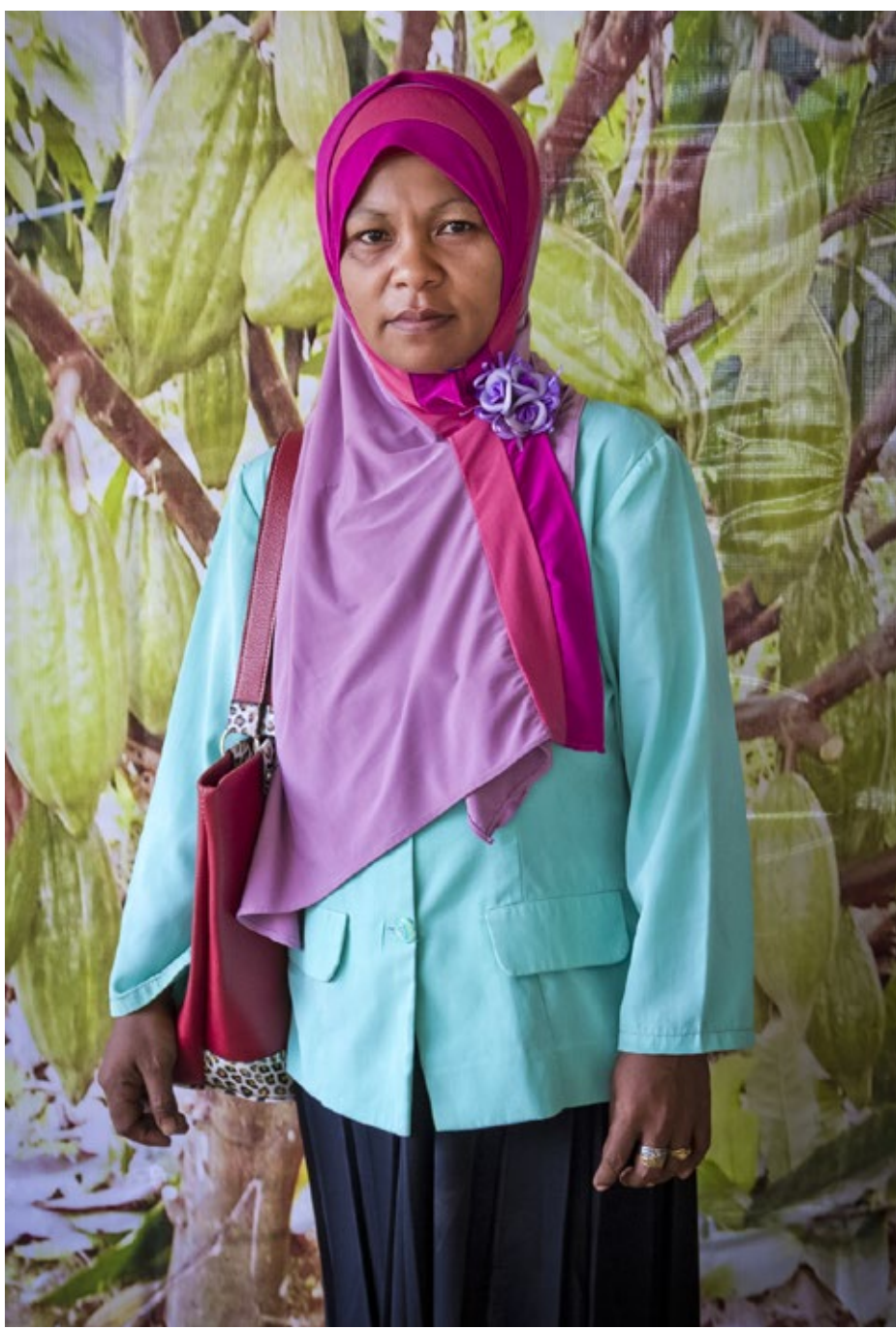

Projects were selected with the aim of arriving at a set of five projects with maximum variation in the sample. However, practical considerations in terms of the IFAD country team interest in and availability for the research meant that in the end, no cases were available in two of the areas ('financial

\begin{tabular}{|c|c|c|c|c|c|}
\hline Focus & $\begin{array}{l}\text { Financial } \\
\text { sector } \\
\text { development }\end{array}$ & $\begin{array}{l}\text { Commodity } \\
\text { value chain } \\
\text { development }\end{array}$ & \multicolumn{2}{|c|}{ Support smallholder production } & $\begin{array}{l}\text { Support other } \\
\text { market actors } \\
\text { (rural traders, } \\
\text { SMEs) }\end{array}$ \\
\hline $\begin{array}{l}\text { Process } \\
\text { to identify } \\
\text { partner }\end{array}$ & $\begin{array}{l}\text { Structured or } \\
\text { semi-structured }\end{array}$ & $\begin{array}{l}\text { Structured or } \\
\text { semi-structured }\end{array}$ & $\begin{array}{l}\text { Structured or } \\
\text { semi-structured }\end{array}$ & $\begin{array}{l}\text { Unstructured/ } \\
\text { opportunistic }\end{array}$ & $\begin{array}{l}\text { Structured or } \\
\text { semi-structured }\end{array}$ \\
\hline $\begin{array}{l}\text { Number of } \\
\text { IFAD projects }\end{array}$ & 3 & 6 & 5 & 6 & 4 \\
\hline $\begin{array}{l}\text { Countries } \\
\text { selected }\end{array}$ & Armenia $^{8}$ & $\begin{array}{l}\text { Rwanda } \\
\text { Uganda }\end{array}$ & Ghana & Indonesia & - \\
\hline
\end{tabular}


sector development' and 'support other market actors'). Instead, one additional case was selected in 'commodity value chain development', the newest and potentially more innovative area of IFAD work. In the end, therefore, the cases represent:

- commodity value chain development: Rwanda and Uganda;

- support smallholder production: Ghana (structured/semi-structured process to select partners) and Indonesia (unstructured process / opportunistic approach).

In each country, local research teams collected data through a mixture of semi-structured interviews, field visits and focus group discussions (FGDs), and a review of secondary research and data, supplemented and validated through stakeholder meetings at the start and end of the project. Participants for interviews were selected purposively from the range of PPPP stakeholders, including local market chain actors, smallholder farmers and other community members, and relevant experts. FGDs were conducted with participating smallholders (with different groups for men and women smallholders), peer groups (i.e. wider members of the same communities that were not participating in the PPPP) and comparison communities which were unaffected by the PPPP, using a mixture of purposeful (generally to select areas or districts) and random (generally to select individual communities) sampling. Wherever possible, the qualitative data from the fieldwork was triangulated by the researchers to mitigate bias and ensure the validity and reliability of findings, and supplemented by quantitative data from secondary sources, largely IFAD monitoring and project review reports.

The country studies were not impact assessments, and in most cases, it is too early to judge the full impacts. They represent instead a snapshot in time, in terms of how the lives of farmers and their communities are changing. However, it was important in the research not only to understand the process around the design and implementation of the PPPPs, but to have some insights into the outcomes of the PPPPs so far for different community members, and how these have been influenced by the way the PPPP was designed, implemented and brokered.

\section{Report outline}

This report is a synthesis of four case studies of IFAD project-supported PPPPs in Ghana, Indonesia, Rwanda and Uganda. The next section presents the analytical approach to the case studies, based on existing literature on PPPPs, as well as discussions with practitioners involved in or brokering partnerships. ${ }^{9}$ The following section presents a brief summary of the key features of the four PPPPs ${ }^{10}$ and the results of the fieldwork. Drawing on this learning, eight enabling factors that support agricultural value chain PPPPs for rural development are identified and presented. Finally the report offers a PPPP checklist, outlining the role for brokers in the process, before drawing conclusions from the research. 


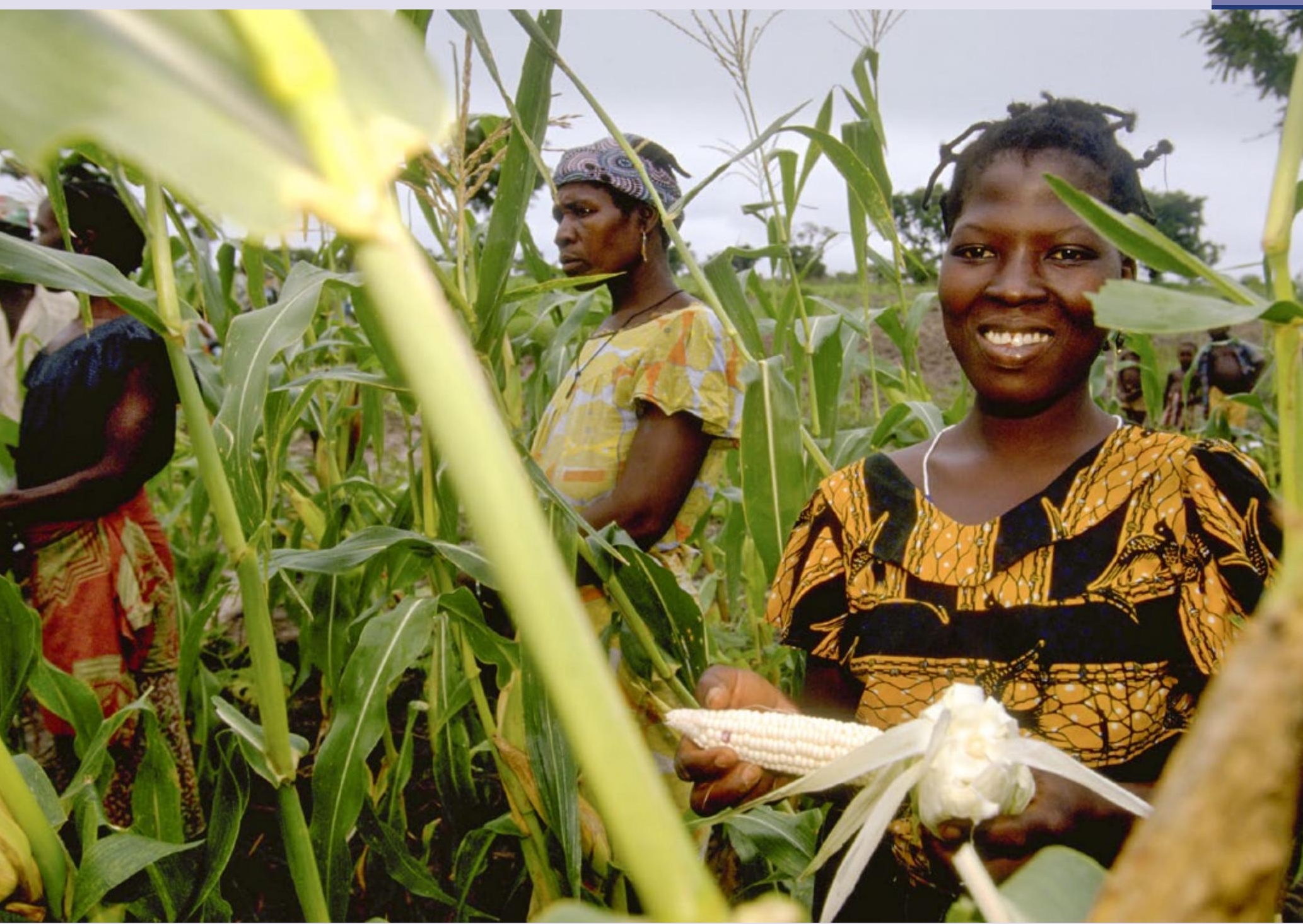

3 Approach to analysis

The four PPPPs were analysed based on three aspects: (a) the rationale for the PPPP - what were the constraints the PPPP sought to overcome and why did the partnership seem to present a solution which neither public nor private sectors could achieve alone; (b) partnership dynamics linked to PPPP design and implementation; and (c) the role of partnership brokers. Within all three aspects, the underlying interest is improving development outcomes for smallholder farmers and rural communities.

\section{The rationale for public- private-producer partnerships}

Public intervention in markets is usually justified because constraints are preventing an 'efficient' outcome from occurring - a market exchange that would raise overall social welfare.
Public intervention may also be justified on equity grounds - that markets are not delivering equitable outcomes or reducing poverty

(Department for International Development 2005). Constraints arise in markets due to market failures, such as missing markets for credit or inputs; institutional barriers, such as poor contract enforcement norms; and systemic weaknesses in market exchange, including the inability of agents to learn about each other, identify areas of complementarity, and build and sustain trust (Spielman et al. 2010).

\section{Market constraints to smallholder inclusion}

Market constraints related to smallholder farmers are particularly acute because of asymmetric information (e.g. between companies and farmers), high transaction costs leading to coordination failure, scale diseconomies, missing or underdeveloped
A farmer in a maize field. () IFAD/CHRISTINE NESBIT 
markets, undeveloped infrastructure and monopoly or near monopoly power often held by other actors in the value chain (World Bank 2007; Poulton et al. 2006). The following are four specific areas where smallholder farmers in agricultural value chains in developing countries commonly face constraints (Bitzer et al. 2009).

- Access to technology: Technological and managerial innovations required to engage in formal value chains, which may not be met by government extension services.

- Access to finance: Smallholder farmers are often not considered credit-worthy because they lack collateral, an assured income and/or have poor reputations for contract compliance.

- Access to markets: The absence of sufficient market demand for crops produced, collapsing local market prices or inaccessibility of markets with high distribution costs. in Uganda. (1) IFAD/ROBERT GROSSMAN
- Lack of farmer organisation: Small-scale farmers face scale diseconomies leading to high transaction costs in accessing inputs and markets, obtaining access to information, technology and finance, and weak bargaining power.

PPPPs do not only entail public sector intervention in markets. They also involve companies in public sector activities, such as extension services. PPPPs are often criticised for introducing profit-driven actors into these activities (De Clerck et al. 2012; Heinrich 2013); however, the rationale for a private sector role is generally on quality or efficiency grounds, or to create market arrangements that will be sustainable after public sector support ends (Heinrich 2013).

\section{Partnership dynamics during design and implementation}

Despite the attractions of partnership, different cultures, languages, incentives and straightforward mistrust can lead them to fail. Much has been written on the dynamics of development partnerships (Brickell and Elias 2013; Ferroni and Castle 2011; Drost et al. 2012; Heinrich 2013; Brinkerhoff 2002; OECD 2008; Van Huijstee et al. 2007), though not all are specific to PPPPs. Elements commonly identified as critical for successful partnership are:

\section{- Ownership and involvement of all}

partners based on jointly agreed objectives, with clear roles and responsibilities, and mechanisms through which the interests of partners can be represented.

- Interdependence where the interests of different partners align around a shared objective (while recognising that partners continue to have differing underlying interests), based on formal and informal mechanisms that align the exchange and use of resources between the partners.

- Governance mechanisms with processes to provide transparency, ensure accountability and foster and maintain trust.

- Risk management, which includes reallocation of risk between partners as well as risk prevention and mitigation.

- Clear and transparent communication through formal and informal spaces 
for dialogue, shared planning and decision-making.

- Monitoring and evaluation, with indicators based on expected results, leading to adaptation of the partnership to improve results.

\section{Partnership brokers}

A PPPP 'broker' is an independent facilitator during the PPPP process. The partnership literature is relatively thin on the role of brokers but points to exploring the feasibility of the partnership, introducing partners, building trust and supporting the negotiation of the partnership agreement as key roles (Warner 2009). Brokers can also help to maintain the effectiveness of the PPPP during implementation by helping partners to respond to changes in the external context on an ongoing basis. The role can require considerable technical skills in negotiation and design of effective arrangements and business models, as well as an understanding of the different cultures and motivations of partners.

Someone trusted from one of the parties can play the role of broker. For example, the government can broker the relationship between farmers and a company as part of a three-way (public-private-farmer) partnership. However, it is more often an external and independent actor, like an NGO or donor, which acts as a broker. Within the same partnership, different actors can be brokers at different points in the evolution of the partnership, or between different partners.

\section{Development outcomes for smallholders and rural communities}

At the heart of the analysis around publicprivate partnerships are questions around results. In the case of agricultural PPPPs in the development sector, this means improvements to the lives of rural communities, through improved access to income-generating activities or improved food security, for example. Potential benefits that have been ascribed to agricultural value chain PPPPs include encouraging investment with high social returns, improving the function of input markets, new and better outlets for smallholders' products, enabling risks and resources to be better shared, promoting economic growth and (in some cases) ensuring a fair share of gains is captured (Poulton and Macartney 2012; Bitzer et al. 2009; Fairtrade Foundation 2014; Abdulsamad et al. 2015). However, most studies note that data on outcomes and impacts are limited.

However, PPPPs have also faced substantial criticism. Significant concerns have been expressed that the top-down and businessdriven nature of many partnerships privileges business interests, while poor farmers and marginalised communities are either excluded or included on unfavourable terms (Bendell et al. 2010; Blowfield 2007; Heinrich 2013; Ministry of Foreign Affairs of The Netherlands 2013; Lund-Thomsen 2009; Reed and Reed 2009; Utting and Zammit 2009). Exclusion comes because commercial incentives and the difficulties of working with often widely dispersed smallholders mean that value chains involve more organised, asset-ready and geographically accessible farmers. Inclusion on unfavourable terms results from value chains that reinforce captive relationships in which smallholders are unable to exit, or which leave them bearing unsustainable risk related to debt financing, environmental degradation and reliance on a single buyer (Willoughby 2014; Abdulsamad et al. 2015). The risk is not only the exclusion or unfavourable inclusion in value chains, but also that the public sector will withdraw its activities from communities that are not part of the value chain, on either the belief or the pretence that the market is providing solutions. 


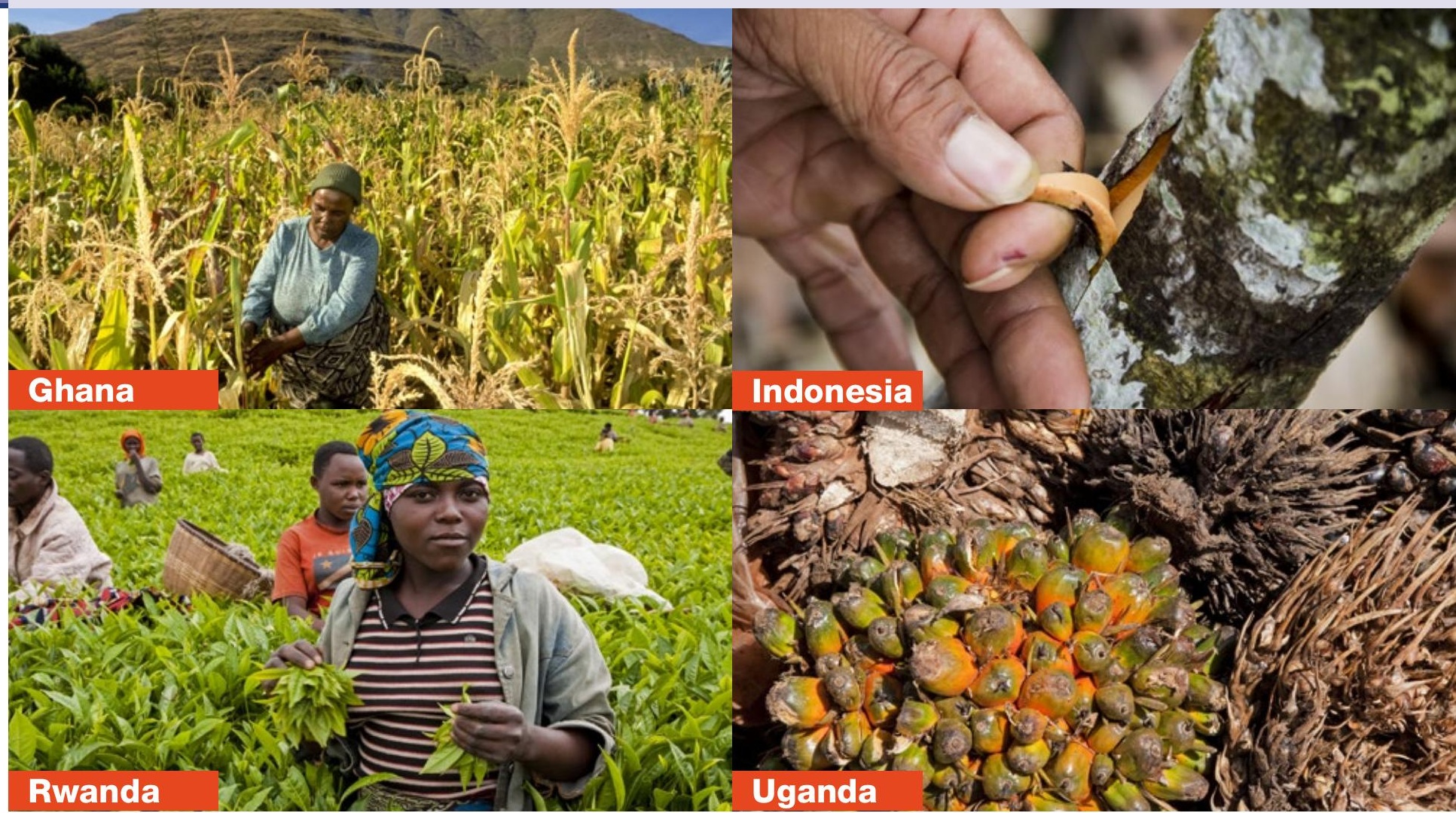

\section{Case studies}

\section{Introduction}

The research explored the design and implementation of four IFAD project-supported PPPPs, and how this affected the outcomes being observed in terms of smallholder livelihoods and rural development. These four case studies, in Ghana, Indonesia, Rwanda and Uganda (see Table 4.1 for an overview), all involved an arrangement between one or more private companies and a government-run implementing unit, which was responsible to the relevant government department, usually the Ministry of Agriculture. All the arrangements also involved smallholder producer organisations as the third partner. IFAD - alongside others such as NGOs - acted as a broker. IFAD also provided funding to the government partner. All the PPPPs aimed to either bring new small-scale farmers into the value chains of crops such as maize, oil palm and tea, or to improve the terms on which farmers were included through better access to credit or training (Table 5.1).

Table 4.1: Case study overview

\begin{tabular}{|c|c|c|c|c|}
\hline & Ghana & Indonesia & Rwanda & Uganda \\
\hline Region & Northern Ghana & Central Sulawesi & $\begin{array}{l}\text { Southern province } \\
\text { (Nshili and Mushubi) }\end{array}$ & $\begin{array}{l}\text { Kalangala District, } \\
\text { Bugala Island }\end{array}$ \\
\hline Commodity & Maize & Cocoa & Tea & Oil palm \\
\hline $\begin{array}{l}\text { IFAD-funded } \\
\text { programme }\end{array}$ & NRGP & READ & $\begin{array}{l}\text { PDCRE } \\
\text { PRICE }\end{array}$ & VODP \\
\hline Dates & $2008-16$ & $\begin{array}{l}2008-14 \\
\text { (reformulated in } \\
2011 \text { to include } \\
\text { PPPP) }\end{array}$ & $\begin{array}{l}\text { PDCRE: 2003-11 } \\
\text { (reformulated in } \\
2005 \text { to include PPPP) } \\
\text { PRICE: } \\
\text { 2011-present }\end{array}$ & $\begin{array}{l}\text { Phase 1: } \\
\text { 1997-2012 } \\
\text { Phase 2: } \\
\text { 2012-18 }\end{array}$ \\
\hline
\end{tabular}




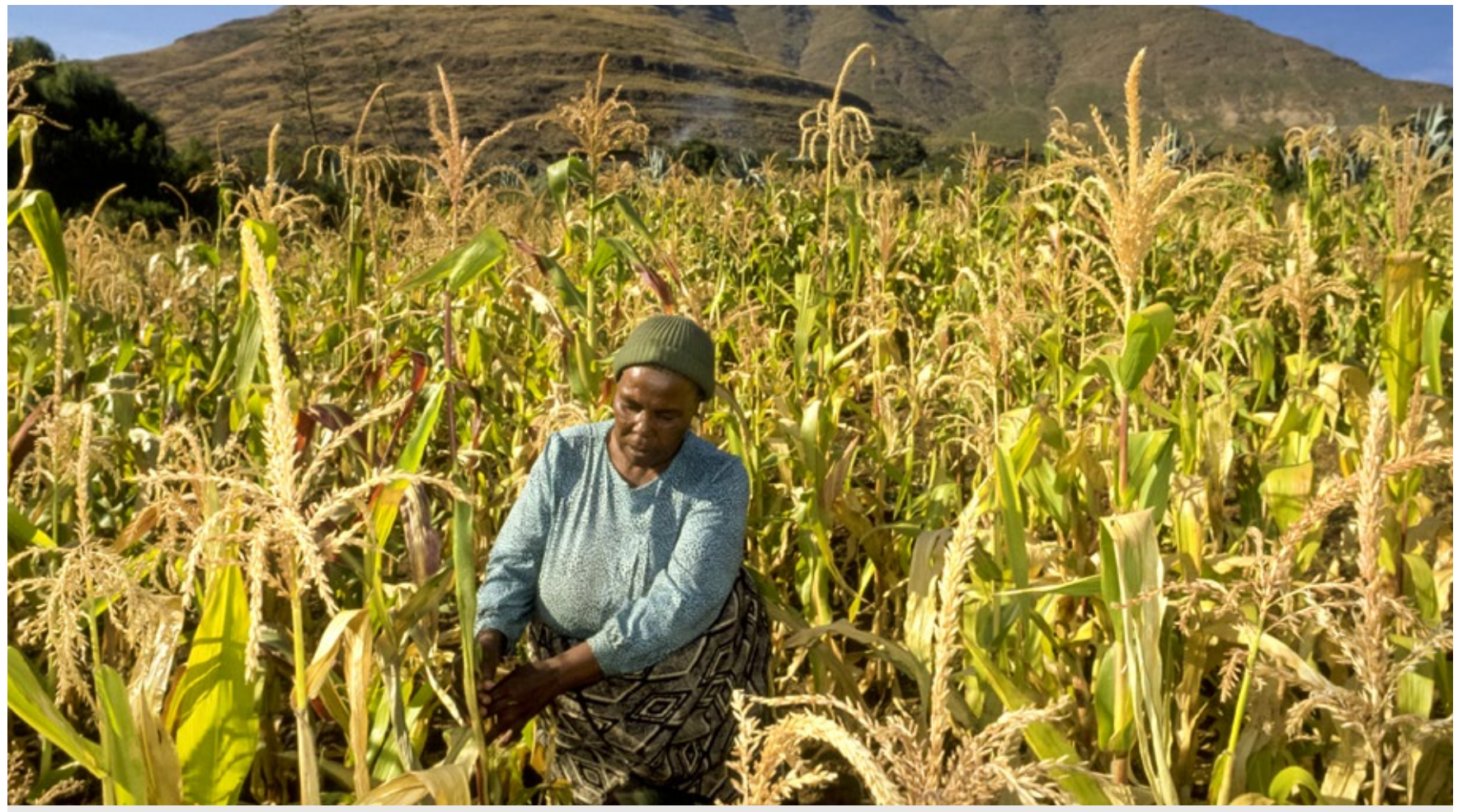

\section{Ghana $^{11}$}

The Northern Rural Growth Programme (NRGP), implemented by the Government of Ghana and supported by IFAD, involves a series of PPPPs that aim to address the challenges facing smallholder farmers in northern Ghana. These include limited access to inputs and services, low productivity and low prices. The PPPPs aim to improve farmer access to finance, infrastructure, production and marketing, by linking the private sector to small-scale producers of maize, shea nut, butternut squash or soybeans. This research focused specifically on the PPPP value chain arrangements for maize, which is both a staple and a cash crop in northern Ghana.

\section{PPPP agreements}

The PPPP has agreements at two different levels, creating and building the capacity of farmerbased organisations (FBOs) and linking them to other stakeholders in the chain:

\section{A fairly informal agreement between NRGP} and the end buyers (Nestle or Akate Farms). Nestle provides training for extension workers related to quality and food safety and, indirectly, purchases crops produced by FBOs. Akate Farms purchases crops directly from the institutional aggregator, Savannah Farmers Marketing Company (SFMC). ${ }^{12}$ Nestle (but not Akate Farms) has a Memorandum of Understanding (MoU) with the government.
2. A formal purchasing arrangement between the FBOs and SFMC. This arrangement fosters access to credit for FBOs through a 'cashless credit system'.

The status of smallholder farmers in the PPPP is unclear. Farmers' organisations are represented in the District Value Chain Committees, yet there is a perception (including among some farmers themselves) that they are 'recipients' rather than active partners involved in decision-making during the programme planning and design phase.

\section{New institutional arrangements created}

1. District Value Chain Committees have been set up, with support from ACDEP, an NGO, to coordinate actors in the value chain, including FBOs, input and service providers and aggregators. They support the 'cashless credit system' and improve farm access to credit, inputs and services.

2. The 'cashless credit system' allows smallholders to receive inputs or services; the providers of which are paid directly by rural banks at a price agreed in the District Value Chain Committees. These loans are repaid to the banks when farmers sell the produce.

\section{Results}

The PPPP has enabled smallholder farmers to produce more and better quality maize. Maize productivity is estimated on average to have more than doubled. Average yields rose from $0.8 \mathrm{MT} / \mathrm{ha}$
A farmer working in a maize field. () IFAD/GIUSEPPE BIZZARRI 
in 2007 in the northern regions to between $1.5 \mathrm{MT} /$ ha to $3.2 \mathrm{MT} /$ ha in $2014 .{ }^{13}$ The sale of surplus maize has boosted household incomes and livelihoods in some cases, ${ }^{14}$ though income stability has not improved since crop yields can vary from season to season and the aggregator has not been consistent in buying maize.

The establishment of FBOs and the District Value Chain Committees bringing together all actors in the local maize value chain has established vital linkages for smallholder farmers and has given them more secure output markets, although women's participation in FBOs and District Value Chain Committees was low. The cashless credit system has given them access to improved inputs and mechanisation services. Twenty-four rural banks (which had previously been reluctant to lend to smallholder farmers) were participating at the time of the fieldwork, from a starting base of two. It has also given farmers more voice through their participation in the committees, which also provides a channel for local arbitration of conflicts and promotes greater transparency in setting prices for inputs and outputs.

However, high exposure to risk on the part of farmers and rural banks threatens programme sustainability. At the time of the fieldwork, recovery of the past season agricultural production loans was slow, and one leading rural bank had decided not to offer agricultural

\section{Table 4.2: Ghana PPPP overview}

\begin{tabular}{|c|c|c|c|c|}
\hline PPPP objective & \multicolumn{4}{|c|}{ Improve productivity and quality of maize in Northern Ghana } \\
\hline \multirow[b]{2}{*}{$\begin{array}{l}\text { Smallholder } \\
\text { inclusion }\end{array}$} & \multirow{2}{*}{\multicolumn{2}{|c|}{$\begin{array}{l}\text { Smallholder constraints addressed } \\
\text { Access to finance and technology, } \\
\text { farmer organisation }\end{array}$}} & \multicolumn{2}{|c|}{ What solution did the PPPP create? } \\
\hline & & & $\begin{array}{l}\text { - } \text { DVCC tc } \\
\text { access } \\
\text { - Enhance } \\
\text { from Ne } \\
\text { - Creation }\end{array}$ & $\begin{array}{l}\text { smallholder farmers to facilitate } \\
\text { redit and inputs } \\
\text { ccess to technology, provided } \\
\text { through the government } \\
\text { FBOs }\end{array}$ \\
\hline & Private sector & \multicolumn{2}{|c|}{ Public sector } & Farmers \\
\hline Partners & $\begin{array}{l}\text { SFMC (domestic company), } \\
\text { Nestle (MNC) } \\
\text { Others linked informally } \\
\text { (e.g. Akate Farms) }\end{array}$ & \multicolumn{2}{|c|}{$\begin{array}{l}\text { Ministry of Food and } \\
\text { Agriculture (through } \\
\text { NRPG) and Department of } \\
\text { Cooperatives }\end{array}$} & FBOs formed by government \\
\hline Roles & $\begin{array}{l}\text { Nestle: provision of } \\
\text { training materials } \\
\text { - SFMC: aggregates } \\
\text { maize from smallholders } \\
\text { and supplies to end } \\
\text { users; source for } \\
\text { payback arrangement } \\
\text { under cashless credit } \\
\text { system }\end{array}$ & \multicolumn{2}{|c|}{$\begin{array}{l}\text { Formation of FBOs } \\
\text { supported by the NGO } \\
\text { ACDEP to provide training } \\
\text { on group formation } \\
\text { - Facilitate DVCCs and } \\
\text { cashless credit system }\end{array}$} & $\begin{array}{l}\text { - FBOs are members of the } \\
\text { DVCCs } \\
\text { - Farmers provide maize } \\
\text { to SFMC (but also sell to } \\
\text { traders) }\end{array}$ \\
\hline
\end{tabular}

- IFAD: Loan funding, technical support, monitoring and evaluation, policy dialogue, facilitates contacts to possible new partners

- ACDEP: Capacity building with farmers and DVCCs, conflict resolution

- NRPG: Has the trust and confidence of the companies, conflict resolution

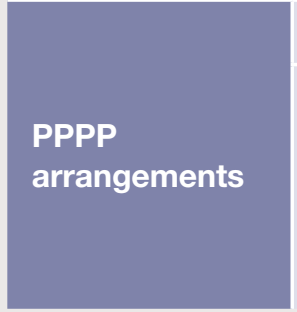

\section{New institutional arrangement created}

- Cashless credit system

- DVCC

\section{New roles that need to be sustained}

- FBOs, input and service providers and aggregators manage DVCCs

- Farmers, input and service providers, aggregators and rural banks participate in cashless credit system 
loans for the 2014/15 cropping year. The cashless credit system is also hampered by limitations placed by the Bank of Ghana on the percentage of rural banks' loan portfolio that can be unsecured.

\section{Key learning}

- Innovative governance mechanisms

The District Value Chain Committee (DVCC) promotes trust and the sharing of information between value chain actors, facilitated by an external broker (ACDEP in this case). It provides a space to share and access transparent information around input or service prices and supports the 'cashless credit system', giving rural banks greater confidence in working with farmers.

- Risk management. It is vital to identify and quantify the risks facing each stakeholder in PPPP arrangements, so that mechanisms for appropriate sharing of risks can be developed. The high exposure to risk on the part of farmers and rural banks in Ghana has threatened programme sustainability.
Poverty is there but the community will never go hungry again - [Why?] We have access to fertiliser, tractor services, good seeds now compared to previous tools which were cutlass and hoe and no modern inputs. We have a dam and did not know how to use it. Now people do dry season farming and there is food throughout the year.

\section{Men's focus group discussion}

This year (2013/14) FBO repayments are poor. The bank believes some actors did not do their work. Monitoring was bad which could have helped solve some of the problem.

\section{Participating rural bank}

Figure 4.1: PPPP arrangement in maize value chain in Ghana

Legend

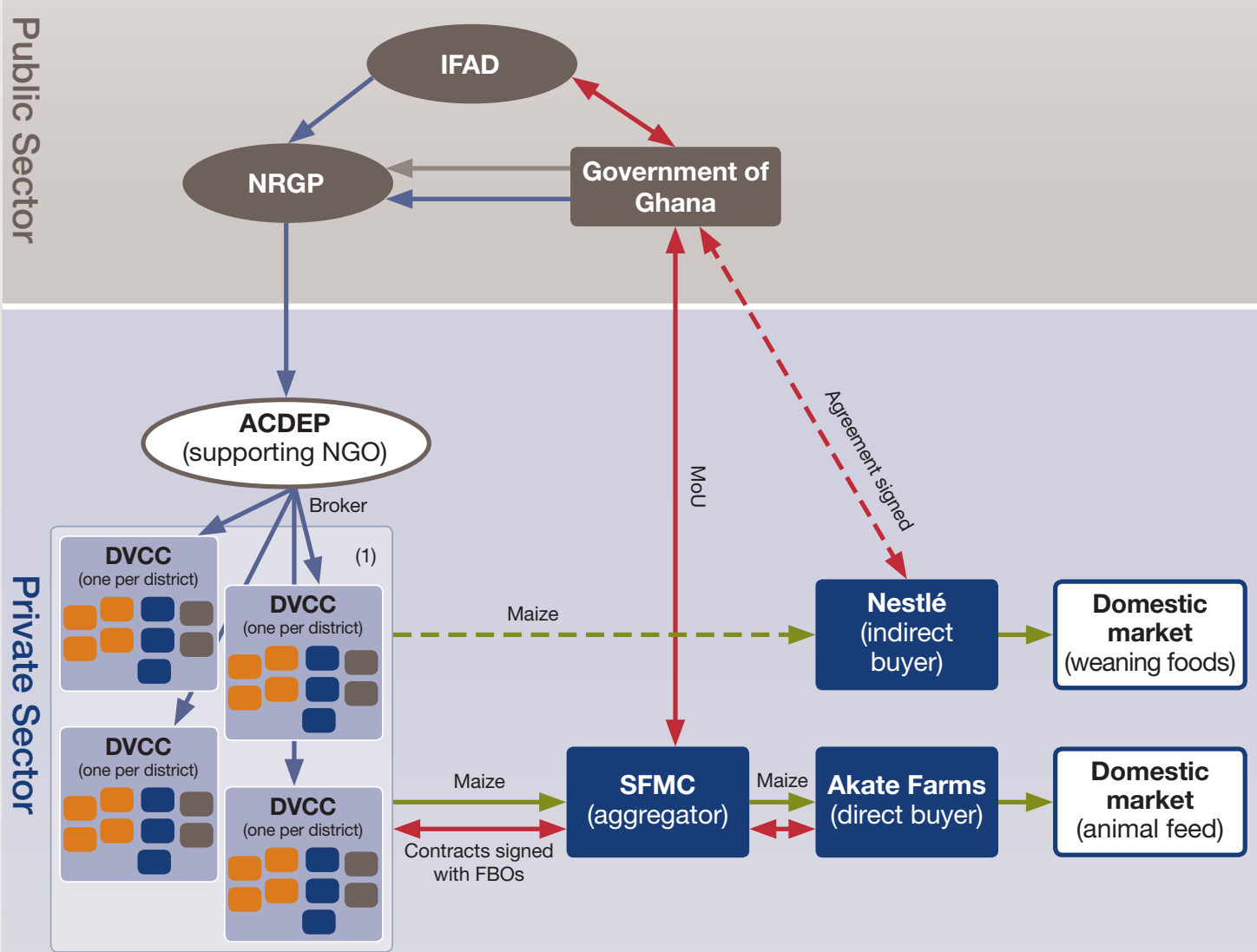




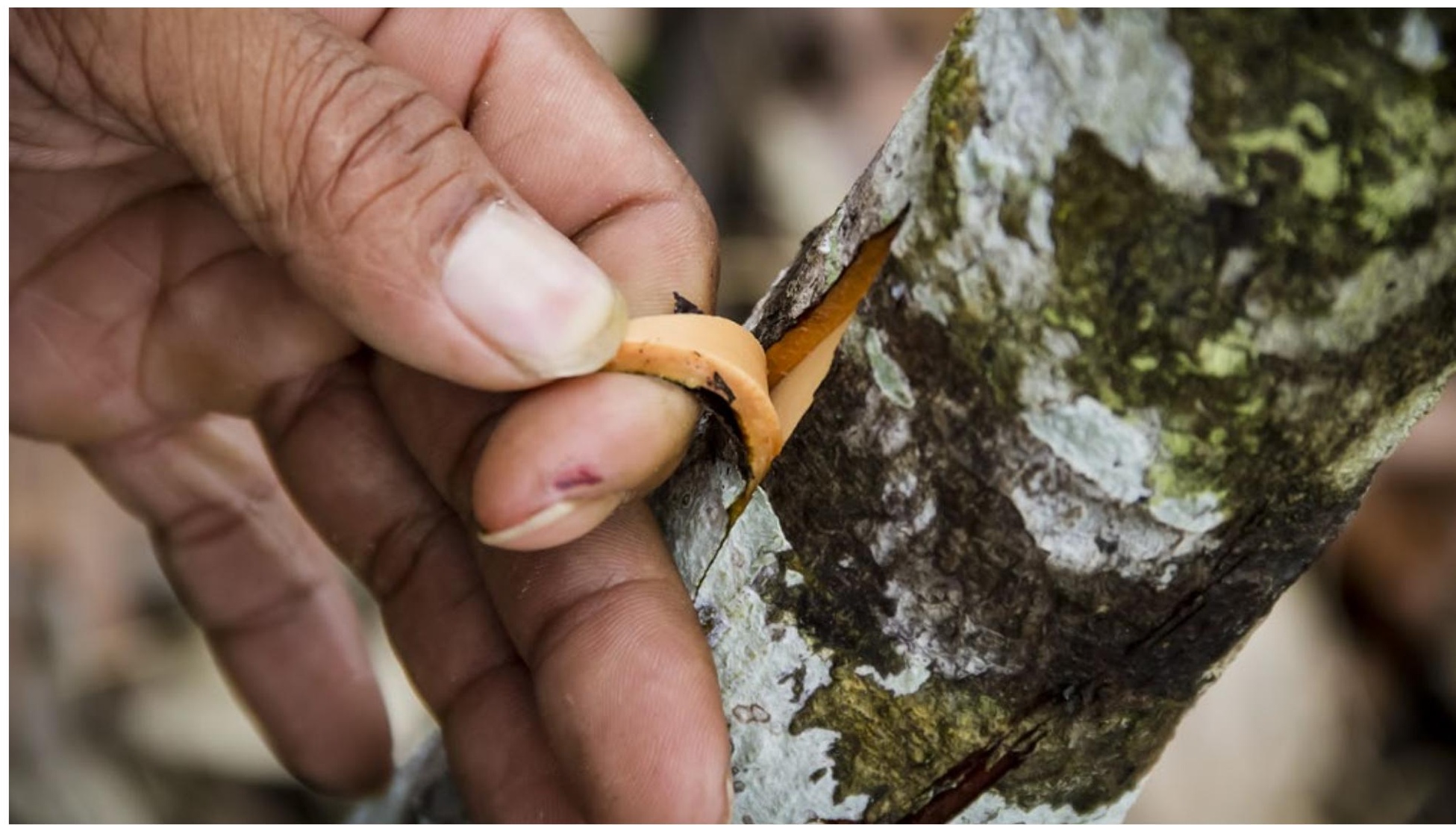

\section{Indonesia ${ }^{15}$}

A An extension worker demonstrates side grafting on cocoa trees for farmers at a Cocoa Development Center (CDC)

in Central Sulawesi, Indonesia. () IFAD/ROGER ARNOLD
The PPPP in Indonesia evolved from an existing government programme, the Rural Empowerment and Agricultural Development (READ) programme (2009-14), implemented by the Government of Indonesia and supported by IFAD in Central Sulawesi. Cocoa production in the region faced serious problems of ageing plants, pests and diseases, insufficient improved planting material and technologies, and poor farm management practices. Neither the READ programme nor supporting units, such as the government's Extension Agency, had sufficient expertise to resolve these challenges.

The READ programme was redesigned to include a PPPP with Mars Symbioscience Inc, a major cocoa buyer in the region, to establish five Cocoa Development Centres (CDCs) for training on improved cocoa farm management techniques to overcome low cocoa productivity. The PPPP design is based on the CDC model and cocoa cultivation technology developed by Mars in South Sulawesi. The PPPP, which is the focus of the research, sits within a much broader redesigned READ programme (not covered by the research).

\section{PPPP agreements}

The government and Mars have a contract and MoU where they agree to work towards improving cocoa productivity, which is also expected to improve farmer welfare. Mars provides the technology package, trains key farmers and extension workers, and provides technical assistance; the government develops the infrastructure, provides extension workers, organises farmer groups and builds capacity among them, and offers farmer financing via a revolving loan fund. The farmer groups also receive assistance from a facilitator (NGO) on group management, communication and accounting.

IFAD played a crucial role in developing these relationships, in a context of generally low trust between public and private sectors in the country. IFAD identified a private partner that it trusted and had the right skills and resources to offer, and acted as a broker to build trust.

\section{New institutional arrangements created}

The key institutions are the CDCs and associated Village Cocoa Centres (VCCs) at farmer group (village) level. The CDCs are the key infrastructure for technology delivery, establishing demonstration cocoa gardens, and monitoring and supporting the VCCs at farmer-group level. The CDCs are under the authority and management of the government's District Management Units, and all 'key farmers' and extension 
workers who receive training through the system are coordinated by the CDCs. The VCCs are the training and experimentation ground for farmer groups where key farmers and extension agents apply their skill and other farmers can learn. There are 200 VCCs developed and operating in the project area.

There is no marketing element to the PPPP, and most farmers still sell to local collectors at village or sub-district level due to frequent marketing of small harvest volumes and the fact they owe money to the collector. Currently, cocoa prices are high, but there is a risk that marketing could become a problem in the future. The next phase of the programme will address marketing aspects.

\section{Results}

The implementation of the PPPP has been uneven. In those areas where the CDC/VCC model is functioning well, there is a strong technology chain to farmers leading to improvements in productivity, technical knowledge and quality. Productivity has reached $100 \mathrm{~kg}$ to $200 \mathrm{~kg}$ per tree per month. Even though this is below optimal levels, ${ }^{16}$ it represents a significant increase since 2010, when productivity averaged $50 \mathrm{~kg}$ per tree per month. The average weight of cocoa beans has increased by 10 to 15 per cent.

Women's participation in cocoa farming activities (seedling production and cocoa maintenance) has increased. However, the research did not establish whether women saw income benefits from this additional work, and how this was balanced with other, pre-existing responsibilities.

However, at the time of the fieldwork, most farmers were yet to see the benefits. Many were still growing the seed, or had trees just at the flowering case study continues over page >

\section{Table 4.3: Indonesia PPPP overview}

PPPP objective

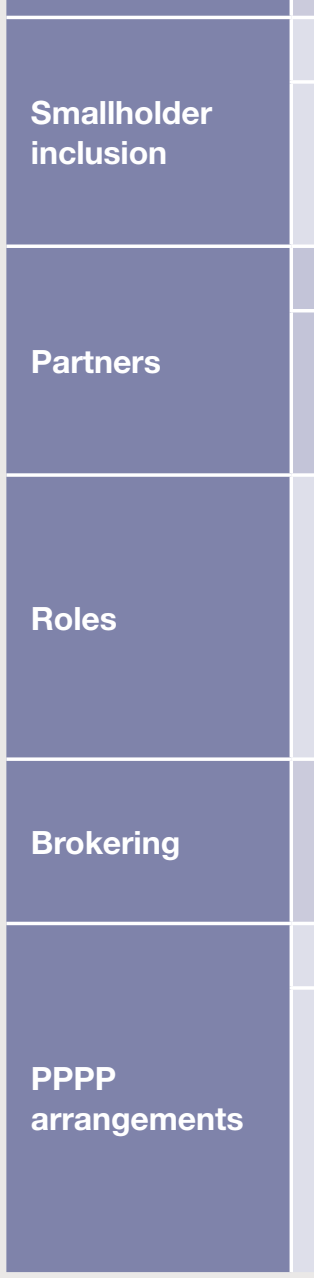

Improve cocoa productivity and retention of farmers in the cocoa sector

\section{Smallholder constraints addressed}

Access to finance and technology, farmer organisation

\section{What solution did the PPPP create?}

System to disseminate improved cocoa technology to extension workers and key farmers

\begin{tabular}{|l|l|l|}
\hline Private sector & Public sector & Farmers \\
\hline Mars (MNC) & $\begin{array}{l}\text { Ministry of Agriculture (through } \\
\text { READ programme) }\end{array}$ & $\begin{array}{l}\text { Farmer organisations (FOs) } \\
\text { focused on cocoa, formed by } \\
\text { the government }\end{array}$ \\
\hline
\end{tabular}

Provide training to lead farmers and extension workers, and technical assistance to CDCs in five districts
- Formation of FOs focused on cocoa, with support and services provided by an NGO

- Provide extension agents for training, and create CDCNCC infrastructure
FOs operate the Village Cocoa Centres (VCCs)

- IFAD: Strong brokering between partners to initiate PPPP, as well as loan funding, technical support, monitoring and evaluation, support on public relations

- NGO: Support services for FOs

New institutional arrangement created

System of CDCs and VCCs

\section{New roles that need to be sustained}

- Extension workers and key farmers undertake training and provide technology and services to farmers

- FOs manage VCCs

- District Management Units (government) manage CDCs 
districts meant important delays in training and VCC development. While 150 farmers and extension agents have attended the training, they do not have enough knowledge to independently apply the technology and improvise in the field, so remain dependent on ongoing support from Mars. With limited resources for the PPPP, Mars has prioritised those (more central) areas where it sources cocoa, neglecting more remote and marginalised districts.

\section{Key learning}

- Clear objectives. The PPPP had a very clear objective of increasing the productivity and quality of cocoa produced by smallholder farmers. This clarity allowed IFAD to play a key role in identifying a private sector partner with a shared interest and strong technical competency. However, assumptions around how much training would be sufficient led to unfulfilled expectations among the partners.

- Develop incentives for the stakeholders to continue in their new roles. The long-term sustainability of the CDCs and VCCs in Indonesia depends on the willingness and ability of stakeholders to carry on new functions. However extension agents in particular lack incentives to specialise in cocoa, undermining long-term sustainability.
The application of Mars technology packages to rehabilitate cocoa gardens by farmers in the villages involved in the PPPP has been demonstrating results. During focus group discussions, farmers spontaneously described the demonstration plot as 'a dream garden', with cocoa plants rich in blossoms and fruits. With the right treatment, drainage, and input composition, soil quality has quickly improved.

\section{Report from focus group discussion}

Figure 4.2: PPPP arrangement for cocoa technology support in Indonesia

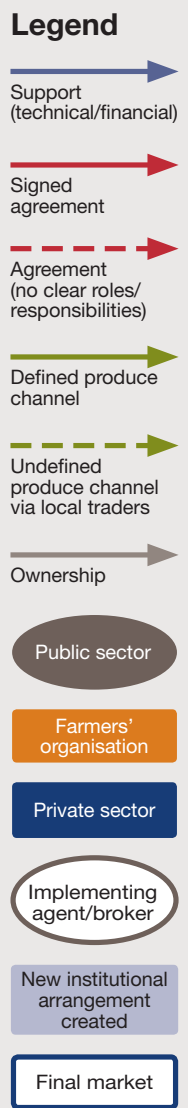

International market products) (chocolate

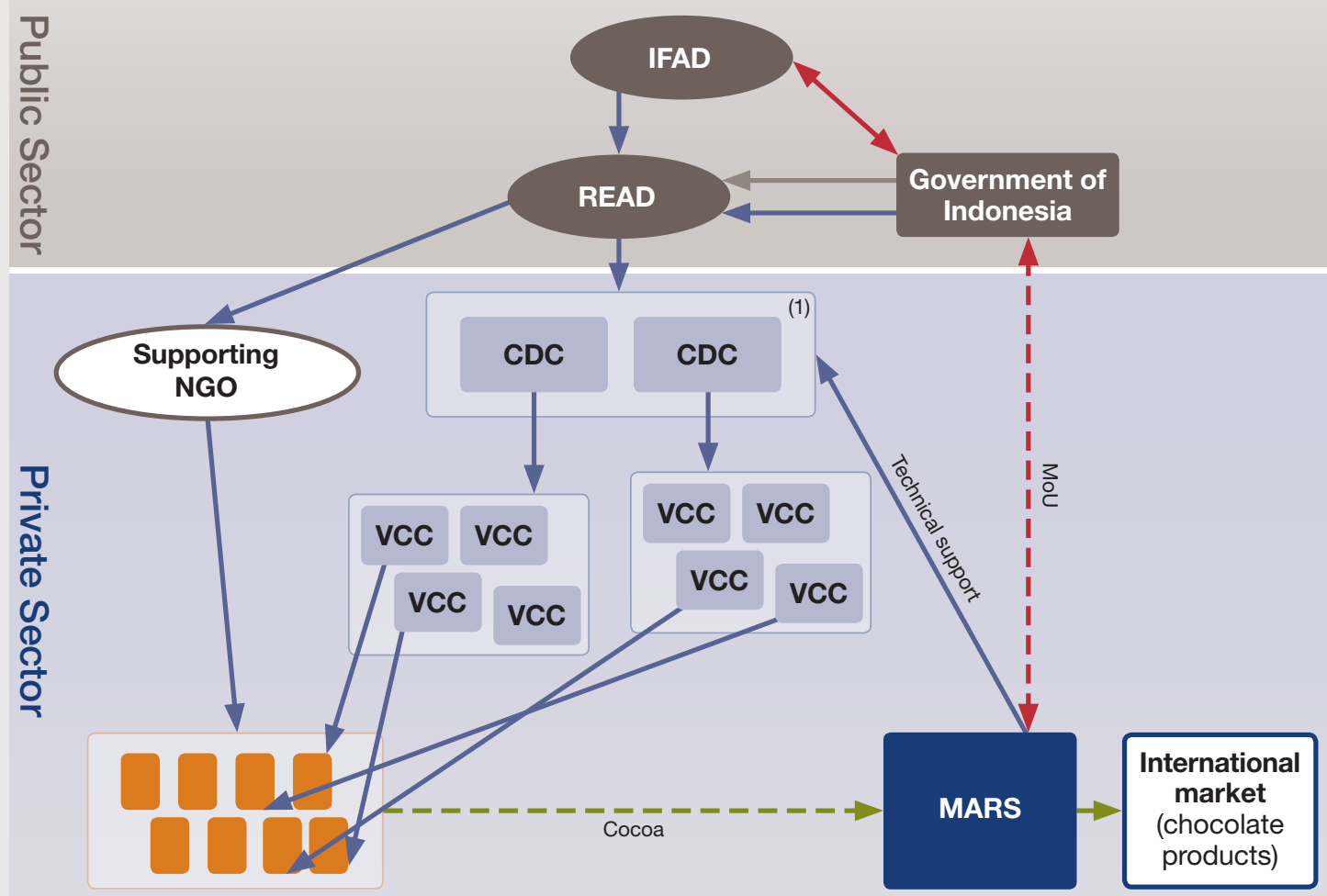

Final market 


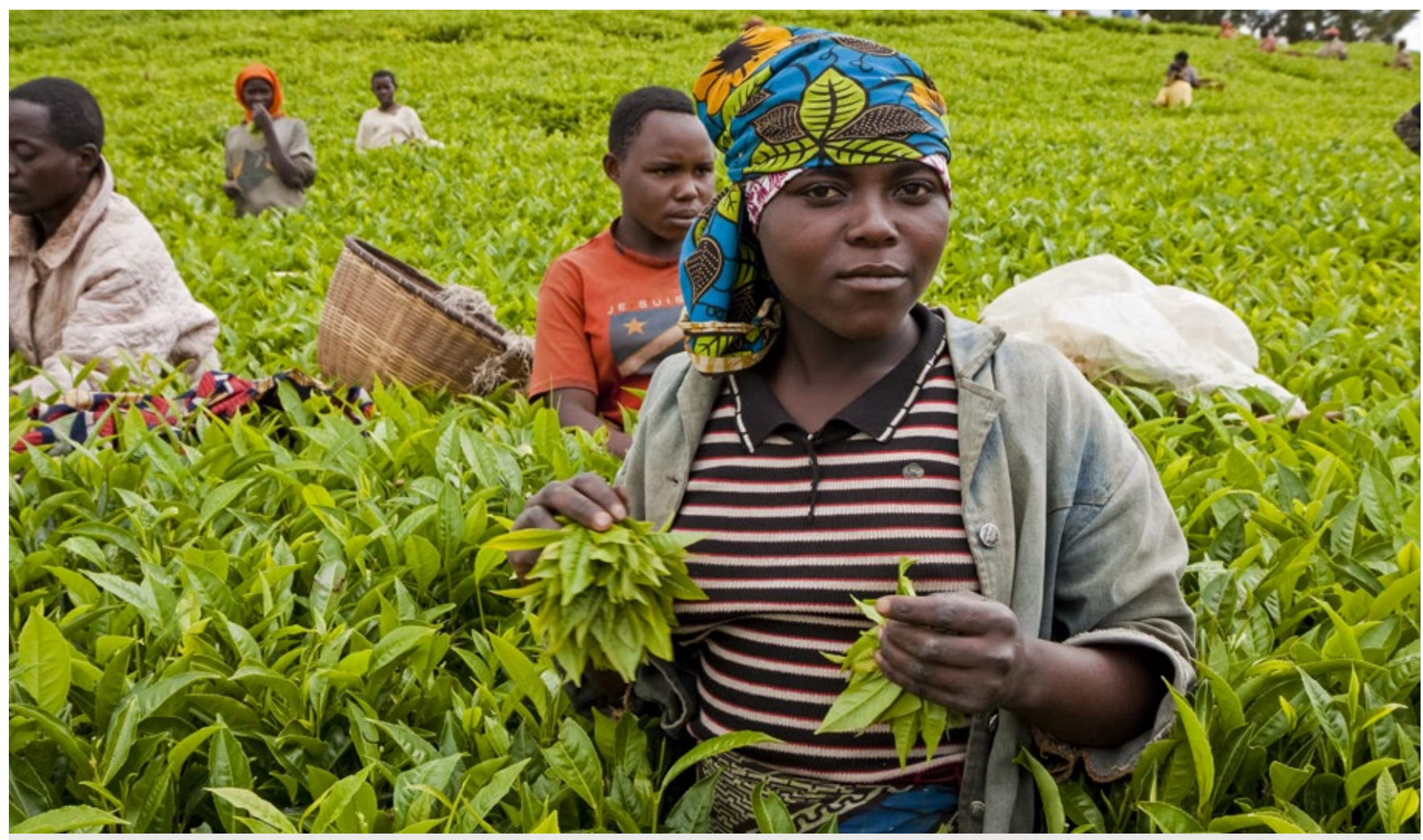

\section{Rwanda $^{17}$}

The case study in Rwanda involves PPPPs in two tea estates in the southern province of the country, one in Nshili and one in Mushubi. These PPPPs were designed and implemented as part of the government's privatisation of the tea sector, and emerged from a previous IFAD-supported, Government of Rwanda project, the Smallholder Cash and Export Crops Development Project (PDCRE). The aim of the PPPPs was to secure substantial public and private sector investment to drive an increase in smallholder incomes and generate new employment opportunities in tea-growing regions in marginalised areas of the country.

\section{PPPP agreements}

The model used for the PPPPs at Nshili and Mushubi was broadly similar. The private sector (in both cases a consortium) leased land from the government to manage a tea plantation and build and operate a tea factory, contributing financing, working capital and technical and managerial skills. The government provided infrastructure improvements (roads and electricity) to support the factory. The government and the private sector have formal agreements, including lease agreements on tea plantations and forests.

Cooperatives were set up by the government with the aim of providing a regular supply of quality green leaves to the factory. The cooperatives took loans from the Banque Rwandaise de Développement (BRD) to finance tea expansion and purchases of fertiliser and other inputs.

\section{New institutional arrangements created}

The PPPP develops the tea value chain, ${ }^{18}$ from inputs through production, processing and marketing, providing farmers with a guaranteed market. The PPPP emphasised developing cooperatives as viable, community-owned businesses (rather than pursuing tea production targets at any cost). The cooperatives are dependent on a single buyer for their crops, though a government-set pricing mechanism ${ }^{19}$ helps protect farmers from extreme falls in tea prices and from an inequitable bargaining position with the companies.

The private investor owns 70 to 85 per cent of shares in the tea factories, ${ }^{20}$ with the government purchasing 15 per cent on behalf of the cooperative, to create greater ownership of the farmers in the PPPP and an opportunity for the farmers to benefit from dividends.

\section{Results}

Tea growers have increased their incomes through selling green leaves and working in the factories as wage labourers, pluckers, cleaners etc. Households have been able to use some of their extra income
A Tea pickers working in the field in Rwanda ( ) IFAD/SUSAN BECCIO 
to invest in animals and other assets ${ }^{21}$ and access health services. ${ }^{22}$ Food security ${ }^{23}$ has also improved. The cooperatives and their members have assets including considerable land planted with tea, ${ }^{24}$ as well as shares in the tea factory.

The PPPPs have also brought improvements in roads and electricity supply in both areas, as a result of government investment, as well as broader economic impacts. They have generated large numbers of permanent and seasonal jobs, as well as temporary work in transportation and construction, in areas where livelihood options were previously fairly limited. Before the PPPPs, up to 40 per cent of the labour force in both areas used to migrate to find seasonal work. Today, there is no seasonal out-migration; rural poor from other areas come to Nshili and Mushubi to find work.

However, although yields of green leaf have increased - from 0.1T/ha/year in 2011 to $0.7 \mathrm{~T} / \mathrm{ha}$ /year in 2013 in Nshili and 2.5T/ha/year in 2013 in Mushubi, these are still below expectations of 6 to 7T/ha/year. Farmers are not seeing sufficient economic advantages in acceptable timeframes, and so are not fully implementing better crop management techniques (weeding, proper use of fertiliser, pruning). This is compounded by high vacancy rates, and, among other factors, ${ }^{25}$ is contributing to lower than expected productivity. Low productivity is undermining smallholders' ability to meet loan repayments. ${ }^{26}$

Due to insufficient supplies of green leaf tea, both factories currently operate well below nominal capacity - 30 per cent in Mushubi (where nominal capacity is 3,500MT/year of made tea) and 40 per cent in Nshili (where nominal capacity is $3,000 \mathrm{MT} /$ year of made tea). This has generated tensions between the investor and the cooperatives. At both sites, the investor considers that the cooperatives are not

\section{Table 4.4: Rwanda PPPP overview}

PPPP objective

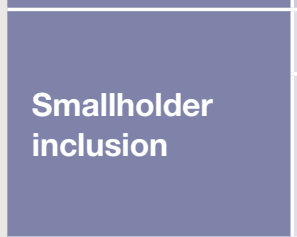

Partners

\section{Brokering}

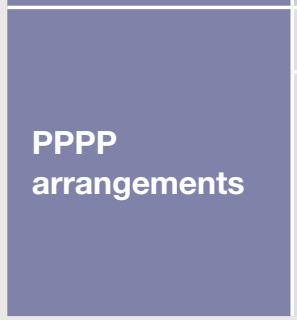

Investment in the tea sector in poor areas of the country

Smallholder constraints addressed

Access to markets, farmer organisation

\section{What solution did the PPPP create?}

- Local tea factory as market for green leaves (Nshili)

- New tea sector/factory (Mushubi)

\begin{tabular}{|c|c|c|c|c|}
\hline \multirow[b]{2}{*}{ Partners } & Private sector & \multicolumn{2}{|c|}{ Public sector } & Farmers \\
\hline & $\begin{array}{l}\text { Private Investor consortia } \\
\text { (Nshili Kivu Tea Plantation } \\
\text { Company in Nshili } \\
\text { and Multisectorielle } \\
\text { d'Investissement de } \\
\text { Gikongoro in Mushubi) }\end{array}$ & \multicolumn{2}{|c|}{$\begin{array}{l}\text { National Agriculture Export } \\
\text { Board (NAEB) through PDCRE }\end{array}$} & $\begin{array}{l}\text { Tea cooperatives formed by the } \\
\text { government }\end{array}$ \\
\hline Roles & $\begin{array}{l}\text { Invest in tea processing } \\
\text { and provide technical } \\
\text { assistance and logistics } \\
\text { (transport, fertiliser) }\end{array}$ & \multicolumn{2}{|c|}{$\begin{array}{l}\text { Formation and training of } \\
\text { tea cooperatives, securing } \\
\text { them a } 15 \text { per cent } \\
\text { shareholding in tea factory } \\
\text { - Provide land and } \\
\text { infrastructure }\end{array}$} & $\begin{array}{l}\text { - Cooperatives represent farmers } \\
\text { at factory board meeting and at } \\
\text { the national level } \\
\text { - Farmers invest in tea and } \\
\text { provide green leaves to the } \\
\text { factory }\end{array}$ \\
\hline Brokering & \multicolumn{4}{|c|}{ IFAD: Loan funding, feasibility study during PPPP design, monitoring and evaluation } \\
\hline & \multicolumn{2}{|c|}{ New institutional arrangement created } & \multicolumn{2}{|c|}{ New roles that need to be sustained } \\
\hline $\begin{array}{l}\text { PPPP } \\
\text { arrangements }\end{array}$ & \multicolumn{2}{|c|}{$\begin{array}{l}\text { Tea value chain linkages (processing factory, } \\
\text { farmer production) }\end{array}$} & \multicolumn{2}{|c|}{$\begin{array}{l}\text { - Farmers to produce green leaves of good } \\
\text { quality and quantity } \\
\text { - Companies process green leaves and } \\
\text { market tea, and provide technical assistance } \\
\text { and logistics }\end{array}$} \\
\hline
\end{tabular}


doing enough to further increase productivity. On the other hand, a lack of transparency and involvement in factory operations creates mistrust for the cooperatives. In addition, in Mushubi, the investor is calling for a new shareholding structure due to cost overruns in factory development, which would diminish the cooperative holding to just 3.5 per cent, creating additional tensions. ${ }^{27}$

\section{Key learning}

- Promoting shared interests. Both PPPPs were designed to incentivise partners to work together to achieve shared success, by ensuring that the factory needed to secure supplies from the cooperative bloc and the farmers to be profitable. However, unless the cooperatives can significantly increase productivity at each site, their viability is at stake.

- Involving smallholder producers. Despite the efforts to build farmer ownership of the PPPP by providing them with equity shares in the processing factories, the poor maintenance of plots and low farmer involvement suggests that the PPPP arrangements do not sufficiently take into account farmer needs and capacities. Challenges around production constraints or alternative income sources in the early years could have been addressed through stronger involvement of farmers in PPPP planning.

\section{A woman farmer in Mushubi who acquired} a 1.5ha tea plot through the PPPP has seen her income rise to eight times higher than the RWF3,000 a month (c. US\$51 a year) she earned before the PPPP. She has bought a cow so that the family can have milk, and can now afford to pay her children's school fees. She is also a member of her local Savings and Credit Co-operative (SACCO).

\section{Focus group discussion}

\section{Taken together, the changes in Mushubi have proved 'transformational', not just for the households involved but others who have experienced the knock-on effects of local development.}

\section{Key informant interview}

Figure 4.3: PPPP arrangement in tea value chain in Rwanda

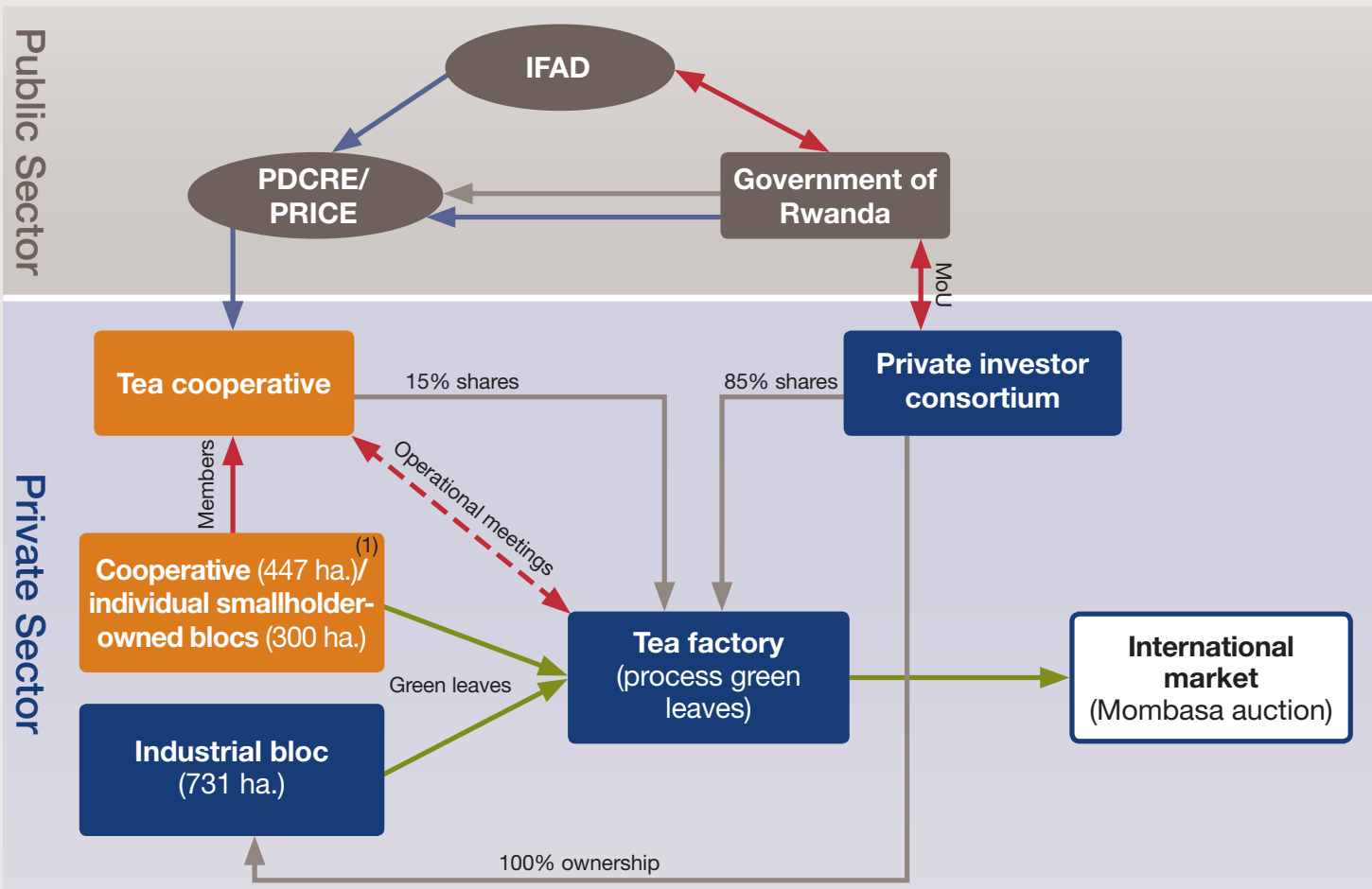

(1) Details used following Nshili's structure, for illustration purposes only. Mushubi details vary, with individual smallholders owning 937 ha. and the industria bloc 460 ha. However, the structure in Mushubi remains broadly the same. 


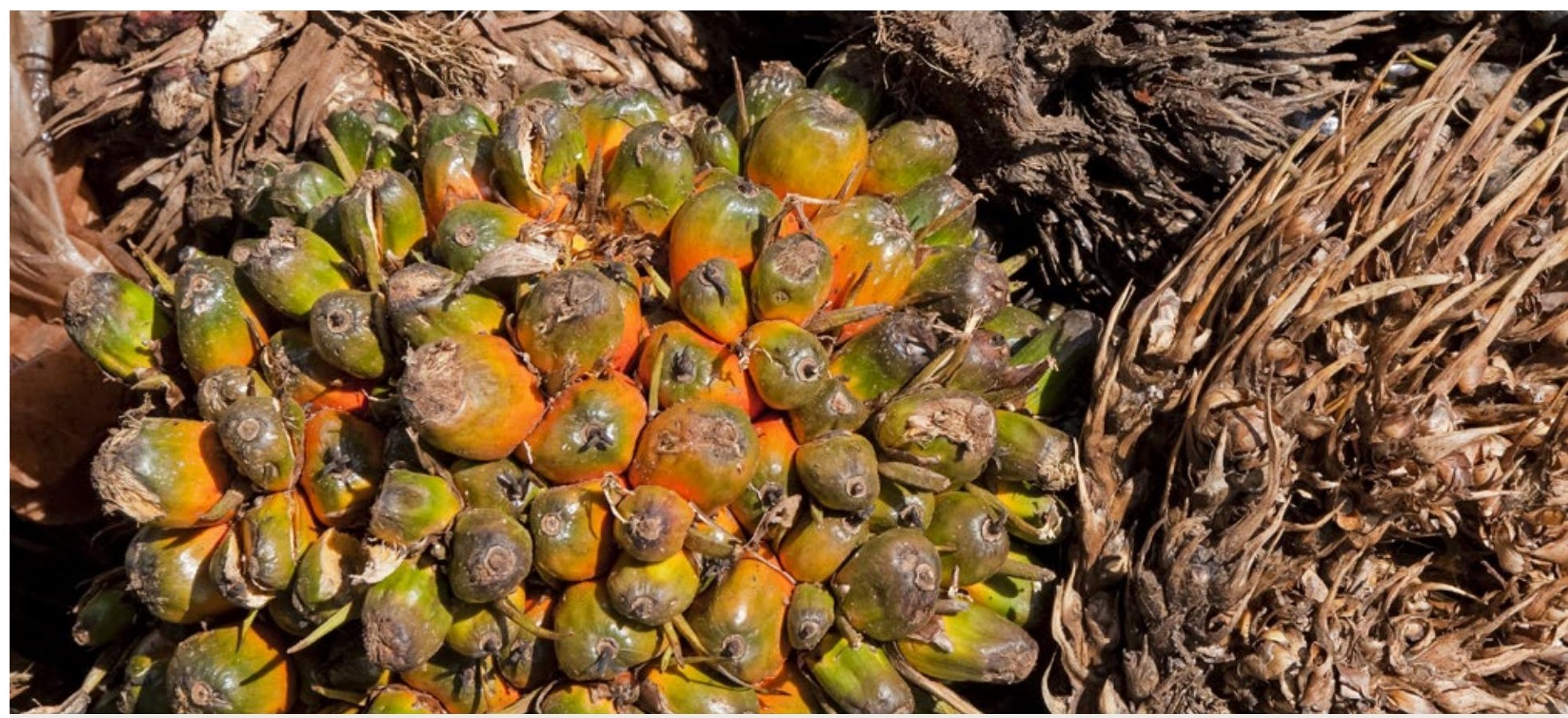

\section{Uganda $^{28}$}

A Close-up The PPPP in Uganda is a component of the of oil palm fruit bunches on Bugala island,

Uganda. O IFAD/SUSAN
IFAD-funded Vegetable Oil Development Project (VODP). The PPPP aimed to establish oil palm production (a new cash crop in Uganda) through private sector-led agro-industrial development in Kalangala District on Bugala Island in Lake Victoria. Specific aims were to achieve import substitution of edible oil, raise smallholder incomes, improve population health through increased uptake of vegetable oil, and diversify exports.

\section{PPPP agreements}

The PPPP is based on an agreement between Bidco and the government of Uganda on the one hand, and a tripartite agreement between the government, Oil Palm Uganda Limited (OPUL, which runs the mill in Kalangala), and smallholder farmers represented by the Kalangala Oil Palm Growers Trust (KOPGT) on the other. Bidco's operations in Uganda are run by Bidco Uganda Ltd (BUL), ${ }^{29}$ which owns 90 per cent of shares in OPUL. KOPGT owns the remaining 10 per cent of shares.

A crude oil palm mill and 10,000ha of plantations $(6,500$ ha owned by the private sector and 3,500ha by smallholders) have been developed in Kalangala, along with a crude oil refinery in Jinja (near Kampala). This model represents a significant renegotiation of the original PPPP plans, which led to an increase in the size of the nucleus estate from 1,000 ha to 6,500 ha.

The farmers are dependent on OPUL to buy their crops; however a pre-set pricing formula, plus a pricing committee and services cost panel are intended to protect farmers by providing transparency and avoiding inequitable negotiations between farmers and the company.

\section{New institutional arrangements created}

The PPPP is an integrated oil palm value chain, with forward and backward linkages from inputs through production, processing and marketing, providing farmers with financing (government loan scheme) and a guaranteed market, with loan repayments linked to crop yields.

KOPGT is the key structure for communication, decision-making, negotiation and dispute resolution between the farmers and the company. It is the commercial interface between farmers and the oil palm mill, through which agricultural inputs, extension services and payments for produce are provided. It also administers the substantial oil palm development loan scheme on behalf of the government. KOPGT's board includes three farmers (of which one is the chair), three government representatives and one representative from civil society.

\section{Results}

Participating smallholders (including women) have benefited from formal legal recognition of their land tenure and have moved from subsistence farming to market-oriented production for income, acquiring new technologies in crop production and management. Improved incomes and income stability have enabled households to meet basic health and education needs, and invest in assets (livestock, vehicles, bicycles and farm assets). For women, who make up 35 per cent of the 
beneficiaries, ${ }^{30}$ oil palm farming has given them access to a cash crop as well as access to credit. Short-term increases in food security have been the result of intercropping food and oil palm together (recommended by the PPPP for the first two years).

Both the government and OPUL have made significant investments in public infrastructure including $400 \mathrm{~km}$ of farm roads for transporting produce and $250 \mathrm{~km}$ of link roads. Water transport services have also been substantially improved, with a modern ferry service to Kalangala. The PPPP has created job opportunities in the mill and on the nucleus estate. ${ }^{31}$ However many of these jobs have been taken by migrants from other parts of the country, putting pressure on existing state-run services.

Despite the many positive changes, there appear to have been important unintended consequences, including increases in domestic violence resulting from changes in incomes and land tenure rights; and a significant rise in the price of land on the island ${ }^{32}$ which, though beneficial in some respects, is fuelling land conflicts, particularly as absentee landowners have begun returning to the area. ${ }^{33}$

Some farmers predict food security problems in the longer term, as not all of those taking part acted on the recommendation to keep some land for food production and mature trees leave little space for intercropping. Farmers with mature oil palm trees confirmed that this was indeed an issue. Farmers also complained of a lack of trust in some processes, e.g. quality assessments for oil palm fruit bunches, and a mistrust in the monopsony position of OPUL, despite mechanisms such as the pre-set pricing formula.

More generally, the PPPP experienced major delays to implementation and additional costs due to public opposition to the development, particularly in the early years; challenges in the government acquiring sufficient land; and limited engagement by smallholders. While KOPGT has played a central role in implementing the PPPP, it faces

\section{Table 4.5: Uganda PPPP overview}

\begin{tabular}{|c|c|c|c|c|}
\hline PPPP objective & \multicolumn{4}{|c|}{ Development of domestic supply of edible vegetable oils } \\
\hline \multirow{2}{*}{$\begin{array}{l}\text { Smallholder } \\
\text { inclusion }\end{array}$} & \multicolumn{2}{|c|}{ Smallholder constraints addressed } & \multicolumn{2}{|c|}{ What solution did the PPPP create? } \\
\hline & \multicolumn{2}{|c|}{$\begin{array}{l}\text { Access to finance, technology and markets, } \\
\text { farmer organisation }\end{array}$} & \multicolumn{2}{|c|}{$\begin{array}{l}\text { New oil palm value chain inclusive of } \\
\text { smallholders }\end{array}$} \\
\hline & Private sector & \multicolumn{2}{|c|}{ Public sector } & Farmers \\
\hline Partners & $\begin{array}{l}\text { Bidco Uganda Ltd (BUL - a } \\
\text { consortium of international } \\
\text { companies) and OPUL } \\
\text { (owned by BUL and KOPGT) }\end{array}$ & \multicolumn{2}{|c|}{$\begin{array}{l}\text { Ministry of Agriculture, Animal } \\
\text { Industry and Fisheries (MAAIF) } \\
\text { through VODP }\end{array}$} & $\begin{array}{l}\text { Kalangala Oil Palm Growers Trust, } \\
\text { with } 10 \text { per cent shareholding in } \\
\text { OPUL } \\
\text { Farmers have developed their } \\
\text { own association (KOPGA). Formal } \\
\text { relationship to KOPGT is unclear }\end{array}$ \\
\hline Roles & $\begin{array}{l}\text { Invest in mill and factory, } \\
\text { provide technical know-how, } \\
\text { source inputs for sale to } \\
\text { farmers (fertiliser, seedings) }\end{array}$ & \multicolumn{2}{|c|}{$\begin{array}{l}\text { - Creation of farmers' trust } \\
\text { (KOPGT), with } 10 \text { per cent } \\
\text { shareholding in OPUL } \\
\text { - Provide farmers' loans, make } \\
\text { land available to company } \\
\text { and formalise land tenure of } \\
\text { farmers, provide incentives (tax } \\
\text { concessions) and infrastructure }\end{array}$} & $\begin{array}{l}\text { - Farmers invest in oil palm and } \\
\text { provide fresh fruit bunches to } \\
\text { OPUL }\end{array}$ \\
\hline Brokering & \multicolumn{4}{|c|}{$\begin{array}{l}\text { - IFAD: Loan funding, technical expertise on partnership agreement and business model, monitoring } \\
\text { and evaluation, support on public relations, support for creation and operation of KOPGT. } \\
\text { - KOPGT: Interface between farmers and the oil palm mill }\end{array}$} \\
\hline & \multicolumn{2}{|c|}{ New institutional arrangement created } & \multicolumn{2}{|c|}{ New roles that need to be sustained } \\
\hline $\begin{array}{l}\text { PPPP } \\
\text { arrangements }\end{array}$ & \multicolumn{2}{|l|}{ Palm oil value chain } & \multicolumn{2}{|c|}{$\begin{array}{l}\text { - Farmers produce fresh fruit bunches (ffbs) } \\
\text { based on prescribed process (use of fertiliser, } \\
\text { harvesting technique) } \\
\text { - Mill purchases ffbs } \\
\text { - KOPGT provides services to farmers (credit, inputs, } \\
\text { technology), sourced from OPUL in some cases }\end{array}$} \\
\hline
\end{tabular}


challenges to develop a long-term, financially viable business model. Most importantly, the lines of accountability between it and the smallholder farmers it is meant to represent are unclear. Farmers have instead set up their own organisation to represent their interests, the Kalangala Oil Palm Growers Association (KOPGA), illustrating the lack of ownership and voice they felt within KOPGT.

\section{Key learning}

- Flexibility to respond to changing circumstances. It is inevitable that in complex and large-scale developments involving numerous partners with different motivations and interests, unanticipated challenges will arise. Good monitoring fostered by IFAD and KOPGT have enabled the PPPP to continue to move forward, with good communication and negotiation towards joint solutions or adaptations.

- Farmers' sense of ownership. While KOPGT has played a central role in implementing the PPPP, the lines of accountability between it and participating smallholder farmers are unclear. The fact that farmers set up KOPGA to represent their interests a year after KOPGT's inception illustrates the lack of ownership they felt within the Trust. ...oil palm trees have contributed to increasing our food crop production because in the gardens of young trees, where plants are still short, a household is allowed to intercrop with beans, maize, sweet potatoes...

Women who grow oil palm make good decisions in homes... what to buy, what we eat and what others eat...

\section{...because there was a monetary value} attached to the size of land a farmer cleared for planting oil palm, most farmers cleared all the land...leaving no land for planting food crops. So in the long term... there will be severe food shortages...

Focus group discussions / key informant interviews

Figure 4.4: PPPP arrangement in oil palm value chain in Uganda

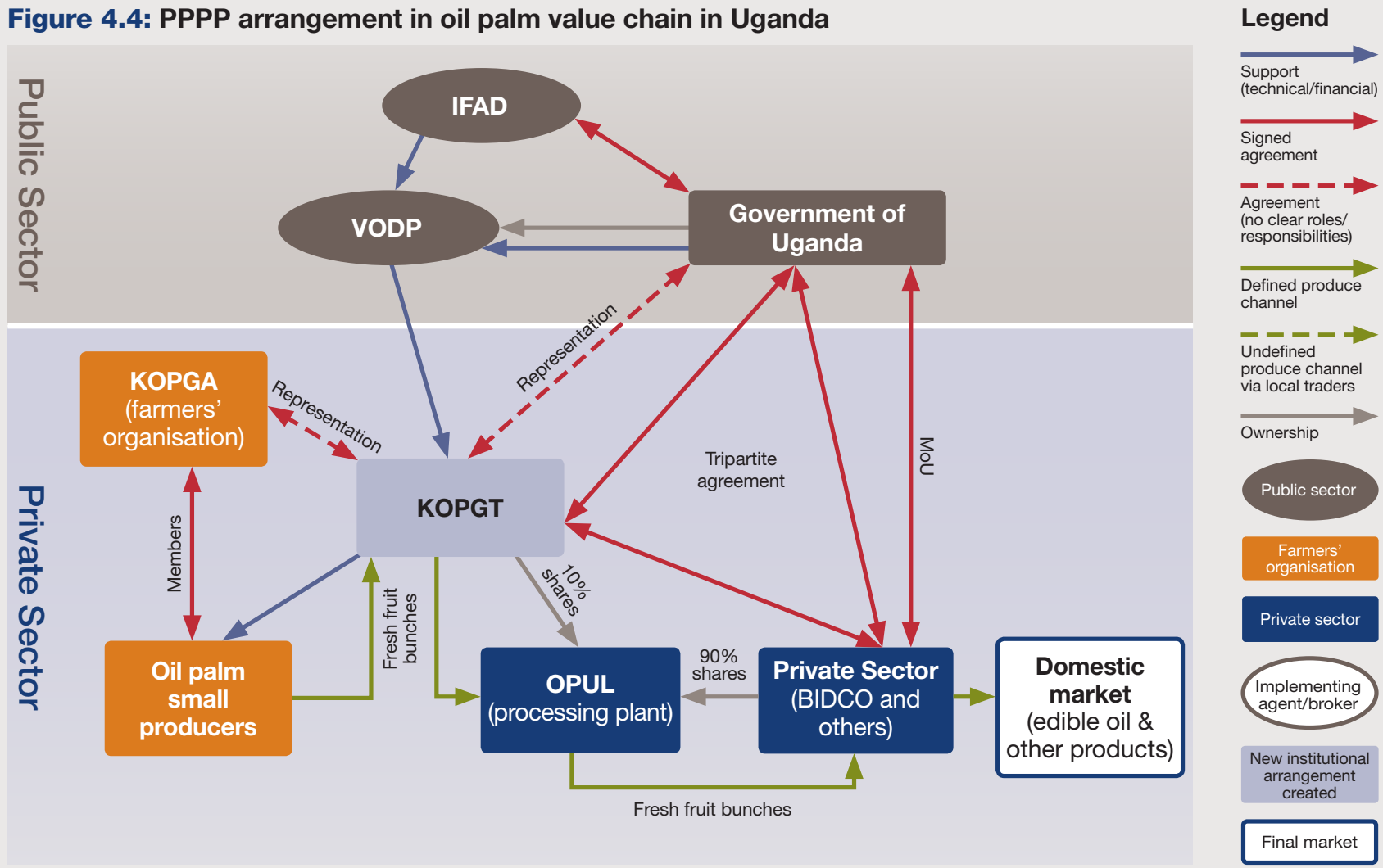




\section{Development outcomes}

This section summarises the main development outcomes described in the four case studies, and how these are linked to the design and implementation of the PPPPs. It is the basis for the enabling factors for agricultural value chain PPPPs set out in Section 5.

\section{Improved yields and quality, but below potential in some cases}

The PPPPs all sought to raise farmers' yields and the quality of crops through improved technology and/or access to inputs and services, as a means of improving livelihoods. In this they were no different to a great number of agricultural development projects, although they specifically relied on private sector partners as the providers of improved technology. In these primary objectives, the PPPPs have all been successful, ${ }^{34}$ although yields in Rwanda and Indonesia have not reached potential or optimal levels. In part this is likely to be a factor of time, as improvements take hold. In some cases, notably Rwanda and Uganda, ${ }^{35}$ poor crop management and low fertiliser use by farmers is a problem. This flags the first learning: successful agricultural PPPPs require farmers to see economic advantages. If farmers do not buy into the PPPP, they are unlikely to perform their roles as expected, with knock-on effects, such as poor credit recovery, or processing plants operating far below capacity that can affect the sustainability of the whole endeavour.

\section{Improved income stability}

Income stability has particularly improved in Uganda where market access has been secured and harvesting takes place monthly. Improved income stability has meant improved access to basic health and education in Uganda, and investment in assets (livestock, vehicles, farm assets). Fourteen out of 47 farmers interviewed as part of the research reported acquiring assets directly from the PPPP and 25 indirectly. Incomes vary but are linked to market prices for oil palm (avoiding price negotiations between farmers and OPUL) and loan repayments are linked to yields, smoothing out volatility. In Ghana, where both prices and markets vary considerably from season to season, income improvements have not been stable however.

\section{Secure market access, with mechanisms to manage pricing, costs and risks, and which take into account the relatively weak bargaining position of farmers, support income stability.}

\section{High exposure to risk related to credit schemes}

As a result of the PPPPs, farmers have benefited from increased access to finance but have also faced higher risk. Late repayments are already causing problems in Ghana - for both farmers and rural banks. In Rwanda and Uganda, loans are over longer periods of time $e^{36}$ but in Rwanda the ability of farmers to repay loans is already looking problematic. Tea production is a long-term investment with risks involved. Bushes take three to four years to start producing, only reaching peak yield after seven to eight years. Farmers bear the risk of upfront investment, with the expectation of return on this investment later. Based on group discussions and key informants' interviews, cooperatives have contracted unsustainable loans using their equity share and land titles as collateral (though measures are now being taken to try to

Table 4.6: Crop yields in the four countries before and after interventions

\begin{tabular}{|c|c|c|c|}
\hline & Baseline & $\begin{array}{l}\text { Yield achieved after } \\
\text { project intervention }\end{array}$ & Expected or potential yield \\
\hline Ghana & $\begin{array}{l}0.8 \mathrm{MT} / \mathrm{ha} / \mathrm{yr}(2008) \text { on } \\
\text { average }\end{array}$ & 1.5 to $3.2 \mathrm{MT} / \mathrm{ha} / \mathrm{yr}$ & 1.8MT/ha (national average) \\
\hline Indonesia & 50kg/tree/month (2010) & $\begin{array}{l}\text { Up to } \\
200 \mathrm{~kg} / \text { tree/month }\end{array}$ & $\begin{array}{l}\text { 400-500kg per tree per } \\
\text { month (achieved during } \\
\text { 2005-06) }\end{array}$ \\
\hline Rwanda & $\begin{array}{l}0.1 T / \text { ha/year (2011) in Nshili } \\
\text { No tea grown previously in } \\
\text { Mushubi }\end{array}$ & $\begin{array}{l}0.7 T / \text { ha/year in } 2013 \text { in Nshili } \\
2.5 T / \text { ha/year in } 2013 \text { in } \\
\text { Mushubi }\end{array}$ & $\begin{array}{l}6-7 \mathrm{~T} / \text { ha/year (projections } \\
\text { used for loan calculation) }\end{array}$ \\
\hline Uganda & No oil palm grown previously & $\begin{array}{l}\text { Up to } 15 T / \text { ha/yr for trees in } \\
\text { sixth year in } 2013 \text {, but falling } \\
\text { again by } 5 \text { per cent in } 2014\end{array}$ & $\begin{array}{l}\text { Yields of } 15 T / \text { ha/yr expected } \\
\text { only in ninth year }\end{array}$ \\
\hline
\end{tabular}




\section{Development outcomes} repayments to yields has mitigated potential risks, although low soil fertility is still a threat in some cases. Arrangements established by PPPPs often expose farmers to greater risks. PPPP design should identify these risks, and consider how they will be mitigated or allocated between partners.

In Uganda and Rwanda, the PPPPs have contributed to wider economic transformation, including job creation in plantations and processing facilities, improved infrastructure (transport, electricity) and general business activity, although it was beyond the scope of the research to look at the detailed impacts of these changes. In Uganda, more than 80 per cent of farms reported to be linked to the road network. Also, the new ferry has increased access to Bugala Island in general. In Rwanda, upgraded roads have facilitated the transport of tea to Mombasa auction and promoted the development of business centres in the areas neighbouring the factory. The management team in Mushubi confirmed the importance of the upgrading of roads and provision of electricity. Even in Ghana where the PPPP was much more targeted, wider effects have included casual employment in tasks such as land stomping, weeding, processing and ploughing; improved cash flow for tractor service providers; and some reports of local spot market traders who have begun differentiating maize based on quality. ${ }^{37}$ daily ferry from Entebbe to Bugala island, Uganda. (C) IFAD/SUSAN BECCIO

Women have benefited from the PPPPs where they were specifically targeted, such as in address this challenge). In Uganda, linking

\section{Positive benefits for non-participants from employment opportunities and infrastructure}

Rwanda and Uganda. In Nshili, in Rwanda, initial provisions targeted 4,800 households of which 30 per cent would be headed by women. Although the number reached is lower - 2,560 households -37 per cent of these are women. In Indonesia, women's participation in farming activities has increased; however, what benefits they derive is unclear.

\section{Unintended consequences related to migration, land use, gender dynamics}

The larger the PPPP, in terms of scale of investment and activities, the more likely it is to be accompanied by wider and often unintended consequences. These were seen in relation to land prices and pressures, particularly in Uganda where absentee landowners have started to return; in relation to migration of labour to the PPPP areas; and in relation to changes to gender dynamics within the farm, household or community.

These unintended consequences are not necessarily negative, but they involve winners as well as losers. There should be effective mechanisms to identify social, economic and environmental impacts, both positive and negative, especially those affecting marginalised community members such as women and the landless or near landless. Otherwise, they risk being excluded or included on unfavourable terms. Finally, it is not possible to predict all the potential consequences in advance, so close monitoring and adaptation is required as implementation proceeds, along with public accountability mechanisms.

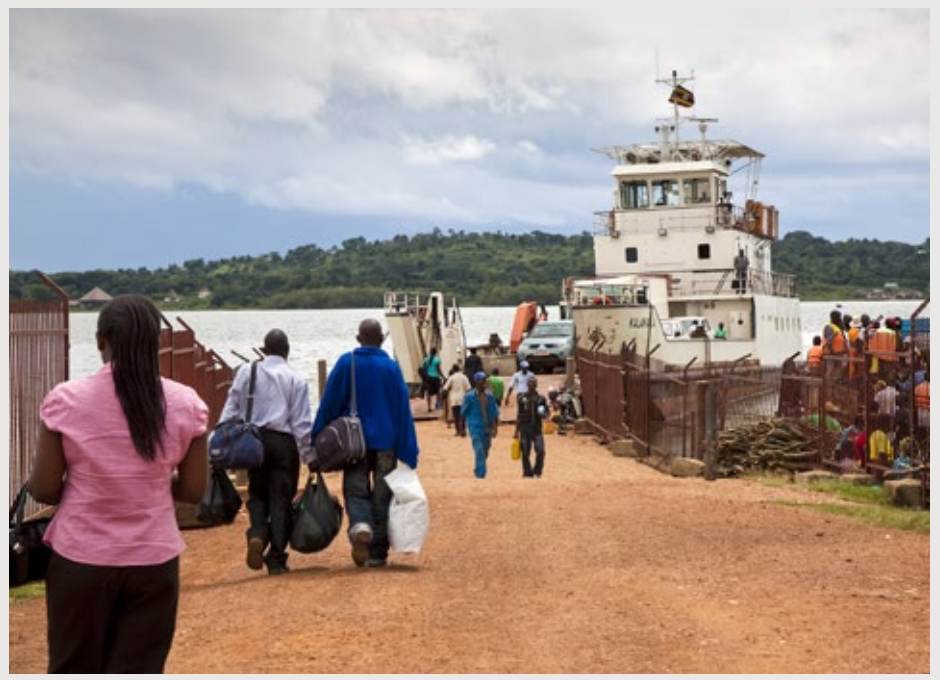

\section{Long-term sustainability is uncertain}

All the PPPPs are facing challenges with long-term sustainability. They have developed new arrangements that organise farmers and enhance access to inputs, credit, technology and/or the market. However, the long-term operations of these arrangements are not secure. This affects, for example, the cashless credit scheme in Ghana, due to high production risk and loan delinquencies; the VCCs in Indonesia, due to insufficient technical capacity to support them; and the long-term business model of KOPGT in Uganda. PPPPs need to create ongoing incentives, capabilities and financing for partners to continue to perform new or improved roles once initial support and brokering is removed. 


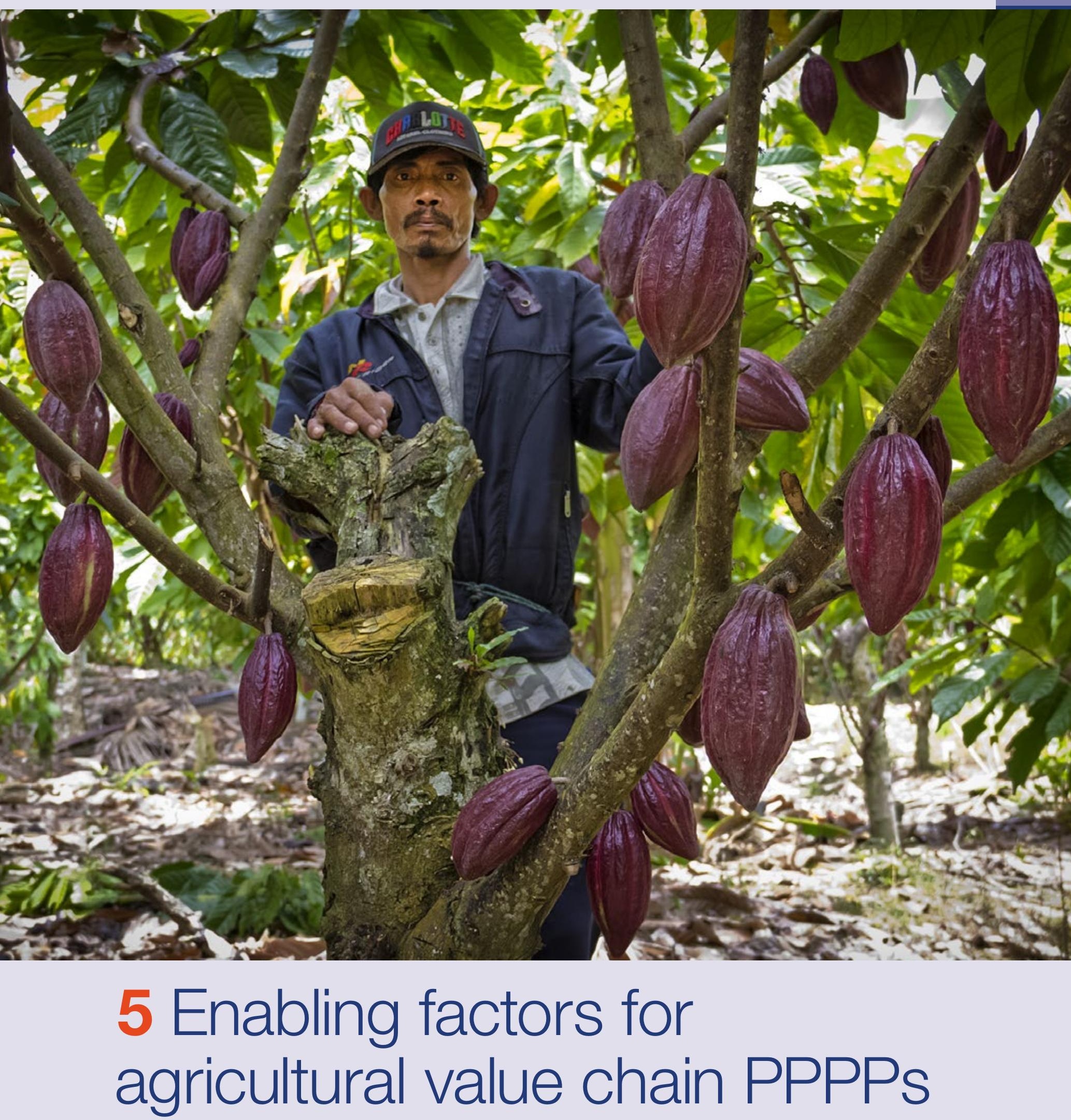

This section sets out eight elements of design and implementation of PPPPs that were identified as contributing to the development outcomes observed in the four case studies. It presents this learning in the form of 'enabling factors' for agricultural value chain PPPPs to improve the livelihoods of farmers and contribute to broader rural development.
Define the rationale
and underlying assumptions

There are many ways in which governments can spend limited resources. The public sector needs to be specific about the constraints it is seeking to address through the PPPP and the rationale
A farmer shows the new fruits on his cocoa trees after learning new techniques at a CDC,

Central Sulawesi, Indonesia.

() IFAD/ROGER ARNOLD 
Table 5.1: PPPP rationale ${ }^{38}$

\begin{tabular}{|c|c|c|c|c|}
\hline & Ghana & Indonesia & Rwanda & Uganda \\
\hline $\begin{array}{l}\text { Smallholder } \\
\text { constraints }\end{array}$ & $\begin{array}{l}\text { Access to finance } \\
\text { and technology, }{ }^{39} \\
\text { farmer organisation }\end{array}$ & $\begin{array}{l}\text { Access to } \\
\text { technology, farmer } \\
\text { organisation }\end{array}$ & $\begin{array}{l}\text { Access to markets, } \\
\text { farmer organisation }\end{array}$ & $\begin{array}{l}\text { Access to finance, } \\
\text { technology and } \\
\text { markets, farmer } \\
\text { organisation }\end{array}$ \\
\hline $\begin{array}{l}\text { Role of private } \\
\text { sector partners }\end{array}$ & $\begin{array}{l}\text { Technology } \\
\text { provision (Nestle) } \\
\text { and marketing } \\
\text { channel (SFMC) to } \\
\text { enable access to } \\
\text { finance }\end{array}$ & $\begin{array}{l}\text { Technology } \\
\text { provision (Mars) }\end{array}$ & $\begin{array}{l}\text { Marketing channel } \\
\text { through factory } \\
\text { investment (NKTP } \\
\text { in Nshili and MIG } \\
\text { in Mushubi), some } \\
\text { technical assistance }\end{array}$ & $\begin{array}{l}\text { Technology } \\
\text { provision and } \\
\text { marketing channel } \\
\text { through mill } \\
\text { investment (OPUL/ } \\
\text { Bidco) }\end{array}$ \\
\hline
\end{tabular}

for partnering with the private sector, including the feasibility of the approach being proposed. A general sense of complementarity and win-win opportunities provides an insufficient rationale to invest in a PPPP. Table 5.1 outlines the PPPP rationale for the four case studies.

The PPPPs all show a relatively clear rationale, responding to the key questions:

\section{- What is the constraint to be overcome?} Constraints included access to technology, finance and markets, and lack of farmer organisation.

- How will working with the private sector overcome this constraint? The two areas where the private sector was seen to bring particular competencies in the PPPPs are in improved agricultural technology and creating linkages to markets.

\section{Feasibility of plans and assumptions}

Understanding the constraints and potential PPPP solutions is not enough, however. Assumptions behind the solutions also need to be identified and feasibility tested. In the case studies, unrealistic forecasts of what could be achieved in terms of farmer mobilisation, productivity gains or inculcating farmers' organisations with a business approach, misunderstandings between the partners, or unfounded assumptions about the roles of actors that are not PPPP partners, created challenges or risks during PPPP implementation.

In Indonesia, the PPPP design assumed that the Mars training package from South Sulawesi could be adapted for the PPPP, with training time reduced to maximise the numbers being trained within the available budget. ${ }^{40} \mathrm{Key}$ farmers and extension agents so trained were expected to have the threshold expertise needed to support the Village Cocoa Centres and to revitalise cocoa production. In reality, although 150 farmers and extension agents had been trained at the time of the fieldwork, they lacked sufficient knowledge to independently apply the technology and improvise in the field, and were dependent on ongoing support from Mars. In addition, Mars had expected the training to improve the capacity of local extension agents, and so reduce their role over time. However the extension agents lacked incentives to specialise in cocoa.

Experience from partnerships in other sectors suggests that underestimating costs and overestimating benefits - often quite significantly - is a common design flaw (Sadka 2006). PPPPs need to be explicit about assumptions being made and why these assumptions are justified, as part of the theory of change - considering whether all actors have incentives to play the roles expected of them. PPPP design should also be backed up by expert technical or feasibility studies in crucial areas like productivity.

\section{Defining the PPPP rationale: The role} of brokers

Brokers can ask the right questions early on, defining clearly the purpose and value of the PPPP (versus other options), and identifying and justifying assumptions. This process should be underpinned by effective feasibility studies and scrutiny of assumptions behind PPPP design, supported by strong technical expertise as required. 


\section{Ensure a clear market pull}

Within development, there is recognition that organising and providing training to small-scale producers and improving their access to services and inputs, without a clear market demand, does not ensure sustainable livelihoods (Bitzer et al. 2009). Value chain PPPPs offer the opportunity to overcome this gap by connecting smallholder farmers directly with markets. In most of the cases studied, the PPPPs support value chain linkages between smallholders and companies. ${ }^{41}$

In Ghana, value chain relationships from farmers to consumers were brokered at two levels. ACDEP brokered maize supply agreements between farmers' organisations and the aggregator, SFMC; government staff brokered a purchase arrangement between SFMC and the end user, Akate Farms. Building linkages to end users like Akate Farms has been a relatively recent step for the programme, and has responded to past marketing challenges at the level of the aggregator. As smallholder farmers have begun to demonstrate that they can reliably produce quality outputs, other companies (e.g. Premium Foods and Yedent) now have agents in northern regions looking to source quality grain.

Agricultural value chain PPPPs tend to be developed based on one of two models - either vertical coordination by the lead firm or more collaborative, relationship-based models (Gereffi et al. 2005; Abdulsamad et al. 2015). In vertically coordinated models, companies exert significant control on supply, with unidirectional information flows regarding standards and grades for the crop. However, given the high degree of power asymmetry between buyer and farmers, this is not necessarily accompanied by an increase in farmers' participation or a redistribution of rewards. The ability to renegotiate or withdraw from a contract can be quite limited (Vorley et al. 2012). Relational models put more emphasis on trust-building, though often at the expense of efficient coordination and value chain management, thereby limiting access to very competitive markets. There are fewer power and information asymmetries and more collaborative exchange, risk-sharing and cooperation (Guidi 2011).
The PPPPs in Rwanda and Uganda follow the first model with a single lead firm (or consortia) coordinating the value chain, setting standards and driving efficiency. These value chains offer farmers secure markets and have also created broader community benefits, particularly linked to PPPP investments in infrastructure (by the public sector) and processing facilities (by the private sector). In Rwanda, for example, the PPPP has been accompanied by significant job creation, the development of small businesses and business centres and a reversal of seasonal labour migration out of the area. ${ }^{42}$ However, in both countries, farmers are highly dependent on the company, and on high levels of upfront investment and debt.

In contrast, the PPPP in Ghana involves multiple private sector actors, some as a formal part of the PPPP (Nestle and SFMC), but others linked in through structures such as the cashless credit system (rural banks and input and service providers). The PPPP allows flexibility for farmers to change crop composition within the system. Several of the farmers reported plans to increase investment in soy, for example, which they saw as more profitable than maize. However, despite the presence of some purchasing arrangements between farmers and the aggregator, markets are less secure than in Rwanda and Uganda. Both parties (farmers and aggregator) have at times reneged on their obligations, where there has been a divergence between the prevailing open market price and the agreed price.

\author{
Men bringing \\ bundles of \\ tea from the \\ field to the tea \\ factory in Nshili, \\ Rwanda. \\ () IFAD/SUSAN BECCIO
}

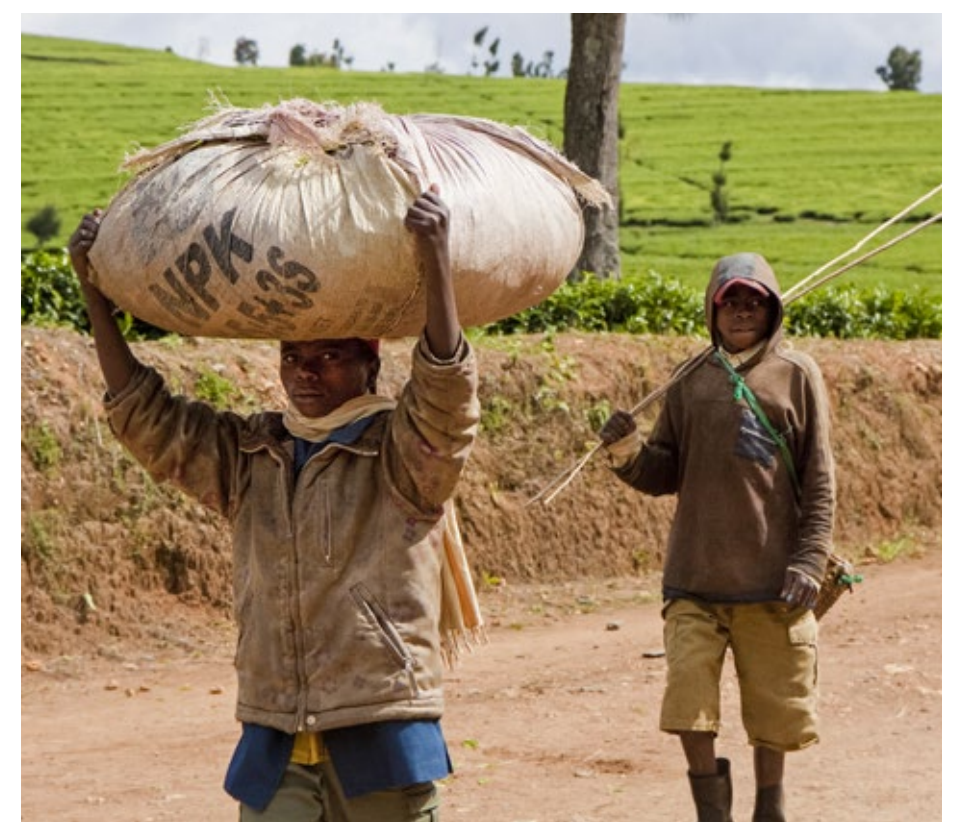


The best model is likely to depend on the circumstances of the value chain, the actors involved and the point in time when the PPPP is being developed. Outcomes will also depend on how the value chain operates, whether risks are adequately shared (see next section) and the mechanisms that address the inherently unequal power relations that exist in vertically coordinated chains. Certain features of the PPPP in Uganda help protect farmers, in both crop pricing and input costs (Box 5.1). These include a price that is linked to the world market price, removing the need for price negotiation between the farmers and the company. There are also committees that oversee pricing and services costs, and bring transparency to the process. Given the lack of competition in Kalangala in the markets for both inputs and oil palm fresh fruit bunches (ffbs), transparent and independent mechanisms are crucial.

\section{Pricing mechanisms in Uganda}

\section{Pricing formula}

Pricing follows a pre-set formula, based on world market prices, the oil extraction rate, which is determined by the quality of harvested ffbs, and the costs involved in palm oil processing. ${ }^{43}$

\section{The fresh fruit bunch pricing committee}

Farmers are represented by KOPGT on the $\mathrm{ffb}$ pricing committee. This is convened every month and is expected to review prices for farmers' fruits sold to OPUL, based on the agreed formula. The pricing formula and other details are enshrined in the tripartite agreement between the company, the farmers and the government. Other members of the committee include government ministries, the Kalangala District Local Government and OPUL.

\section{Services cost panel}

The services cost panel reviews the prices charged for OPUL-supplied inputs and services covered by PPPP loans, and verifies value for money. Decisions are reached after the suppliers of goods and services have quoted rates chargeable, and verifications of specifications and prices have been carried out by technical teams called valuation committees. Members include representatives from KOPGA, KOPGT, OPUL and one government official.

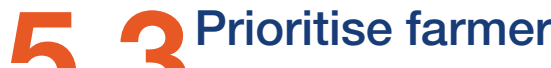 5. 3 ownership of the PPPP}

Ownership and involvement of all partners based on jointly agreed objectives, with clear roles and responsibilities, are frequently identified as critical for successful partnerships. The PPPPs in the case studies required commitments and activities not only from public and private sectors but also from farmers. Operationalising the concept of PPPPs is not easy, however. Where farmers are not part of negotiation and design, the partnership is unlikely to fully reflect their priorities and interests. The poor maintenance of plots in Rwanda or side-selling of fertiliser in Uganda and maize in Ghana can be seen as indicative of weak farmer commitment and ownership (alongside short-term economic pressures). These problems arise despite laudable efforts in both Rwanda and Uganda to build ownership by providing farmers with equity shares in the processing factories.

To take the case of Uganda, the challenge is with farmers' ownership of KOPGT, which represents them in the PPPP. Although farmers have spokespersons on the Board, KOPGT is not fully answerable to them. In response, farmers have set up their own representative body, the Kalangala Oil Palm Growers Association (KOPGA), to represent their interests, although the relationship, roles and governance structure between KOPGT and KOPGA are not well defined.

Other research on agricultural PPPPs and value chains more generally finds the same challenge of top-down processes that prioritise preparing farmers to participate in the value chain but fail to meet their priorities and aspirations. However well intentioned, this can lead to farmers being used for purposes not determined by them, and to poorly functioning partnerships as a result (Fairtrade Foundation 2014; Bitzer et al. 2009; Bitzer and Glasbergen 2013; Willoughby 2014).

Experience from inclusive business initiatives (Vorley and Thorpe 2014) suggests that arrangements in which large companies work directly with the poorest and most marginalised farmers often fail to effectively include them. The alternative is to build links with and 
support for existing smallholder production (rather than organising smallholders for the purpose of joining new value chains). This could mean connecting companies to an aggregator (as in Ghana) or to processors that can aggregate smallholder production, or to an already motivated and established producer organisation. The risk of this approach is that it includes only better-off smallholders.

However, government partners in PPPPs can support the inclusion of more smallholders in existing production networks, such as by providing infrastructure or making training accessible to women.

Experience from one initiative in Indonesia ${ }^{44}$ that has created new producer organisations in the context of a donor-funded inclusive value chain finds that such organisations are most successfully built from the bottom up, with responsibilities kept at the lowest level of farmer organisation possible, and farmers given a role in designing structures and direct control over activities. This approach succeeded in increasing farmers' commitment and sense of ownership from the outset, ${ }^{45}$ especially when contrasted with other similar projects in Indonesia that had focused on technical production problems with farmers as passive actors. Initiatives where the farmers' apex organisation was effectively supervised and controlled by a nucleus estate were especially problematic. However, the time taken to set up viable farmers' organisations was considerable - 14 years from developing local farmers' groups through to building the primary and then secondary cooperative. At the secondary cooperative level, where control by farmers is indirect, trust and a sense of ownership are still relatively weak (Jelsma et al. 2009).

PPPP brokers can help build smallholder capacity in structures such as these, and help them organise and bargain effectively, through access to information and to professional advice and expertise. In Uganda, IFAD has helped farmers to access technical support (e.g. bringing in consultants or other technical experts). Brokers can also help build the capacity of weaker members of producer organisations, and improve governance such that leaders' accountability towards their members is more effective. However, there is a fine line between supporting and undermining the autonomy of producer organisations. Support should be committed for the long term but with a clear phasing-out strategy (World Bank 2007).

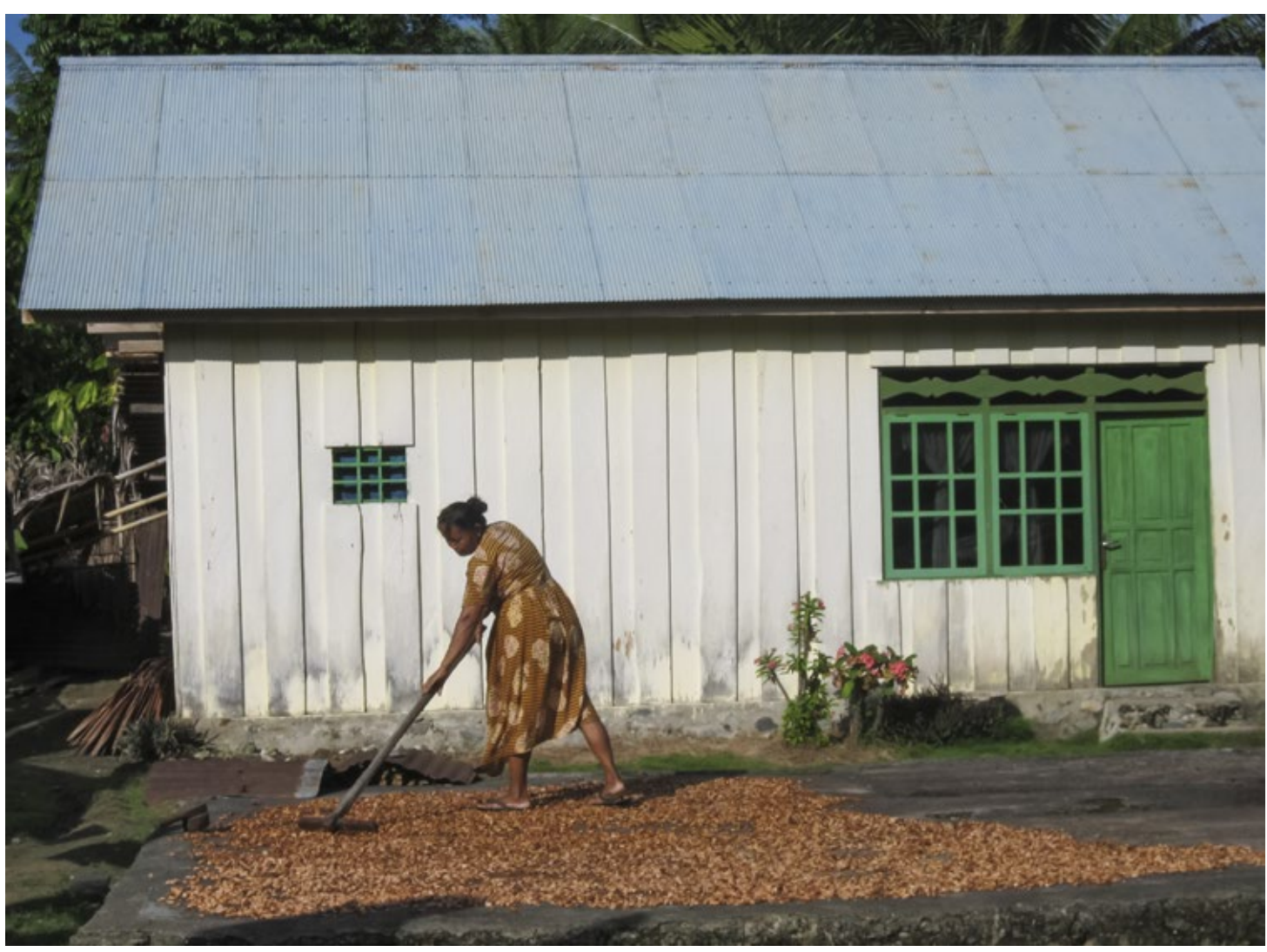




\section{Developing PPPPs: The role of brokers}

Brokers can build smallholder capacity to participate as partners in the PPPP, helping them to organise effectively, access information and negotiate a fair deal. Ideally this means involving farmers directly in the initial PPPP negotiation and design.

\section{Align incentives of - partners and build trust}

An effective partnership means selecting the right partners, creating the right incentives for collaboration and building trust. Choosing the right private sector partner for a PPPP requires an understanding of the constraints to be overcome, and the competencies of different private sector partners. Competitive bidding and partner due diligence processes, or working with already established partners are all strategies to identify companies' capabilities and motives ${ }^{46}$ Competitive bidding, such as that used in Uganda, improves the bargaining position of the government and is likely to be important in complex PPPPs, especially where companies receive direct benefits or incentives from the government (e.g. tax breaks or subsidies) to ensure transparency and avoid corruption (actual or perceived).

$\checkmark$ A maize field. () IFAD/RADHIKA CHALASANI
However, bidding processes are challenging, especially for inexperienced governments. When

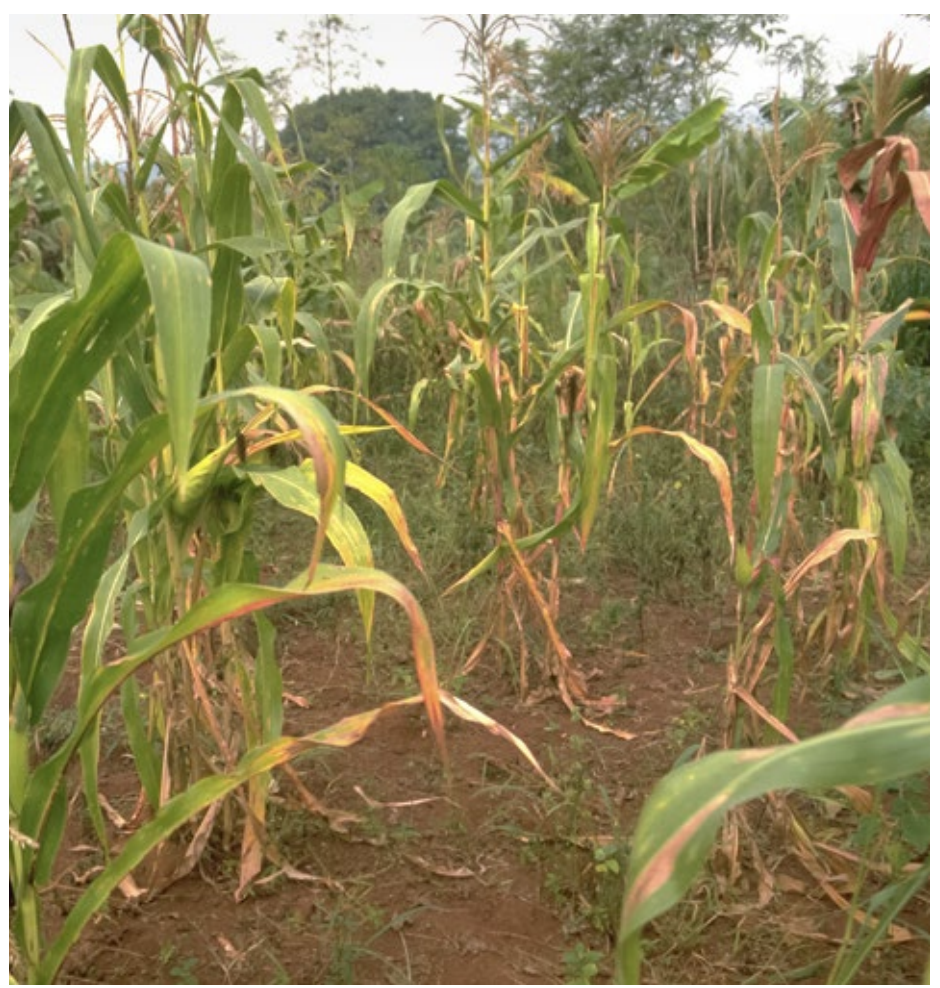

organisations with different backgrounds (such as governments and companies) do business in a context of weak institutions, a good reputation or history of good experience can be more important, especially where particular skills or qualities make one company an obvious candidate.

In Indonesia, the government had serious doubts about working with profit-driven companies, but IFAD presented a PPPP as a potential opportunity to resolve the challenge of low cocoa productivity, and was in a position to build understanding between public and private sectors. IFAD identified Mars as a partner with the right skills and resources to offer, based on good experiences of collaborating with the company in Papua New Guinea. As the company's benefits from the PPPP were indirect (i.e. a general improvement in cocoa productivity and quality), the risk of not having a competitive bidding process was relatively low.

Once the private sector partner is selected, agreements are needed to create incentives for partners to perform their intended roles and responsibilities and to feel confident that the other partners will perform their roles. Incentives are most fully aligned when there is interdependence, commitment and ownership of shared PPPP objectives by all partners, each of whom has something to lose if objectives are not achieved. If each partner has 'skin in the game' in this way, there is reason to believe they will work to achieve shared objectives, even in the face of unexpected developments.

Interdependence between companies and smallholder farmers tends to emerge when the achievement of company goals, such as security or quality of supply, depends on successful smallholder production. This may occur because the crop is only or largely produced by smallholders (e.g. cocoa), or because the volumes required for the company to break even include trade with smallholders. Where such an arrangement increases the risk to the company and its cost of capital, governments can counteract this effect by helping to lower risk, e.g. through a loan guarantee. However, governments should also remember that the risk to a company's investment is an incentive for it to perform well, so should avoid providing excessive guarantees (UNECE 2008). 
In Rwanda, the government's agreement with the private investor stipulated that the size of the company plantation should not exceed 30 per cent of the total acreage. The aim was to ensure that the factory needed to secure supplies from the cooperative bloc and smallholders, creating interdependence. In Uganda, the company negotiated a substantial redesign of the original PPPP plans, increasing the size of the nucleus estate from 1,000ha to 6,500 ha (versus 3,500 ha smallholder production). While the company still has an interest in successful smallholder production, since the mill cannot run at capacity without it, this change has inevitably diminished the stake the company has in the success of the smallholders.

Other experience in the oil palm sector suggests that the share of land for the nucleus estate in relation to smallholder schemes determines the interdependence of the actors (Jelsma et al. 2009). Where the company has a large production area, it is less dependent on smallholders for a significant share of its mill feedstock, and they are less likely to receive the attention and investment required. Smallholders may instead be seen as a side activity, fulfilling government or donor requirements or to facilitate access to low cost credit.

While formal, contractually established arrangements can be important in PPPPs with intense levels of collaboration (Bitzer et al. 2009), they are not the only option. One study of farm agribusiness linkages in Africa found no evidence that formal contractual agreements drive sound linkages between smallholder farmers and buyers, and emphasised instead the development of mutual trust over the longer term requiring a perception of 'fair play' on both sides, underpinned by a sound understanding of quality requirements, quality control methods, payment terms and expected delivery schedules (Dannson et al. 2004).

At issue is the substantial asymmetry in information and bargaining power between farmers and other partners. For example, buyers commonly make any price agreed conditional on farmers meeting quality requirements or standards that are specified in advance. However, these terms are not always clearly stated or farmers fail to understand them
(Technoserve 2011). In Uganda, despite the transparent mechanism to set prices, farmers complain that they do not understand the formula, the quality assessments by OPUL and the monthly deductions to service loans. The lack of trust in turn leads actors (farmer, company or government) to view partners as 'others', to whom they feel little obligation (Holmes 2012).

Building trust between parties that are not used to working together or thinking of each other as partners - or who have a history of poor relationships - is unlikely to occur spontaneously. Rather, significant leadership is required. This may come from within the partnership organisations, but often brokers are particularly crucial (Guidi 2011). IFAD has been central to partnership development and promoting trust to grow between the partners in both Uganda and Indonesia, for example. IFAD's role was to help partners understand the opportunities and risks of the PPPP and overcome negative perceptions, opening the door for collaboration. Brokers can also provide capacity support for farmers and ensure they have access to information and are helped to negotiate fair deals. For example, in Ghana, ACDEP supports farmers to review contracts, to understand the terms being set out and to maintain fairness. Establishing greater direct interaction between partners, including between companies and farmers, e.g. through training, at buying points or through text messages, can also build shared understanding and trust (Holmes 2012).

\section{Interdependence: The role of brokers}

Brokers can facilitate contact with potential partners, developing trust and building understanding between the non-traditional partners that make up PPPPs (government, local company, multinational and farmers), with often conflicting organisational cultures. Brokers can also help partners understand their potential benefits and identify common objectives. To play this role effectively, the broker itself needs the trust of the partners.

Technical support on partnership agreements and business models from actors that understand private sector interests can help governments identify the best possible deal, not only value for money but in terms of aligning incentives around shared PPPP objectives. 


\section{Manage risks through identification, distribution and mitigation}

Risk is an inherent part of agriculture, and connecting farmers to more formal value chains can expose them to a system that is sensitive to shocks, particularly if growing a crop for export, or if dependent on imported inputs (Bolwig et al. 2008). Yet, few PPPPbased projects have adequate risk management or mitigation strategies in place (Spielman et al. 2010). Unless risk is managed, the weakest value chain actors (normally the farmers) tend to bear a disproportionate share, and it can also raise costs and undermine the sustainability of the PPPP as a whole. For example, in Ghana, farmers are required to pay loans in full, even in years when crops fail or the aggregator fails to purchase their produce. This has implications not only for the farmers affected but also for the PPPP as a whole. One leading rural bank has decided not to offer agricultural loans for the 2014/15 cropping year as a result.

PPPP design should firstly identify risks and how risks are distributed. Mechanisms are then needed to manage, mitigate or share risk, avoiding excessive unmitigated risk burden on one party. Risk mitigation measures include safety nets such as supply chain risk management (stabilisation or compensation) funds, micro-insurance schemes against bad weather and shared investments to improve the functioning of the value chain. Working through aggregators or other intermediaries who deal in multiple products can also help smallholders spread their risks by diversifying into other markets for different quality grades or rotational crops (Bright and Seville 2010). Good communication between partners and ongoing monitoring can also identify new risks that arise during implementation.

In Uganda, risks related to farmers' ability to repay loans have been partly mitigated by linking loan repayments to yields, for example. ${ }^{47}$ The loans are recovered through deductions from farmers' payments once harvesting begins, with deductions in instalments of 33 per cent of each monthly harvest, over an eight to ten year period. This helps to reduce the risk of non-payment of loans or of unsustainable debt burden in years when the harvest is poor, though very low yields could still create problems.

Again, assumptions behind the design of PPPPs and specific mechanisms such as loan schemes also need to be identified and tested for feasibility, or risks can be exacerbated. In Rwanda, for example, projections around short-term productivity gains that now look unrealistic have raised doubts over the sustainability of loans to farmers. ${ }^{48}$ These projections were based in part on assumptions around farmers' crop management and use of fertiliser that are not being met. The design also failed to take account of the high vacancy rate. ${ }^{49}$ Measures are now being taken to try to address these issues, such as helping farmers in gap filling and maintenance programmes to increase yield, as well loan renegotiation.

\section{Build the capacity to 6. 0 respond to changes in complex market systems}

PPPPs operate within market systems in which partners face bounded rationality. Agricultural markets consist of many individual but interdependent parts, with the dynamics of the system emerging from interactions between these parts. Individuals are both affected by and adapt to other actors' decisions, and as a result, PPPP interventions may lead to unforeseen outcomes - challenges as well as opportunities.

For example, in Ghana the cashless credit system and brokering by the government have been successful in engendering trust among rural banks and encouraging them to lend to smallholder farmers where previously they had been reluctant. The number of participating rural banks stood at 24 when the fieldwork took place, from a starting base of two. ${ }^{50}$ However, as the PPPP has expanded (and other similar programmes are implemented in northern Ghana), liquidity challenges have arisen for these banks, with lending restricted by the Ghanian government's prudent financial requirements. This challenge was not foreseen.

This unpredictability is not undesirable or indicative of failure. It is not possible to design a PPPP that anticipates all the ways in which changes might affect the market system. Instead, 
PPPPs need mechanisms to identify these changes, and the flexibility to respond and adapt to the unexpected. This can include reinforcing positive results, dampening negative effects, overcoming challenges and resolving disputes that may arise. However, this does not imply that PPPPs should be infinitely flexible. PPPPs need to respond to the unexpected within the objectives of the partnership, and if a PPPP is not achieving its objectives and no way can be found for it to do so, then it should be terminated.

Effective monitoring of the PPPP based on appropriate indicators that proactively identify outcomes that are being achieved is the first step. In the PPPP in Uganda, good monitoring has played an important role in identifying problems and helping partners to jointly develop solutions. IFAD has been central to this process, with six-monthly missions to review implementation, and develop detailed action plans and timetables to address gaps, and a process to discuss and endorse the findings with the PPPP partners. In contrast, in Ghana, monitoring and evaluation did not identity and resolve some of key challenges quickly enough, such as poor timing of input delivery to farmer-based organisations and problems with loan repayments.

Performance monitoring and indicators are needed which focus on what the PPPP is seeking to achieve. These are different in emphasis from impact evaluation, which focuses on attribution between interventions and specific outcomes. Although partners will ultimately have different information needs linked to their different interests and audiences (e.g. shareholders for companies and citizens for governments), there is value in developing a shared set of core performance indicators. These should reflect joint PPPP objectives. ${ }^{51}$

Spaces for communication and negotiation between the partners are also needed to identify solutions and adapt to changing circumstances. Regular dialogue brings together partners to discuss PPPP performance and whether it is on track to meet objectives, and it supports development of joint solutions where needed. An accessible and independent broker can ensure these mechanisms give a voice to all partners, build capacity among farmers' groups to participate, and facilitate dialogue around differences or conflicts that arise.

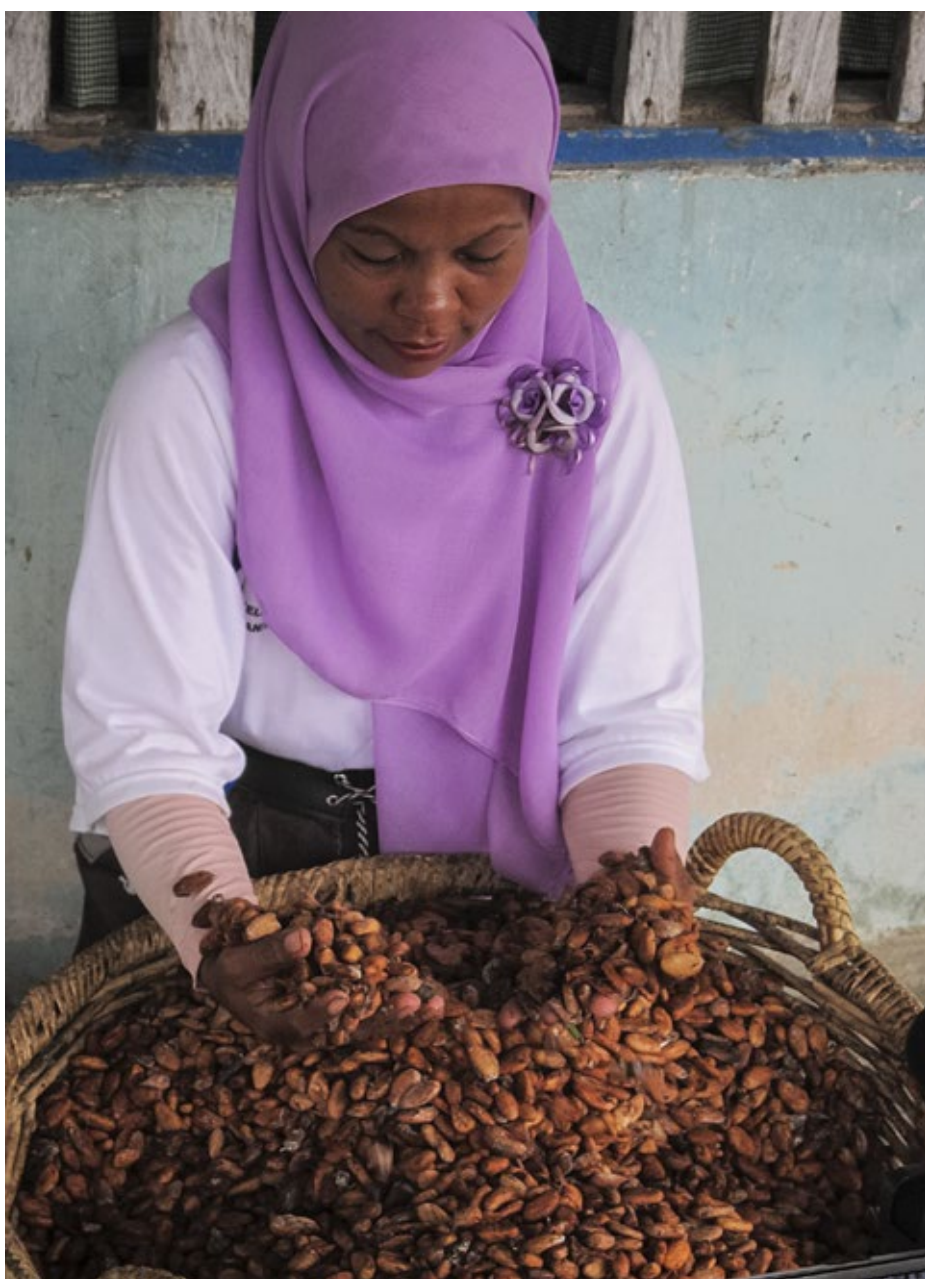

In Rwanda, there are regular meetings

A A cocoa farmer with her harvest of dried cocoa beans in Indonesia. (๑) IFAD/JOANNE LEVITAN to discuss productivity, fertiliser, prices,

transportation and supply of quality green leaves.

Solutions are developed, the implementation of which is monitored and discussed in follow-up meetings. Regular meetings also take place between the government and the private investor consortia to assess the extent to which mutual responsibilities are being taken care of. In Uganda, IFAD undertakes ongoing monitoring to track performance, identify issues and lead a process for the partners to jointly develop solutions.

In the case study PPPPs, brokers including IFAD, the government or NGOs have tended to play the key role in dispute resolution. For example, in Ghana, conflicts have resulted from price disparity between what aggregators have agreed with smallholder farmers and prices offered by itinerant traders at the local markets, or due to government-announced minimum prices through the National Buffer Stock Company. 
> A woman prepares oil

palm seedlings

for nursery on

Bugala island,

Uganda.

() IFAD/SUSAN

BECCIO

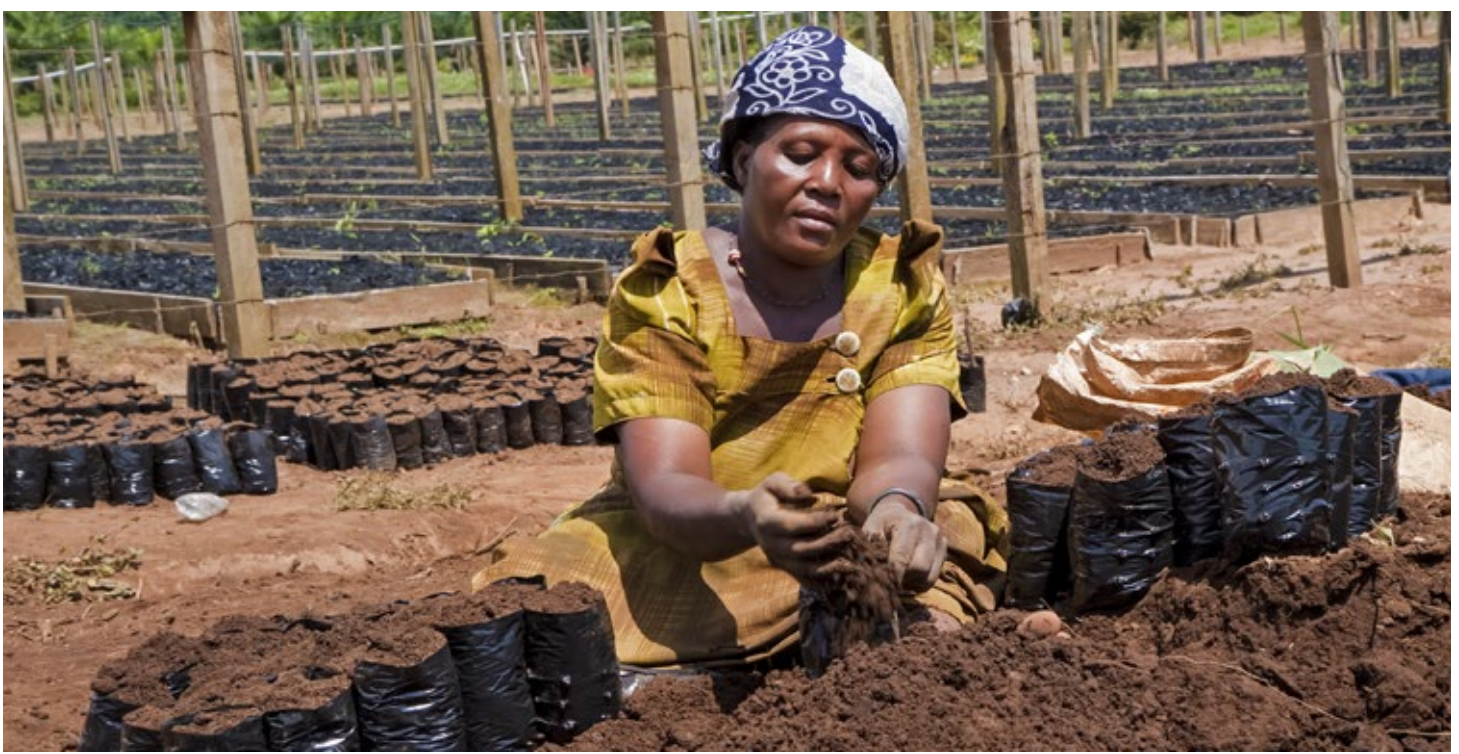

These conflicts are usually resolved through the District Value Chain Committees, supported by the NGO, ACDEP.

In the long term, once brokers have exited, independent mechanisms for dispute resolution are needed. Examples from other countries include the Sisal Board in Tanzania, which brokers disputes between companies and producers, and has specifically made space for smallholders' and women's representatives. In the Philippines, the government has set up a process to approve agricultural investment agreements and to settle disputes to protect agrarian reform beneficiaries (representing the majority of smallholders) from unfair contract terms (Vorley et al. 2012).

\section{Adapt to changes: The role of brokers}

Brokers can support dialogue between the partners. An accessible and independent broker can ensure that mechanisms for dialogue give a voice to all partners and can facilitate dialogue around differences or conflicts that arise, supporting development of joint solutions.

They can support monitoring and evaluation of PPPP progress to ensure that the PPPP is on track to meet its objectives, identify the problems that will arise, and adapt to changing circumstances.

\section{Take a proactive 5. approach to public accountability and transparency}

The impacts of PPPPs frequently extend beyond direct partners to a wider group of external stakeholders. These can include positive spillovers that benefit wider communities. However, they also include negative externalities related, for example, to environmental impacts, changes in land tenure arrangements or poor working conditions. The larger the scale of PPPP activities and its likely impacts, the more important it is to proactively identify and address these impacts, involving potentially affected stakeholders in the decision-making process. This is not a one-time activity at design, but an ongoing process as PPPP implementation proceeds.

While accountability processes have costs for PPPPs, as time is needed to consult stakeholders and respond to concerns raised, not doing so may have even greater costs. In Uganda, the PPPP has dealt with ongoing allegations related to negative environmental impacts, improper tax concessions and evictions..$^{52}$ The PPPP has invested considerable time and effort to respond to concerns, abandoning proposals to release ('degazette') public forest land for oil palm production, setting up an Impact Monitoring System (IMS), undertaking an independent study of tax concessions, ${ }^{53}$ engaging with stakeholders and encouraging visits to the project. While this responsiveness is to be welcomed, a more proactive approach can be more effective.

A reactive approach to stakeholder engagement, particularly in the context of a crisis situation, means attempting to build relationships in a context of extremely low trust (International Finance Corporation 2009; OECD 2008; Forrer et al. 2010). Proactive engagement builds goodwill and a sense of cooperation that can help if problems arise. It requires an early and 
consistent involvement of stakeholders such as community groups, NGOs, politicians, value chain partners and customers, with adequate information provided in a meaningful format during planning and continuing through implementation. By early detection of (changing) concerns and interests, PPPPs can manage expectations, identify potential issues and reduce the risk of conflict and costly crisis management. This is particularly true in highly visible, prominent projects, which are more vulnerable to reputational risks. Accountability requirements built into contracts, so that private sector partners are open to these measures, and strong champions inside the government are also important.

\section{Public accountability: The role of brokers}

Brokers can support public engagement and accountability. Private sector actors in particular are less likely to be familiar or comfortable with accountability processes, which trusted brokers can encourage and facilitate.

\section{Facilitate sustainable 5. O market systems}

There is a risk that the way PPPPs are set up undermines long-term viability, if the design focuses on the success of the initial donor-supported PPPP. Instead the focus needs to move beyond donor programmes (or corporate social responsibility projects) to create sustainable market systems.

To create a sustainable system, there is a need to consider how financing in the new institutional arrangements developed by the PPPP should work long term. In Uganda, the PPPP has been designed with commercial operations in mind from the start, building in a financing mechanism for KOPGT, the intermediary between the farmers and the company. However, this mechanism is linked to farmer loan repayments, meaning that the financing will cease once loans are repaid. This situation is being reviewed in order to develop a longterm business and financing plan, considering options such as charging for extension or other services or taxing fresh fruit bunches marketed by farmers. A successful plan will need the roles of KOPGT to be clearly defined relative to the services it delivers to farmers and to the farmers' association, KOPGA.

Financing is not the only issue, however. Incentives also need to be created for actors to perform new roles on an ongoing basis. In Indonesia the Cocoa Development Centres (CDCs) and Village Cocoa Centres (VCCs) form the new arrangement for delivering improved cocoa technology to farmers; farmer groups and government extension agents are intended to act as the key instruments of technology dissemination through these structures. Long-term sustainability therefore depends on the willingness and ability of these actors to carry on these functions. However, at the time of the fieldwork, extension agents were not strongly engaged, as there are no clear incentives for them to specialise in a single commodity, such as cocoa, and this remains a challenge. Farmer groups, on the other hand, were actively engaged - maintaining group seed and experimental gardens at the VCC level, encouraged by the positive changes in cocoa productivity in the demonstration gardens. However, they are presently unable to manage the VCCs without continued technical support. In response, IFAD has initiated a new partnership with the NGO Swisscontact, to further strengthen the capacity of these groups.

There is a fine line between piloting new approaches or making up-front investments (e.g. in farmer organisations and capacity building) to support market systems that work better for development, and creating arrangements that undermine sustainability. The key is in focusing interventions on actions that modify the incentives, capabilities and behaviour of different actors - public and private sectors, value chain actors and service providers - to ensure they will continue their roles in the long run.

\section{Sustainability: The role of brokers}

Brokers can focus attention beyond the immediate project, ensuring that actors have the long-term capacity, financing and incentives to play new roles, even once initial funding and support is removed.

They can develop a clear exit strategy. Planning for broker exit should start early. Otherwise the risk is that brokers become part of how PPPP implementation works, creating dependence, particularly among the less powerful partners. 


\section{PPPP checklist}

Drawing on the enabling factors and the roles of brokers identified throughout the research, this section provides a 'PPPP checklist' for partners and brokers involved in the design and implementation of PPPPs. The checklist is not intended as a blueprint - much of the detail of how PPPPs are designed and implemented is context-specific, depending on the nature of the PPPP, the value chain and the partners involved. However, it provides guidance in the form of key principles and questions, and outlines the support that brokers can provide at each step of the PPPP process.

\section{Rationale}

PPPP checklist

What is the constraint?

- Establish what constraints need to be overcome (technology, finance, market access, farmer organisation) and what skills, resources and technical competence are needed.

\section{Which private sector partner? \\ - Does the PPPP represent a large investment with a single company? Is there capacity to manage a bidding process? Are there likely to be good competitors? Is the risk of corruption (real or perceived) high? If so, competitive bidding is important. If not, then finding an effective partner with proven capabilities and a good reputation can be more effective.}

\section{Is a PPPP the right solution?}

- Does the public sector have the required skills, resources and competencies to address the constraints efficiently and to a high quality?

- If not, are there companies that can fill them efficiently and effectively?

- Note, however, that some services may not be judged on efficiency but other criteria such as ethical or equity reasons. These are best left to the public sector rather than PPPPs.

\section{Design}

Broker's role

Ask the right questions to define the purpose and value of the PPPP.

\section{Facilitate}

contact with potential company partners.

Identify and justify assumptions.

Ensure effective feasibility studies.

\section{PPPP checklist}

Prioritise farmer ownership of the PPPP

- Do farmers' organisations already exist? If so, they should be included in early planning and negotiation. If not, then time needs to be built in to support development of new representative organisations from the bottom up.

- Identify capacity building or support that farmers' organisations need to participate in the PPPP on more equal terms.

\section{Align incentives of partners}

- PPPPs need a shared objective - a common outcome that all partners have an interest in. All should stand to lose if this objective is not achieved.

- Incentives can also be created or reinforced by PPPP design, e.g. contract penalties for non-achievement or ensuring dependence of companies on smallholder production.

\section{Build trust}

- How is power distributed across the PPPP? (E.g. this may depend on the structure of the value chain and on who exerts control.)

- Where power is unequal, arrangements such as pricing mechanisms, capacity building and expert technical support can build trust and maintain partner ownership.

- Trust is also generated when partners understand decision-making and perceive it to be fair, e.g. quality assessments.

\section{Manage risks through identification,} distribution and mitigation

- What are the main risks that partners face under the PPPP (e.g. production, market, price)? Can these risks be managed through PPPP design (e.g. by including safety nets, stabilisation funds, micro-insurance), or through reallocating them more effectively (e.g. linking credit repayment to yields)?

- Remaining risks should be distributed fairly, considering which parties are best able manage them.

\section{Broker's role}

Involve farmers directly in the initial PPPP negotiation and design.

Build smallholder capacity to organise effectively, access information and negotiate a fair deal.

Help partners identify benefits and common objectives.

Help ensure transparency and dialogue to build understanding between different organisational cultures.

Support weaker participants to engage in the PPPP on more equal terms.

Provide or procure technical expertise as needed. 
The checklist is divided into rationale, design, implementation and sustainability. Note that there is no neatly defined line between design and implementation. In many cases, processes are developed during design, but their effective use depends upon the way they are implemented (monitoring or governance mechanisms are examples here). However, for the sake of simplicity, those elements linked to the way incentives and trust are developed between the partners and how risk is managed across the PPPP are listed under design; while those elements dealing with how the PPPP responds to external events and stakeholders are listed under implementation.

\section{Implementation}

PPPP checklist

Broker's role

Build the capacity to respond to changes in complex market systems

- Indicators should measure progress in the shared objective of the PPPP, as well as capture other changes at the household, community, market and environmental level (intended or not).

- Results should be used to adapt the PPPP to amplify positive outcomes or address negative impacts.

- Regular meetings between partners can review progress and develop action plans and implementation timetables.

\section{Deal with differences and conflicts}

- Spaces should allow disagreements or areas of dispute between partners to be raised with confidence, and addressed.

- All partners need sufficient knowledge and information to participate in this dialogue and have confidence that their voice will be heard.

\section{A proactive approach to public} accountability and transparency

- PPPP stakeholders need access to adequate information about the PPPP in a meaningful format, during both planning and implementation.

- Spaces are also needed for external stakeholders to raise concerns related to the PPPP. It will be important to show how this dialogue affects actual decision-making (such that the voices of stakeholders are heard). If communication is happening but leading to no changes, it is only likely to breed cynicism.

\section{Sustainability}

PPPP checklist

What is the sustainability

strategy for the PPPP?

- What are the temporary arrangements needed in the early stages of the PPPP (e.g. capacity building arrangements) versus those which are intended to continue long term (e.g. farmers' organisations, extension services)?

- Is there an exit strategy for the short-term arrangements?

- Are the long-term arrangements self-sustaining financially (or do they depend on subsidies or donor funding)? If they are not self-sustaining initially, a financing or business plan will need to be developed.

- Beyond financing, are these arrangements sustainable in that the actors involved have an interest or incentive to remain involved after the initial project ends?

- Note that planning for long-term sustainability needs to start during design and be adapted and developed through implementation.

\section{Plan for broker exit}

- What role(s) do the broker(s) play in PPPP implementation (e.g. building trust, supporting dialogue, building capacity, monitoring and evaluation)?

- Which of these need to continue after the broker exits (e.g. dialogue) versus those which might no longer be needed (e.g. capacity building)? Will actors from within the PPPP perform the long-term roles? Are appropriate structures and processes in place?

\section{Broker's role}

Ensure actors have long-term capacity, financing and incentives to play new roles.

Brokers also need a clear exit strategy. 


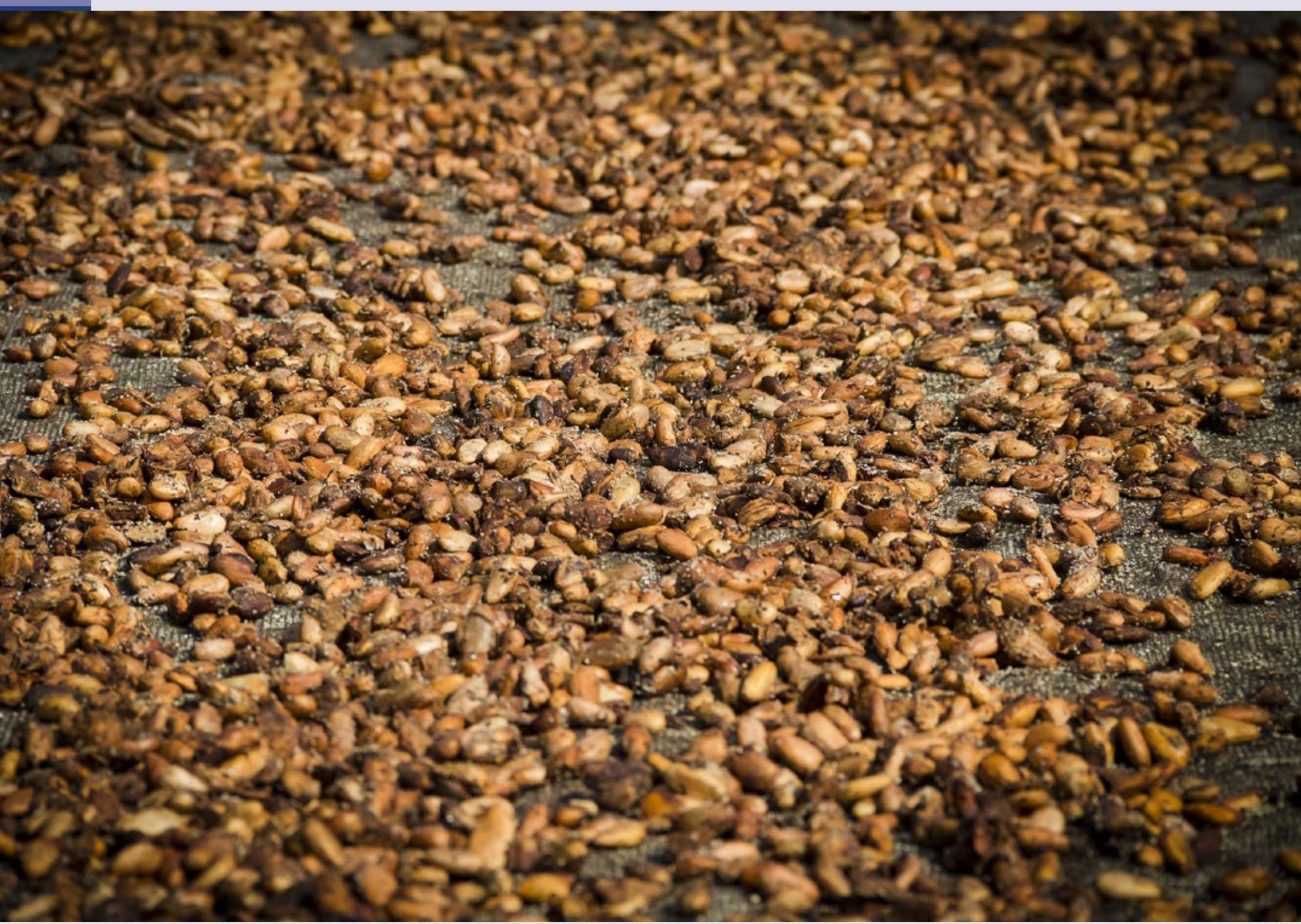

7 Conclusions

A A farmer's cocoa dries in the sun. (1) IFAD/ROGE ARNOLD
Public-private partnerships for development have gained substantial currency among donors, governments and the private sector, in agriculture among other sectors. This research takes learnings from the outcomes being achieved in four agricultural value chain PPPPs brokered in the frame of IFAD-funded projects in Ghana, Indonesia, Rwanda and Uganda. It provides new insights to support partners and brokers to develop agricultural value chain PPPPs that contribute to smallholder livelihoods and rural development, in the form of eight enabling factors, which are listed below.

\section{Define the rationale and underlying} assumptions. PPPPs should have a clear rationale, responding to the key questions: 'what is the constraint to be overcome?' and 'how will working with the private sector overcome this constraint?' Potential partners with the right competencies need to be identified, e.g. through competitive bidding, partner due diligence processes, or working with already established partners. Assumptions behind the rationale and proposed solutions need to be identified and feasibility tested. 2. Ensure a clear market pull. Value chain PPPPs offer the specific opportunity to secure market access for smallholder farmers by connecting them directly with markets. Outcomes will depend on aspects of design, including risk-sharing and mechanisms that address unequal power relations that exist in vertically coordinated value chains.

3. Prioritise farmer ownership of the PPPP. The PPPP is a partnership not only of public and private sectors but also of farmers. For PPPPs to be successful, all partners, including farmers need to have ownership of the PPPP, with clear roles and responsibilities that reflect their priorities and interests. 


\section{Align incentives of partners and build} trust between the partners. Agreements are needed to create incentives for partners to perform their intended roles - and to feel confident that the other partners will perform their roles. Incentives are most fully aligned when all partners own the PPPP objectives and where each has something to lose if the objectives are not achieved. Building trust between parties that are not used to working together or thinking of each other as partners - or who have a history of poor relationships requires significant leadership from within the partnership organisations or from brokers.

5. Manage risks through identification, distribution and mitigation. Unless risk is managed, the weakest value chain actors (normally the farmers) bear a disproportionate share, and this can also raise costs and undermine the sustainability of the PPPP as a whole. PPPP design should firstly identify risks and how risks are distributed. Mechanisms are then needed to manage, mitigate or share risk, avoiding an excessive unmitigated risk burden on one party.

6. Build the capacity to respond to changes in complex market systems. Agricultural markets consist of many individual but interdependent parts, with the dynamics of the system emerging from interactions between these parts. PPPP interventions may lead to unforeseen outcomes - challenges as well as opportunities. PPPPs need mechanisms to identify these changes, and the flexibility to respond and adapt to the unexpected. This includes performance monitoring, with indicators that reflect joint PPPP objectives, and spaces for communication, negotiation and conflict resolution.

\section{Take a proactive approach to public} accountability and transparency. The impacts of PPPPs frequently extend beyond direct partners to a wider group of external stakeholders. The larger the scale of PPPP activities and its likely impacts, the more important it is to proactively identify and address negative externalities, engaging and involving potentially affected stakeholders.

\section{Facilitate sustainable market systems.}

Agricultural value chain PPPPs are time-limited interventions to establish new markets, institutional or systemic arrangements that address underlying constraints in areas such as input markets, credit systems and technology diffusion. Interventions need to focus on actions that modify the incentives, capabilities and behaviour of different actors to ensure they will continue their roles in the long term.

\section{Discussion of findings}

While the four case studies point overall to the potential for PPPPs to deliver positive development outcomes, the jury is still out in terms of the long-term impacts on poverty and rural development. Most of the projects are still mid-way through implementation, and the value chain relationships and arrangements that are being developed need to operate over a longer time frame before their impacts can be properly judged. This is especially true for crops that require considerable upfront investment before results are realised.

This evidence gap is not particular to IFAD A recent informal survey across the Donor Committee for Economic Development member agencies confirmed the need for more information and clarity around the approaches used in public-private partnerships to measure results, the outcomes of impact assessments, and good practice principles for donor engagement and results measurement (Heinrich 2013). Many of the criticisms of PPPPs and other value chain approaches are linked to perceptions that claims of positive outcomes are not substantiated by the evidence. As a result, some business leaders have also recognised the need for better and more consistent indicators of progress, and credible evidence on results of 'inclusive business' ${ }^{54}$ initiatives (Sustainable Food Lab 2015).

Despite this recognition of the evidence gap from some of the business community, it is ultimately the role of the public sector, including donors, to invest in creating a solid evidence base that identifies the impacts of PPPPs over the long term. This includes building systems and processes for monitoring and evaluation of PPPPs from the beginning, but also supporting long-term evaluations, including several years after the initial development project has ended. Evaluations (short- and long-term) need to consider the sustainability of changes identified, how they are embedded in institutions, whether market actors have changed their behaviour and the commercial viability of arrangements (Ruffer and Wach 2013). Impact evaluation should also 


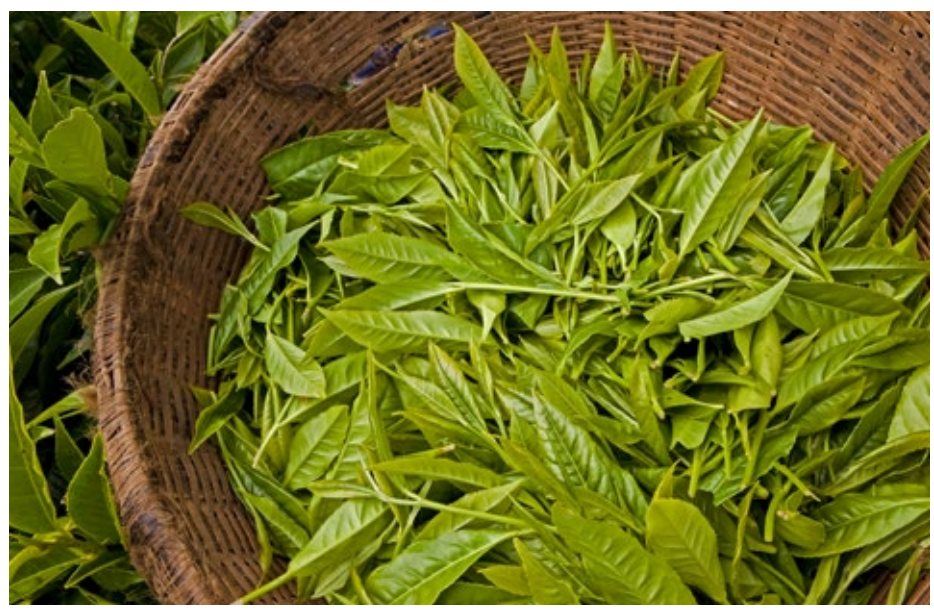

Tea leaves in a basket after collection. (-) IFAD/SUSAN BECCIO

measure broader impacts (positive and negative) beyond participating farmers.
Despite this evidence gap, PPPPs remain popular among bilateral and multilateral donors, as well as some companies and developing country governments, as mechanisms that seek to increase private investment in agriculture in ways that can better include small-scale producers. Yet this research suggests that the involvement of public and private actors is not, in itself, enough to achieve commercially-viable business models with improved outcomes for farmers. In fact one of the unexpected results was that strong government ownership of the PPPP, such as in Uganda and Rwanda, did not emerge as an enabling factor to improve the livelihoods of farmers, which depends more on the way the PPPP is designed, including especially the role of the 'fourth $\mathrm{P}^{\prime}$ - producers. However, in these two countries, government investment in infrastructure was highlighted as important by both farmers in the PPPP and non-participating community members. This suggests that more focus in agricultural PPPPs could be placed on this type of broader, horizontal impact generated directly as a result of the government's role, which can benefit those who are unlikely to be reached by private sector value chains.

Involving the private sector did not guarantee the long-term commercial viability of the arrangements. On reflection, this finding is not entirely a surprise, since sustainability and scalability are also challenges for many company-led 'inclusive business' approaches. Including poor producers in formal value chains is a complex task with constraints related to lack of infrastructure, low levels of skills and knowledge, and high transaction costs (to name a few), which create significant practical difficulties. The risk with both company-led and PPPP approaches is that the effort invested to ensure the success of pilot projects can undermine the ability to reach commercial scale. This is particularly challenging in 'greenfield' interventions, such as the PPPP in Uganda, which supports smallholders to enter new value chains, compared to initiatives that improve the terms on which smallholders are already engaging in markets (Vorley and Thorpe 2014). In this respect, the PPPP in Ghana - although not without challenges - offers a promising model since it works through already existing market systems, influencing the behaviour of different market actors (through partnerships but also other modes of engagement) in overcoming constraints faced by farmers. Approaches that work to improve existing market systems offer the potential for large-scale impact through reaching diffuse beneficiaries, and may not require such heavy financial and technical support at the pilot stage, with the inherent risk of failing to move to commercial scale.

The challenge of more diffuse market systems approaches, however, is the complexity of measuring impact and attributing it to programme interventions (creating further difficulties in developing a credible evidence base). The link between intervention and impact is generally not linear, and impacts may be spread across a wide area, number and types of beneficiaries, rather than easily identifiable within a single company value chain. That said, there are methodologies that can support evaluation of more 'systemic' changes that are taking place, and increasing guidance is available on measuring results and attribution in these contexts. ${ }^{55}$

Overall, the conclusion is that agricultural value chain PPPPs are a variation on, rather than a radical departure from, other value chain approaches, bringing similar opportunities for small-holder producers, but also similar challenges. The enabling factors and PPPP checklist set out in this report support partners and brokers to design and implement PPPPs in ways that can lead to better development outcomes for both communities and producers. More evidence is still needed, however, around the long-term impacts of PPPPs for both smallholder livelihoods and broader rural development. 


\section{Annex 1}

\section{Summary of outcomes identified and links to PPPP design and implementation}

\section{Key outcomes}

\begin{tabular}{l|l} 
Ghana & Improved access to inputs and services leading to improved \\
& yields (from 0.8 MT/ha/yr in 2008 on average to 1.5-3.2 MT/ \\
- & Imp/yr in 2014) \\
- & though income in incomes and livelihoods in some cases, \\
- Improved household food security \\
- High exposure to production risk, accompanied by loan \\
- defaults \\
- Women largely felt excluded from activities
\end{tabular}

Indonesia $^{5}$

- Cocoa plant rehabilitation and improved productivity and quality. In 2010 productivity was 50kg per tree per month, but is now up to 100-200kg per tree per month ${ }^{58}$

- Women's participation in farm activities has increased to 17 per cent, compared to 5 per cent in control villages - though benefit to women is not established ${ }^{59}$

Rwanda

Uganda
- Green leaf yields increased from 0.1T/ha/year in 2011 to $0.7 \mathrm{~T} /$ ha/year in 2013 in Nshili, and to 2.5T/ha/year in 2013 in Mushubi

- New employment opportunities created on tea plantations and in the two new factories. Up to 40 per cent of the working labour force in the tea regions used to migrate, now others are coming to seek opportunities

- Farmers report stability in incomes, and improved food security

- Farmers able to meet basic health and education needs, and invest in assets such as livestock. For example, 84 per cent of tea growers in Mushubi and 80 per cent in Nshili were affiliated to medical health insurance (Mutuelle de Santé) for the first time ${ }^{60}$

- Economic transformation, with small business creation and expansion of business centres

- Current productivity levels are insufficient for loans to be sustainable

- Average yields have reportedly been high, with trees in their sixth year yielding up to 15 tonnes per hectare per year; ${ }^{6}$ however, this has been followed by a general drop in yields, attributable to three years of low rainfall

- Improved income stability, enabling people to meet basic health and education needs, and invest in assets (livestock, vehicles, farm assets) (14 out of 47 peers reported acquiring assets directly from the PPPP and 25 acquired assets indirectly)

- Improved food security reported

- Women comprise one third of farmer leadership positions and 35 per cent of beneficiaries ${ }^{62}$

- Improved land tenure security for participating farmers. At the beginning of the PPPP, 77 per cent were Kibanja tenants with less than three acres of land and no outright land ownership. Today tenants have had their land surveyed and recorded; however, land conflicts also reported by 35 of 43 female farmers and 55 of 58 male farmers

- Economic transformation, with new investment in business activity, e.g. in construction and tourism, and a second financial institution

- Employment opportunities created in the palm oil mill and plantation - though largely filled through migrant labour

- Farmers report better environmental management and awareness but there are also persistent reports of encroachment on lake shore buffer zone and clearance of forests on private land

\section{Links between outcomes and PPPP}

- DVCCs and cashless credit system translate to increased farm yields

- Improved income and food security linked to surplus maize from greater productivity and stronger market linkages; however, high cost of inputs negates income improvements in some cases

- Poor price negotiation process negatively affects incomes and income stability

- Training in food safety improves quality of maize consumed

- Lack of risk mitigation measures means risk exposure is high

- Improved farmer technical knowledge and inputs have led to productivity and quality gains. However, more time is needed for most farmers to see benefits following grafting or planting

- Gender impacts were not specifically considered in PPPP design

- Income improvements from yield improvements, selling green leaves and working in the factories

- Women have been specifically targeted, and have also benefited

- General economic transformation from investment in infrastructure (roads, electricity grid and water facilities)

- The PPPP targeted women's inclusion with provisions for 30 per cent of tea growers to be women

- Poor assumptions about productivity and inadequate risk mitigation measures have created potentially unsustainable loan burden

- Farmer loans during pre-harvest phase contribute to incomes, income stability and household assets

- A number of risks (e.g. production risk) have been managed, e.g. through linking loan repayment to yield

- Livelihood opportunities designed to include women

- Intercropping in early years improved food security, but becomes a problem once trees mature and intercropping is no longer possible ${ }^{63}$

- Land conflicts as a result of rising land pressure/land prices, ${ }^{64}$ particularly as some absentee landlords have begun to return

- General economic transformation from investment in infrastructure (roads, ferry, electricity)

- Employment created mostly filled by migrant labour creating social pressures on island, e.g. on health, education and water 


\section{Annex 2}

\section{Bibliography}

Abdulsamad, A.; Stokes, S. and Gereffi, G. (2015) Public-Private Partnerships in Global Value Chains: Can They Actually Benefit the Poor?, Leveraging Economic Opportunities (LEO) Report \#8

Beekmans, A.; Dallinger, J. and Molenaar, J.W. (2014) Fair Company-Community Partnerships in Palm Oil Development, Oxford: Oxfam International

Bendell, J.; Collins, E. and Roper, J. (2010) 'Beyond Partnerism: Toward a More Expansive Research Agenda on Multi-stakeholder Collaboration for Responsible Business', Business Strategy and the Environment 19.6: 351-55

Bitzer, V. and Glasbergen, P. (2013) 'Exploring the Potential of Intersectoral Partnerships to Improve the Position of Farmers in Global Agrifood Chains: Findings from the Coffee Sector in Peru', Agriculture and Human Values 30.1: 5-20

Bitzer, V.; Van Wijk, J.; Helmsing, B. and Van der Linden, V. (2009) 'Partnering to Facilitate Smallholder Inclusion in Value Chains', presented at EADI Seminar, Promoting Sustainable Global Value Chains: The Role of Governance, Maastricht School of Management, 26 November 2009

Blowfield, M. (2007) 'Reasons to be Cheerful? What we Know about CSR's Impact', Third World Quarterly 28.4: 683-95

Bolwig, S.; Ponte, S.; du Toit, A.; Riisgaard, L. and Halberg, N. (2008) Integrating Poverty, Gender and Environmental Concerns into Value Chain Analysis: A Conceptual Framework and Lessons for Action Research, DIIS Working Paper no 2008/16, Copenhagen: Danish Institute for International Studies

Brickell, E. and Elias P. (2013) Great Expectations: Realising Social and Environmental Benefits from
Public-Private Partnerships in Agricultural Supply Chains, London: Overseas Development Institute

Bright, D. and Seville, D. (2010) Think Big Go Small: Adapting Business Models to Incorporate Smallholders into Supply Chains, Oxford: Oxfam International

Brinkerhoff, J. (2002) 'Government-Non-Profit Partnership: A Defining Framework', Public Administration and Development 22: 19-30

Brinkerhoff, D.W. and Brinkerhoff, J.M. (2011) 'Public-Private Partnerships: Perspectives on Purposes, Publicness and Good Governance', Public Administration and Development 31: 2-14

Dannson, A.; Ezedinma, C.; Wambua, T.R.; Bashasha, B.; Kirsten, J. and Satorius, K. (2004) Strengthening Farm-Agribusiness linkages in South Africa: Summary Results of Five Country Studies in Ghana, Nigeria, Kenya, Uganda and South Africa, Rome: Food and Agriculture Organisation

De Clerck, D.; Demeulemeester, E. and Herroelen, W. (2012) 'Public Private Partnerships: Look Before You Leap into Marriage', Review of Business and Economic Literature 57.3: 249-61

De Palma, A.; Leruth, L. and Prunier, G. (2009) Towards a Principal-Agent Based Typology of Risks in Public-Private Partnerships, IMF Working Paper, August, Washington DC: International Monetary Fund

Department for International Development (2005) 'Making Market Systems Work Better for the Poor (M4P): An Introduction to the Concept', ADB-DFID Learning Event Manila, February 2005, www.eldis.org/vfile/upload/1/ document/0708/DOC21034.pdf (last accessed May 2015)

Dorward, A.; Kydd, J.; Morrison, J. and Poulton, C. (2005) 'Institutions, Markets and Economic Co-ordination: Linking Development Policy 
to Theory and Praxis', Development and Change 36.1: $1-25$

Drost, S.; Van Wijk, J. and Mandefro, F. (2012) Key Conditions for Successful Value Chain Partnerships: A Multiple Case Study in Ethiopia, The Partnership Resource Centre, Working Paper 33, March 2012

Elliott, D.; Gibson, A. and Hitchins, R. (2008) 'Making Markets Work for the Poor: Rationale and Practice', Enterprise Development and Microfinance 19.2: 101-19

Fairtrade Foundation (2014) A Seat at the Table? Ensuring Smallholder Farmers are Heard in Public-Private Partnerships, London: Fairtrade Foundation

Ferroni, M. and Castle, P. (2011) 'Public-Private Partnerships and Sustainable Agricultural Development', Sustainability 3: 1064-73

Forrer, J.; Kee, J.E.; Newcomer, K.E. and Boyer, E. (2010) 'Public-Private Partnerships and the Public Accountability Question', Public Administration Review May-June

Gaventa, J. (2011) 'Participation Makes A Difference: But Not Always How and Where We Might Expect', Development Outreach April: 72-74

Gereffi G.; Humphrey, J. and Sturgeon, T. (2005) 'The Governance of Global Value Chains', Review of International Political Economy 12.1: 78-104

Guidi, D. (2011) Sustainable Agriculture Enterprise: Framing Strategies to Support Smallholder Inclusive Value Chains for Rural Poverty Alleviation, CID Research Fellow and Graduate Student Working Paper No. 53, Center for International Development at Harvard University, October

Heinrich, M. (2013) Donor Partnerships with Business for Private Sector Development: What Can We Learn from Experience?, Working Paper, Donor Committee for Enterprise Development, Cambridge

Holmes, S. (2012) Key Success Factors and Best Practices in Outgrower Schemes, Agribusiness
Forum presentation, www.emrc.be/documents/ document/20111107141531-agri11-workshop_vtechnoserve.pdf (last accessed May 2015)

Horton, D.; Prain, G. and Thiele, G. (2009) Perspectives on Partnership: A Literature Review, International Potato Center (CIP), Lima, Peru, Working Paper 2009-3

International Finance Corporation (2009) Stakeholder Engagement and the Board: Integrating Best Governance Practices, Global Corporate Governance Forum, Focus 8, Washington DC: International Finance Corporation

International Fund for Agricultural Development (2013) IFAD and Public-Private Partnerships: Selected Project Experiences, Rome: IFAD, www.ifad.org/pub/partnerships/ppp.pdf (last accessed May 2015)

Jelsma, I.; Giller, K. and Fairhurst, T. (2009) Smallholder Oil Palm Production Systems in Indonesia: Lessons from the NESP Ophir Project, Wageningen University

Jochnick, C. (2012) Systems, Power and Agency in Market-based Approaches to Poverty, Oxfam America Research Backgrounder series, www.oxfamamerica.org/explore/ research-publications/systems-power-andagency-in-market-based-approaches-to-poverty/ (last accessed May 2015)

Kent Business School; International Institute for Environment and Development; Oxfam and Unilever (2012) Measuring Fairness in Supply Chain Trading Relationships: Methodology Guide, International Institute for Environment and Development and Oxfam

Kindornay, S.; Higgins, K. and Olender, M (2012) Models for Trade Related Private Sector Partnerships for Development: Preliminary Report, Ottawa: The North-South Institute

Lund-Thomsen, P. (2009) 'Assessing the Impact of Public-Private Partnerships in the Global South: The Case of the Kasur Tanneries Pollution Control Project', Journal of Business Ethics 90.1: 57-78

Ministry of Foreign Affairs of the Netherlands Policy and Operations Evaluation Department 
(IOB) (2013) Public-Private Partnerships in Developing Countries. A Systematic Literature Review, IOB Study 378

Moore, M. and Schmitz, H. (2008) Idealism, Realism and the Investment Climate in Developing Countries, IDS Working Paper 307, Brighton: IDS, www.iadb.org/intal/intalcdi/ pe/2009/02458.pdf (last accessed May 2015)

Narrod, C.; Roy, D.; Okello, J.; Avendaño, B.; Rich, K. and Thorat, A. (2009) 'Public-Private Partnerships and Collective Action in High Value Fruit and Vegetable Supply Chains', Food Policy 34.1: 8-15

Organisation for Economic Co-operation and Development (2012) Recommendation of the Council on Principles for Public Governance of Public-Private Partnerships, Paris: OECD

Organisation for Economic Co-operation and Development (2008) Public-Private Partnerships: In Pursuit of Risk Sharing and Value for Money, Paris: OECD

Poulton, C. and Macartney, J. (2012) 'Can Public-Private Partnerships Leverage Private Investment in Agricultural Value Chains in Africa? A Preliminary Review', World Development 40.1: 96-109

Poulton, C.; Kydd, J. and Dorward, A. (2006) 'Overcoming Market Constraints on Pro-Poor Agricultural Growth in Sub-Saharan Africa', Development Policy Review 24.3: 243-77

Reed, A.M. and Reed, D. (2009) 'Partnerships for Development: Four Models of Business Involvement', Journal of Business Ethics 90: 3-37

Ruffer, T. and Wach, E. (2013) Review of M4P Evaluation Methods and Approaches, Hove: ITAD, www.itad.com/wp-content/uploads/2013/05/ M4P-Evaluation-Review_ITAD_Final-Copy.pdf (last accessed May 2015)

Sadka, E. (2006) Public-Private Partnerships: A Public Economics Perspective, Working Paper WP/06/77, Washington DC: International Monetary Fund

Spielman, D.J.; Hartwich, F. and von Grebmer, K. (2010) 'Public-Private Partnerships and
Developing-country Agriculture: Evidence from the International Agricultural Research System', Public Administration and Development 30.4: 261-76

Seville, D.; Shipman, E. and Daniels, S. (2015) Towards a Shared Approach for Smallholder Performance Measurement: Common Indicators and Metrics, Sustainable Food Lab, http://sustainablefoodlab.org/ images/performance_measurement_2014/ PDFs/March2015-SustainableFoodLab_ SharedApproachesFramework-Digital.pdf (last accessed May 2015)

Swanson, Burton E.; Bentz, Robert P. and Sofranko, Andrew J. (1997) Improving Agricultural Extension: A Reference Manual, Rome: Food and Agriculture Organization of the United Nations (FAO)

Technoserve (2011) Outgrower Schemes: Enhancing Profitability, Technical Brief, September 2011, Technoserve and IFAD

The Springfield Centre (2014) The Operational Guide for the Making Markets Work for the Poor (M4P) Approach, 2nd edition funded by SDC and DFID, Durham: The Springfield Centre

Tomlinson, B. (2012) 'Global Aid Trends: A Growing Private Sector Orientation in Multistakeholder Aid Architecture' in Tomlinson, B. (ed.), Aid and the Private Sector: Catalysing Poverty Reduction and Development, Philippines: The Reality of Aid International Organising Committee

Trienekens, J.H. (2011) 'Agricultural Value Chains in Developing Countries: A Framework for Analysis', International Food and Agribusiness Management Review 14.2

Tschumi, P. and Hagen, H. (2008) A Synthesis of the Making Markets Work for the Poor (M4P) Approach, Berne: Swiss Agency for Development and Cooperation (SDC)

United Nations Economic Commission for Europe (UNECE) (2008) Guidebook on Promoting Good Governance in Public-Private Partnerships, United Nations: New York and Geneva 
Utting, P. and Zammit, A. (2009) ‘United Nations-Business Partnerships: Good Intentions and Contradictory Agendas', Journal of Business Ethics 90.1: 39-56

Van Huijstee, M.M.; Francken, M. and Leroy, P. (2007) 'Partnerships for Sustainable Development: A Review of Current Literature', Environmental Sciences 4.2: 75-89

Vermeulen, S. and Cotula, L. (2010) Making the Most of Agricultural Investment: A Survey of Business Models that Provide Opportunities for Smallholders, Rome, London, Bern: FAO, IFAD, IIED, SDC, www.ifad.org/pub/land/ agri_investment.pdf (last accessed May 2015)

Vorley, W. and Thorpe, J. (2014) Success Factors for Lead Firms to Shape Inclusive Procurement, IIED Issue Paper, London: International Institute for Environment and Development (IIED)

Vorley, B.; Cotula, L. and Chan, M. (2012) Tipping the Balance: Policies to Shape Agricultural Investments and Markets in Favour of Small-scale Farmers, Oxford: Oxfam

Warner, M. (2009) Partnerships for Sustainable Development: Do We Need Partnership Brokers?, London: Overseas Development Institute

Wiggins, S.; Kirsten, J. and Llambí, L. (2010) 'The Future of Small Farms', World Development 38.10: $1341-48$

Willoughby, R. (2014) Moral Hazard?: 'Mega' Public-Private Partnerships in African Agriculture, Oxford: Oxfam

World Bank (2007) World Development Report 2008: Agriculture for Development, Washington DC: World Bank 


\section{Endnotes}

${ }^{1}$ Adapted from definition of public-private partnership in Ministry of Foreign Affairs of The Netherlands, 2013.

2 See for example www.beamexchange.org/en/ guidance/measuring-results/

${ }^{3}$ IFAD has also published its own experiences in working with public-private partnerships (PPPs) (International Fund for Agricultural Development 2013), and these two publications together seek to document and share IFAD's learning on PPPs, with the aim of improving development outcomes.

${ }^{4}$ For example, evidence of early forms of state advancement and dissemination of agricultural information dates back to imperial China, where the state was concerned with improving revenues from land taxes (Swanson et al. 1997). ${ }^{5}$ Adapted from Ministry of Foreign Affairs of The Netherlands, 2013

${ }^{6}$ In the context of the report, structured or semi-structured process refers to those PPPPs that were designed as such, and where an active search for private sector partners was conducted, such as a bidding process, private sector outreach or marketing surveys. There may be joint venture or tripartite agreements between farmers and companies.

${ }^{7}$ An unstructured/opportunistic process refers to those PPPPs that responded to a need or seized an opportunity to build linkages between existing programmes and private sector partners, which did not follow a planned process. ${ }^{8}$ Armenia had been selected as a case to represent PPPPs aimed at financial sector development, but due to internal constraints, the research was ultimately not able to take place.

${ }^{9}$ During the initial research framing, preliminary interviews were held with 14 individuals involved in PPPs from NGO, academic/expert, farmer, business and multilateral sectors. Following the fieldwork, the initial findings were reviewed at an international workshop involving 34 representatives from the case study countries and international community, including from donor, $\mathrm{NGO}$, academic, public and private sectors.

${ }^{10} \mathrm{~A}$ more detailed report is also available for each of the four country case studies. These can be accessed via www.ids.ac.uk/publication/ brokering-development.

${ }^{11}$ The case study can be found at: www.ids.ac.uk/publication/ifad-public-privatepartnership-ghana-case-study
${ }^{12}$ Savannah Farmers Marketing Company is a registered private limited company with five staff. It was established in 2005 by ICCO (the Netherlands-based inter-church organisation for development cooperation) and ACDEP, a network of church-based NGOs in Ghana. These two organisations are the main stakeholders in SFMC, and are holding shares in trust for farmers, as it is envisaged the company will become farmer-owned in the future.

${ }^{13}$ Yields in 2007 are based on NRGP baseline data. Yields in 2014 are based on estimates reported during focus group discussions.

${ }^{14}$ Some participating farmers reported increases in assets such as motorcycles and mobile phones, and are investing in livestock.

${ }^{15}$ The case study can be found at: www.ids.ac.uk/publication/ifad-public-privatepartnership-indonesia-case-study

${ }^{16}$ For example, during 2005-06, farmers could produce as much as $400 \mathrm{~kg}$ to $500 \mathrm{~kg}$ per tree per month.

${ }^{17}$ The case study can be found at: www.ids.ac.uk/publication/ifad-public-privatepartnership-rwanda-case-study

${ }^{18}$ In Nshili, a tea plantation (formerly government-run) already existed but there was no factory. Green leaves that were produced had to be processed at a factory $52 \mathrm{~km}$ away, and roads were in an extremely bad condition. In Mushubi, tea was introduced for the first time through the programme.

${ }^{19}$ The World Bank devised this national pricing system for Rwanda. Prices are based on a percentage of the made-tea price (at 4.3 conversion rate, i.e. $4.3 \mathrm{~kg}$ of green leaves to $1 \mathrm{~kg}$ of made tea). Gradually, the green leaves price will increase from 35 per cent (July 2012), 40 per cent (July 2013), 45 per cent (July 2014), and 50 per cent (July 2015) of auction prices until 2017. Should the international auction price fall, a national minimum average price set by the government should apply (at least RWF100-105/kg of green leaves).

${ }^{20}$ In Mushubi, the Tea Factory is owned by Nile Tea Company (NTC) a consortium made of the private investor (70 per cent of shares), the cooperative (15 per cent) and the government (15 per cent). In Nshili, the tea factory is owned by Nshili-Kivu Tea Plantation Company, also a consortium (85 per cent of shares) and the 
cooperative (15 per cent).

${ }^{21}$ Tea growers have acquired dairy cows and small animals (goats, pigs, chickens) in both Nshili and Mushubi, which are both contributing to food security and providing manure as fertiliser.

22 From a baseline of zero, 84 per cent of tea growers in Mushubi and 80 per cent in Nshili now have health insurance (through the Mutuelle de Santé). In Mushubi, the President of COTHEGAB, who is also a health official, confirmed that the cooperative mobilises its members around health issues (vaccination, sanitation, hygiene, reproductive health issues).

${ }^{23}$ The number of households in Mushubi eating three meals a day increased from 4 per cent to 9 per cent between 2004 and 2010. In Nshili they increased from 5 per cent to 10 per cent in Nshili. 24 747ha in Nshili and 937ha in Mushubi.

${ }^{25}$ Other factors include high altitude, poor ability of soil to retain water, use of a low-yield tea clone (which accounts for 70 per cent of the area planted), and insufficient knowledge on pest and disease control.

${ }^{26}$ Farmers are expected to start serving their loan at year three, for an eight-year period at 8.5 per cent interest rate, based on yields of 6-7T/ha/yr. Measures are now being taken to try to address these risks.

${ }^{27}$ This was a new issue at the time of the fieldwork, and the government and investor were about to start negotiations to address the matter.

28 The case study can be found at: www.ids.ac.uk/publication/

ifad-public-private-partnership-uganda-case-study

${ }^{29}$ Bidco is a Kenyan multinational company producing consumer goods. Bidco Uganda Limited (BUL) is a partnership between Bidco and three other multinationals: Wilmar International, Josovina, and Archer Daniels Midlands (ADM). ${ }^{30}$ According to KOPGT. Women are also reported to make up one-third of farmer leadership positions.

${ }^{31}$ An estimated 3,000 jobs have been created by the PPPP, although this includes jobs in the factory at Jinja, as well as in Kalangala, according to the Completion Report produced by the government at the end of phase 1 of the programme.

${ }^{32}$ From UGX150,000 per acre in 2002 to

UGX800,000 in 2008.

${ }^{33}$ Around two-thirds of participants in the focus groups reported greater incidence of land conflicts since the introduction of oil palm.

${ }^{34}$ However, not all farmers have benefited from increased yields, because of circumstances that range from poor crop management to poor soil quality to begin with, and limited access to training services provided.

${ }^{35}$ In Uganda, yields have generally been good on average, but vary between farmers.
${ }^{36}$ In Rwanda, farmers are expected to start serving their loan at year three, for an eight-year period at a rate of 8.5 per cent interest. In Uganda, farmers are expected to start serving their loan once harvesting begins, from approximately year three, at 10 per cent. Deductions are in instalments of 33 per cent of each monthly harvest, over an eight to ten year period depending on the yield.

${ }^{37}$ Local spot market traders are reportedly differentiating maize as a spillover of the training on post-harvest practices and food safety provided to participating smallholder farmers. Some farmers sorted the maize they sold on the local spot markets using the practices taught at the PPP training sessions, and attracted a 20 per cent price premium. ${ }^{38}$ This rationale is based on an analysis of the case study in the light of the literature, rather than stated project goals or a theory of change. It focuses on the rationale from the perspective of why a PPPP was needed, rather than all of the objectives of the IFAD programme.

${ }^{39}$ There was also a marketing component in Ghana, but at the level of smallholders. This was primarily linked to enhanced access to credit, rather than market access per se. However, the PPPP did build market linkages further downstream to strengthen the value chain (see page 31).

${ }^{40}$ The original Mars training module includes four weeks of technical training and two weeks of business training, which is 25 per cent theory and 75 per cent practical. In the PPPP this is compressed into four days, which is 75 per cent in class (theoretical) and 25 per cent in field (practical) training.

${ }^{41}$ The exception is Indonesia, although in the next phase of the programme, as trust between partners has been established, a marketing component is being introduced.

${ }^{42}$ While up to 40 per cent of working labour force in the PPPP areas used to migrate in the quest of seasonal labour, farmers reported that seasonal migration has stopped and other rural poor are coming to the PPPP areas to seek opportunities as a result of tea development and factory presence. 43 The formula is expressed as $\mathrm{ffb}=(\mathrm{H} / \mathrm{J}) \times \mathrm{K}$ where $\mathrm{ffb}$ is the farm gate price per tonne of fresh fruit bunches of a standard quality; $\mathrm{H}$ is the price of crude palm oil ex-mill; $\mathrm{K}$ is the oil extraction rate per tonne; and $\mathrm{J}$ is a constant. The oil extraction rate normally varies between 18 and 23 per cent and is highly sensitive to the quality of harvested ffbs, as well as the speed and efficiency of delivery to the mill after harvest. The constant reflects the costs involved in palm oil processing and is normally understood to be in the range of 1.15-1.25, depending on the efficiency of plant management. Bidco applies 1.25. 
44 The Ophir smallholder oil palm project, part of the government of Indonesia's Nucleus Estate Smallholder (NES) programme. It is an $8,000 \mathrm{ha}$ oil palm plantation, with 4,800 ha managed by smallholders and 3,200ha managed by the nucleus estate (Jelsma et al. 2009).

${ }^{45}$ This model also created a sense of peer pressure among farmers, which helped convince smallholders to maintain high standards in their fields.

${ }^{46}$ Where the public sector partner does not understand private sector capabilities and motives, this can lead to adverse selection (Poulton and Macartney 2012).

47 However, risks clearly still remain, e.g. low yields due to poor quality soils or poor crop management could create difficulties with loan repayment, and lead to farmer defaults.

${ }^{48}$ Farmers are expected to start serving their loan after three years, based on an assumption of green leaf yields of $6 \mathrm{~T} / \mathrm{ha} /$ year. National yield average is $7 \mathrm{~T} / \mathrm{ha}$. While yields display an upward trend, they are still far below this target - standing at between $0.7 \mathrm{~T} / \mathrm{ha} /$ year and 2.5T/ha/year in 2013 . 49 There are many factors contributing to the relatively low yields. At Nshili, this is due to poor tea bush care prior to privatisation, a high vacancy rate (after infilling, new bushes have low yield in first few years), high altitude, poor ability of soil to retain water, and use of a low-yield tea clone (which accounts for 70 per cent of the area planted). In addition there has been inadequate application of fertiliser by farmers; insufficient knowledge on pest and disease control and irregularities in executing basic crop husbandry practices (weeding, pruning and plucking). At Mushubi, production constraints include limited use of fertiliser (due to a complicated and lengthy procurement system and transport delays) and lack of casual labour at peak times (many labourers opt for potato production).

${ }^{50}$ However, recent default rates among farmerbased organisations following poor weather are once again undermining trust and willingness of rural banks to commit fully.

${ }^{51}$ See Sustainable Food Labs (2015) for one attempt to develop common indicators for smallholder performance measurement by a group of companies, standards organisations, NGOs and development agencies.

${ }^{52}$ On 19 February 2015, a group of more than 100 farmers filed a lawsuit against Bidco Uganda and the landowner who leased the land to the company, claiming they were evicted from their land illegally and were paid little or no compensation [www.theguardian. com/global-development/2015/mar/03/ ugandan-farmers-take-on-palm-oil-giants-overland-grab-claims].

${ }^{53}$ The study was undertaken in 2002, finding that the concessions were justified as the benefits in terms of foreign exchange savings, employment and poverty reduction were considered to outweigh the cost to government in lost tax revenues.

54 'Inclusive business' is a general term for business-led approaches that are designed to reach and improve the lives of the poor, particularly as producers who are introduced into new value chains or who have the terms in which their involvement in existing value chains improved. It also includes initiatives that improve the lives of the poor as consumers or as wage labour.

${ }^{55}$ See for example www.beamexchange.org/en/ guidance/measuring-results/

${ }^{56}$ Based on estimates during FGDs.

${ }^{57}$ Note that the outcomes that the research was able to attribute to the PPPP were limited, as many of the broader household and community benefits are linked to the wider READ programme, and not only to the activities of the PPPP.

${ }^{58}$ However, yields are still below maximum potential. Cocoa yield in Indonesia in 2000 was $561 \mathrm{~kg} / \mathrm{ha}$, with the potential to be as high as about 1.5 tonnes per hectare (based on FAO data).

${ }^{59}$ The research did not establish whether women received income benefits from the additional work, and whether the work was creating a benefit or a burden for women alongside other (care) responsibilities.

${ }^{60}$ Evaluation de l'Impact du Projet de Développement des Cultures de Rente et d'Exportation (PDCRE), 01/01/2004 to 31/12/2009, CIBLE sarl; April 2010.

${ }^{61}$ Yields of this level would normally be expected only in the ninth year. IFAD, Vegetable Oil Development Project - Phase 2. Supervision Report, 23 September - 4 October 2013.

${ }^{62}$ According to KOPGT.

${ }^{63}$ While the project recommended that each farmer designates some of their land for food production, many farmers reportedly cleared all of their land, since there was a monetary value attached to the size of land a farmer cleared. Concerns were expressed during focus group discussions about long-term food security, especially once the oil palm trees become too large to allow intercropping. Some individuals who were no longer able to intercrop reported food shortages already.

${ }^{64}$ The value of land rose from 150,000 Ugandan shillings per acre in 2002 to 800,000 shillings in 2008. 



\section{Brokering Development:}

\section{Enabling Factors for Public-Private-Producer}

Partnerships in Agricultural Value Chains

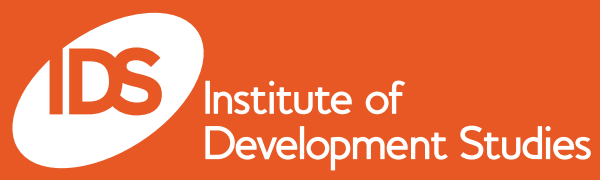

Institute of Development Studies

Brighton BN1 9RE UK

Tel: +44 (0) 1273606261

E-mail: ids@ids.ac.uk

www.ids.ac.uk

twitter.com/IDS_UK

f facebook.com/idsuk

vou wwW.youtube.com/user/idssussex

$\bullet$ www.flickr.com/photos/ids_uk/

https://soundcloud.com/ids_uk

\section{JIFAD}

Investing in rural people

International Fund for Agricultural Development

Via Paolo di Dono, 44 - 00142 Rome, Italy

Tel: +39 0654591

Fax: +3906 5043463

E-mail: ifad@ifad.org

www.ifad.org

www.ruralpovertyportal.org

(B) ifad-un.blogspot.com

f www.facebook.com/ifad

ษి instagram.com/ifadnews

www.twitter.com/ifadnews

rou www.youtube.com/user/ifadTV

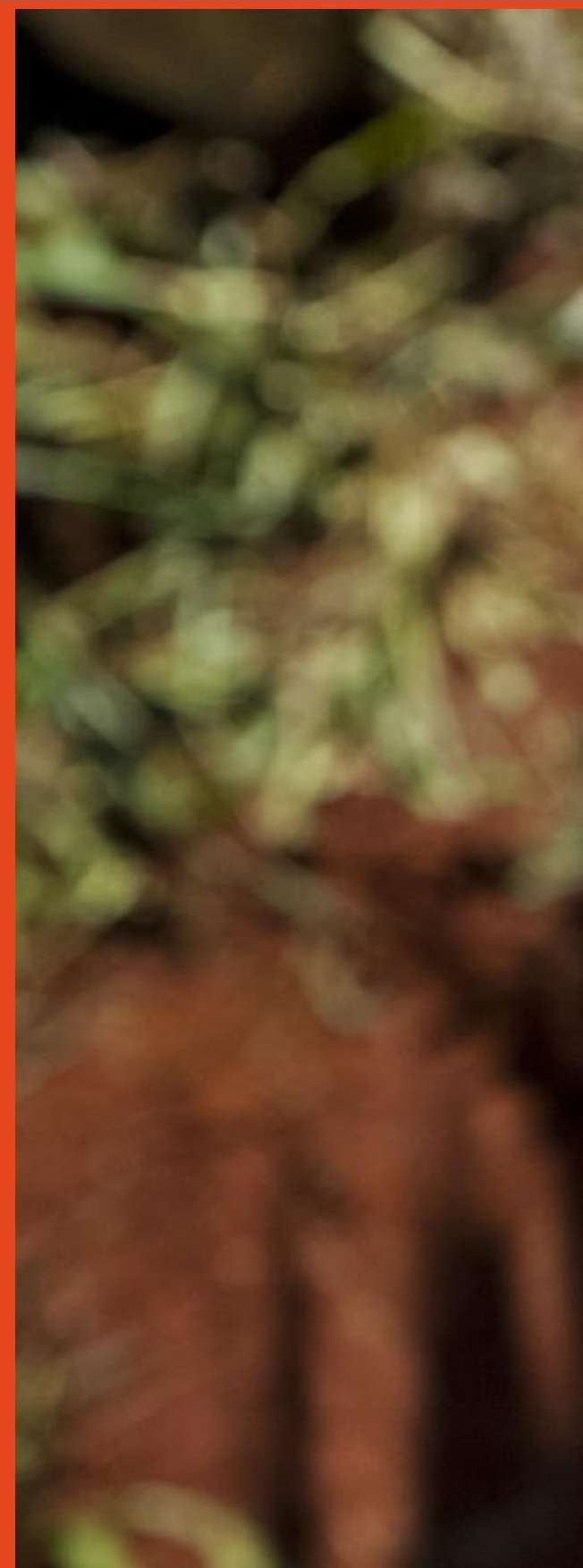

